\title{
Cardiac and fibroblastic properties after HIF-1a stabilization
}

\author{
Cumulative Doctoral Thesis \\ In partial fulfillment of the requirements for the degree \\ "Doctor rerum naturalium (Dr. rer. nat.)" \\ in the Molecular Medicine Study Program \\ at the Georg-August University Göttingen
}

\author{
submitted by \\ Melanie Vogler \\ born in Heilbad Heiligenstadt
}

Göttingen 2015 


\section{Members of the Thesis Committee:}

Supervisor:

Prof. Dr. med. Dörthe M. Katschinski

University Medical Center, Georg-August-University Göttingen

Institute of Cardiovascular Physiology

Humboldtallee 23

37073 Göttingen, Germany

Second member of the thesis committee:

Prof. Dr. Susanne Lutz

University Medical Center, Georg-August-University Göttingen

Institute of Pharmacology

Robert Koch Straße 40

37075 Göttingen, Gemany

Third member of the thesis committee:

Prof. Dr. Jörg Großhans

Georg-August-University Göttingen

Department of Developmental Biochemistry

Justus von Liebig Weg 11

37077 Göttingen, Germany

Date of Disputation: $21^{\text {th }}$ May 2015 


\section{AFFIDAVIT}

Here I declare that my doctoral thesis entitled "Cardiac and fibroblastic properties after HIF$1 \alpha$ stabilization" has been written independently with no other sources and aids than quoted.

\section{Melanie Vogler}

Göttingen, March 2015 


\section{List of Publications:}

Hypoxia Modulates Fibroblastic Architecture, Adhesion and Migration: A Role for HIF-1 $\alpha$ in Cofilin Regulation and Cytoplasmic Actin Distribution

Melanie Vogler*, Sabine Vogel*, Sabine Krull, Katja Farhat, Pia Leisering, Susanne Lutz, Christina M. Wuertz, Dörthe M. Katschinski, Anke Zieseniss

*both authors contributed equally

PLoS ONE 8.7 (2013): e69128

Pre- and post-conditional inhibition of prolyl-4-hydroxylase domain enzymes protects the heart from an ischemic insult

Melanie Vogler*, Anke Zieseniss*, Amke R Hesse, Elif Levent, Malte Tiburcy, Eva Heinze, Nicolai Burzlaff, Gunnar Schley, Kai Uwe Eckardt, Carsten Willam, Dörthe M Katschinski *both authors contributed equally

Pflügers Archiv - European Journal of Physiology (2015): DOI 10.1007/s00424-014-1667-z 


\section{Table of contents}

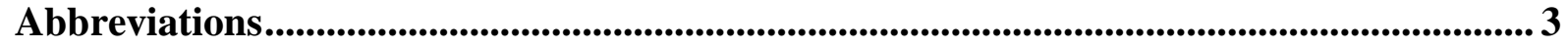

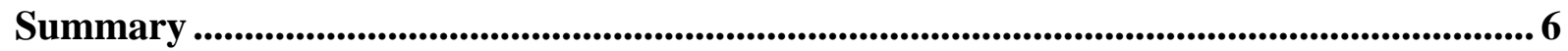

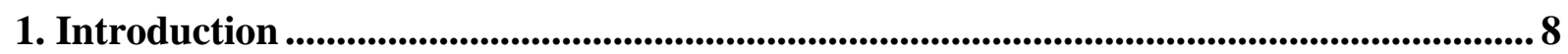

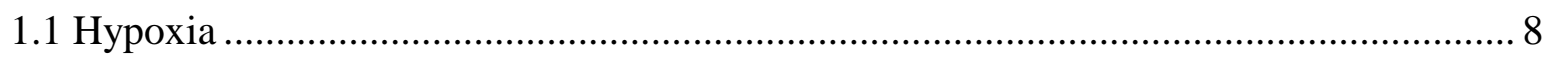

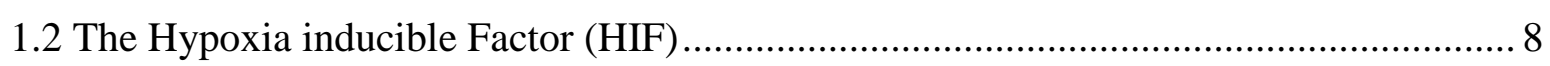

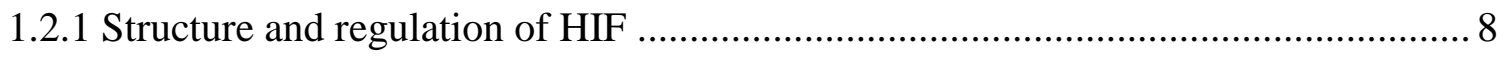

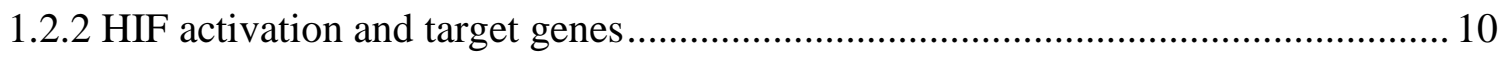

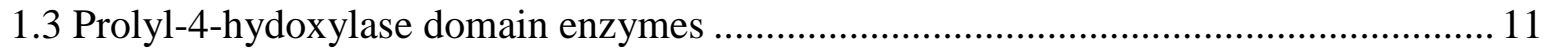

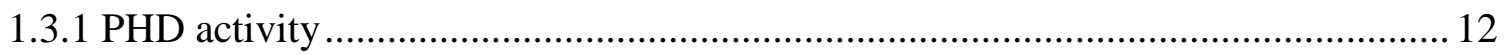

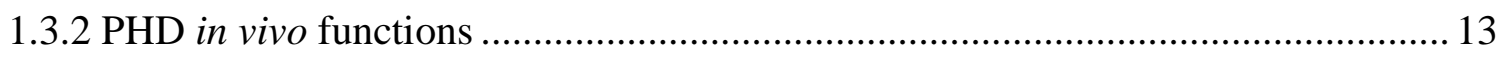

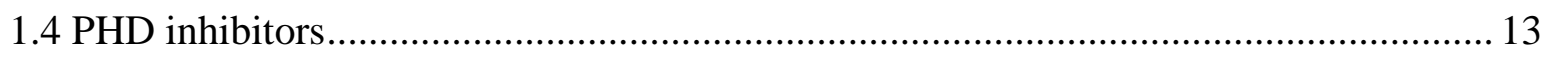

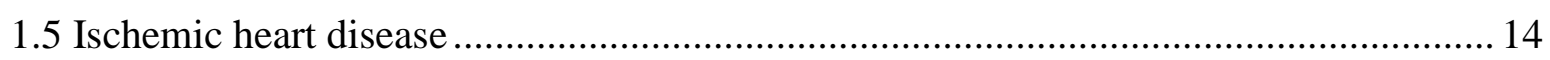

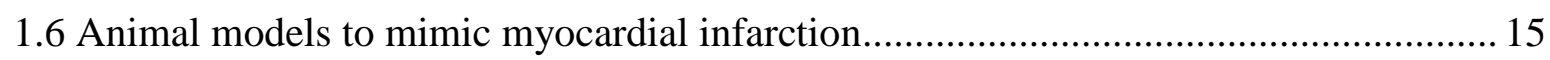

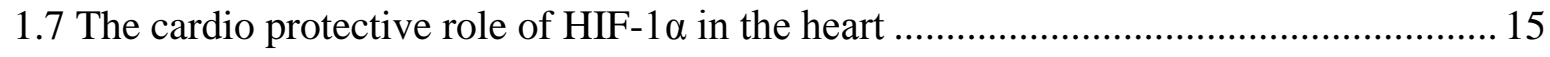

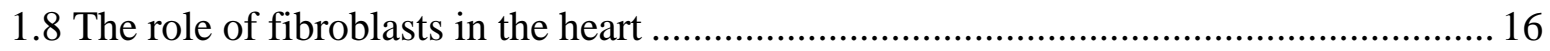

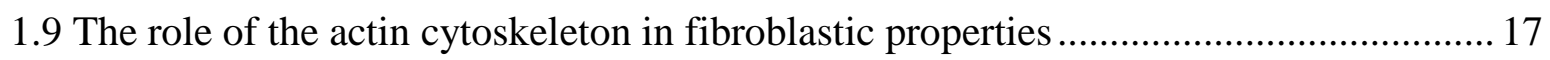

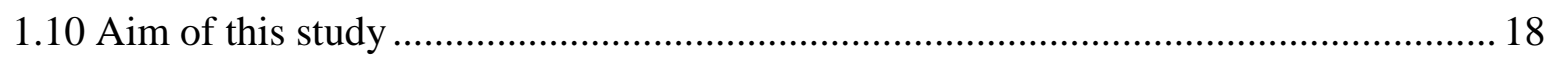

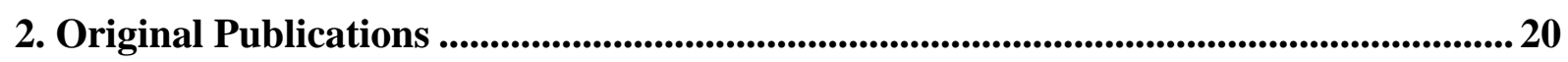

2.1 Hypoxia Modulates Fibroblastic Architecture, Adhesion and Migration: A Role for HIF-1 $\alpha$ in Cofilin Regulation and Cytoplasmic Actin Distribution ................................... 21

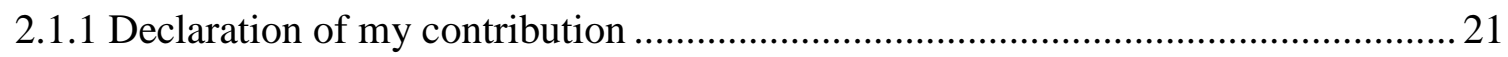

2.2 Pre- and post-conditional inhibition of prolyl-4-hydroxylase domain enzymes protects

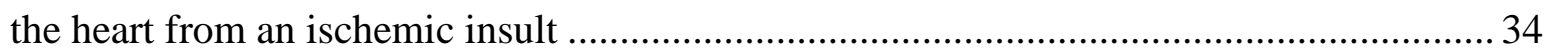

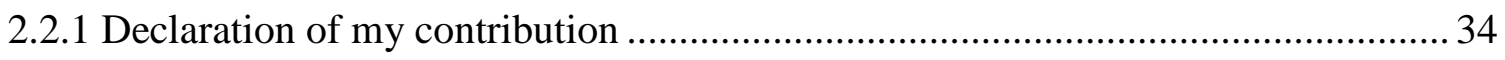

3. Unpublished data................................................................................................................44

3.1 Establishment of fibroblast-specific PHD2 knock out mice ..................................... 44

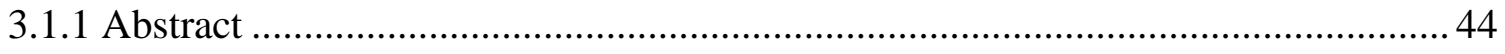

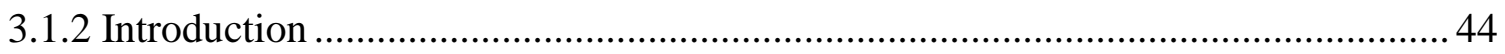

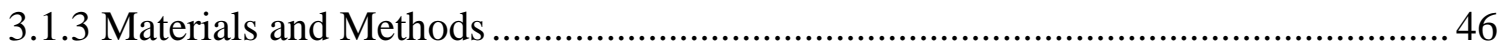

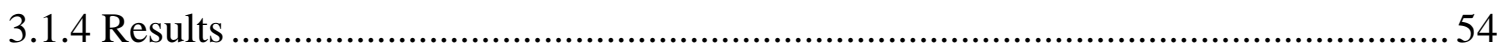

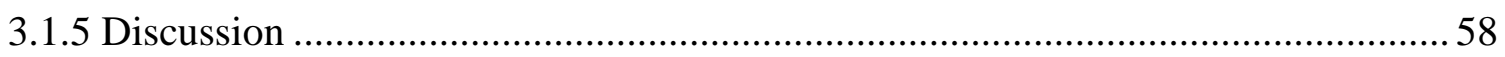

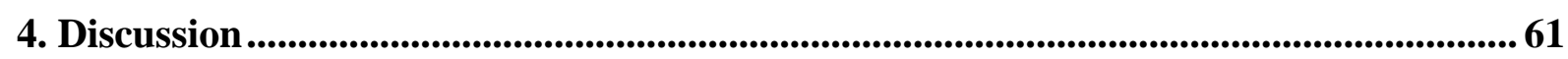

4.1 PHD inhibition as a therapeutic approach in ischemic heart disease ........................... 61 
4.2 The role of hypoxia and HIF-1 $\alpha$ in fibroblastic properties and actin dynamics ............63

5. Summary and Outlook................................................................................................................................ 65

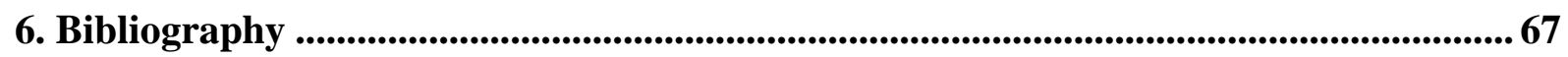

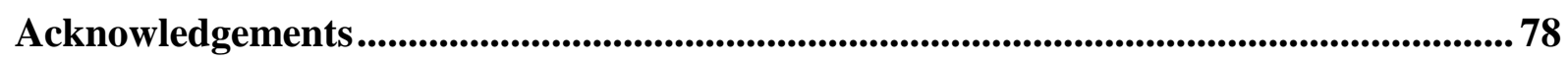

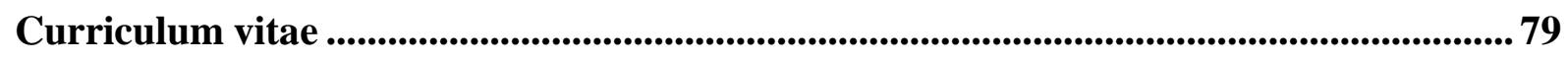

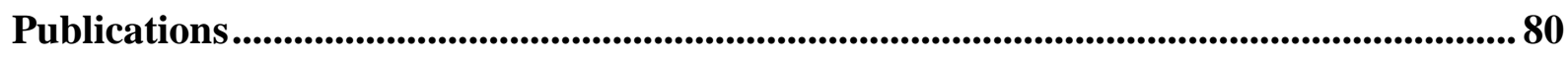

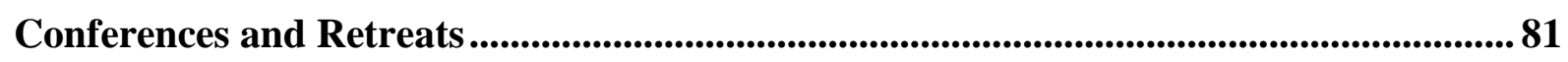

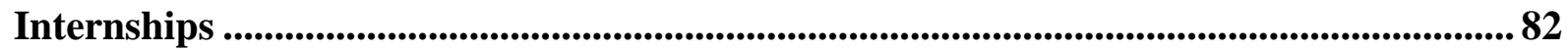




\section{Abbreviations}

Abbreviation

2OG

4HQs

4-OHT

AAR

ADP

AON

APS

ARNT

ATP

AWTH

bHLH

bp

BSA

c1 and c2

CBP

CD39

CD73

Cdc42

cDNA

CHAPS

CREB

Cre-ERT

$\mathrm{Ct}$

C-TAD

CYA

CYP

CYP2D6

CYP3A4

DFO

DHB

DMEM

DMOG

DMSO

DNA

E

e.g.

\section{Denotation}

2-oxoglutarate

4-hydroxy-2-oxo-1,2-dihydroquinoline glycinamid analogs

4-hydroxytamoxifen

area at risk

adenosine diphosphate

area of necrosis

ammonium persulfate

aryl hydrocarbon receptor nuclear translocator

adenosine triphosphat

anterior wall thickness

basic helix-loop-helix

base pairs

bovine serum albumin

L929 shHIF-1 $\alpha$ clone 1 and 2

CREB binding protein

cluster of differentiation 39 or ectonucleoside triphosphate

diphosphohydrolase 1

cluster of differentiation 73 or ecto-5'-nucleotidase

cell division control protein 42 homolog

complementary DNA

3-[(3-Cholamidopropyl)-dimethylammonio]-1-propansulfonat cAMP response element-binding protein

tamoxifen-inducible Cre-recombinase combined with a mutated estrogen receptor ligand-binding domain

threshold cycle

C-terminal transactivation domain

cytoplasmic actin

cytochrome $\mathrm{P} 450$ enzymes

cytochrom P450 2D6

cytochrome $\mathrm{P} 4503 \mathrm{~A} 4$

desferrioxamine

dihydroxybenzoate

dulbecco's modified eagle's medium

dimethyloxalylglycine

dimethyl sulfoxide

deoxyribonucleic acid

embryonic day

exempli gratia (for example) 


\begin{tabular}{|c|c|}
\hline ECG & electrocardiogram \\
\hline ECL & enhanced chemiluminescence \\
\hline $\mathrm{ECM}$ & extracellular matrix \\
\hline EDTA & ethylenediaminetetraacetic acid \\
\hline EHM & engineered heart muscle \\
\hline EPO & erythropoietin \\
\hline ERT & mutant estrogen-receptor ligand-binding domain \\
\hline FACS & fluorescence-activated cell sorting \\
\hline FAK & focal adhesion kinase \\
\hline FAS & fractional area shortening \\
\hline FCS & fetal calf serum \\
\hline FIH & factor inhibiting HIF \\
\hline FRT & FLP recognition target \\
\hline FSC & forward-angle light scatter \\
\hline FSP1 & fibroblast specific protein-1 \\
\hline GAP & GTPase activating protein \\
\hline gDNA & genomic DNA \\
\hline GEF & guanine nucleotide-exchange factor \\
\hline GLUT-1 & glucose transporter 1 \\
\hline HIF & hypoxia inducible factor \\
\hline $\mathrm{HO}-1$ & heme oxygenase-1 \\
\hline HRE & hypoxia responsive element \\
\hline HRP & horseradish peroxidase \\
\hline HSP90 & heat shock protein 90 \\
\hline i.e. & id est (that is) \\
\hline i.p. & intraperitoneally \\
\hline ICA & 2-(1-chloro-4-hydroxyisoquinoline-3-carboxamido) acetate \\
\hline iNOS & inducible nitric oxide synthase \\
\hline IPAS & inhibitory PAS \\
\hline IPC & ischemic preconditioning \\
\hline $\mathrm{kb}$ & kilobase \\
\hline $\mathrm{kDa}$ & kilodalton \\
\hline $\mathrm{Km}$ & Michaelis-Menten constant \\
\hline LAD & left anterior descending artery \\
\hline LVEDD & left ventricular enddiastolic diameter \\
\hline LVESD & left ventricular endsystolic diameter \\
\hline MEM-NEAA & minimum essential medium eagle - non-essential amino acids \\
\hline MI & myocardial infarction \\
\hline MMP & matrix metalloproteinase \\
\hline mRNA & messenger RNA \\
\hline NLS & nuclear localization signal \\
\hline
\end{tabular}




\begin{tabular}{|c|c|}
\hline N-TAD & N-terminal transactivation domain \\
\hline ODD & oxygen-dependend degradation domains \\
\hline $\mathrm{P} / \mathrm{S}$ & penicillin/ streptomycin \\
\hline PAGE & polyacrylamide gelelectrophoresis \\
\hline PAK & p21 activated kinase 1 protein \\
\hline PAS & PER-ARNT-SIM \\
\hline PBS & phosphate buffered saline \\
\hline $\mathrm{PC}$ & post-conception \\
\hline PCR & polymerase chain reaction \\
\hline PER & period circadian protein \\
\hline PHD & prolyl-4-hydroxylase domain enzyme \\
\hline Phd2 ko & Phd2 knock out \\
\hline Phd2wt & Phd2 wildtype \\
\hline $\operatorname{Phd} 2^{\text {flox flox }}$ & floxed Phd2 \\
\hline PHI & Prolyl-4-hydroxylase domain enzyme inhibitor \\
\hline $\mathrm{Pi}$ & inorganic phosphate \\
\hline Postn & periostin \\
\hline pVHL & von Hippel-Lindau protein \\
\hline PWTH & posterior wall thickness \\
\hline qRT-PCR & quantitative real-time PCR \\
\hline Rac & Ras-related C3 botulinum toxin substrate \\
\hline Rho & Ras homologue \\
\hline RNA & ribonucleic acid \\
\hline ROCK & Rho-associated protein kinase \\
\hline $\mathrm{rpm}$ & rounds per minute \\
\hline RT & room temperature \\
\hline SDS & sodium dodecyl sulphate \\
\hline SEM & standard error of the mean \\
\hline shRNA & short hairpin RNA \\
\hline $\operatorname{shC}$ & non-target control shRNA cells \\
\hline SIM & single-minded protein \\
\hline TAM & tamoxifen \\
\hline TEMED & tetramethylethylenediamine \\
\hline TGF- $\beta$ & transforming growth factor- $\beta$ \\
\hline TNF- $\alpha$ & tumor necrosis factor- $\alpha$ \\
\hline Tris & tris(hydroxymethyl)aminomethane \\
\hline TTC & 2,3,5-triphenyltetrazolium chloride \\
\hline $\mathrm{U}$ & units of activity \\
\hline VEGF & vascular endothelial growth factor \\
\hline$\alpha$-SMA & $\alpha$-smooth muscle actin \\
\hline
\end{tabular}




\section{Summary}

The cellular oxygen sensing prolyl-4-hydroxylase domain proteins (PHDs) are essential regulators of the $\alpha$-subunit of hypoxia-inducible transcription factors (HIFs) which are known to induce a variety of genes affecting cell survival, metabolism and angiogenesis. It was shown by the Institute of Cardiovascular Physiology, University Medical Center Göttingen, that stabilization of HIF-1 $\alpha$ in cardiomyocyte-specific PHD2 knock out mice results in a tissue protective effect in acute myocardial infarction (MI) (Hölscher et al., 2011). Thus, pharmaceutical stabilization of HIF-1 $\alpha$ with small molecule PHD inhibitors could be a suitable approach to induce cytoprotection in case of ischemia. Besides cardiomyocytes, fibroblasts are essentially involved in the organisation of the myocardium as well as in postischemic remodeling. In order to develop new cardio-protective therapeutic strategies, there is a strong need to further define fibroblast-specific functions in hypoxia and the role of HIF-1 $\alpha$ in fibroblastic properties. Therefore, the aims of this thesis were (i) to evaluate the effect of a pharmaceutical PHD inhibition using the isoquinoline analog 2-(1-chloro-4hydroxyisoquinoline-3-carboxamido) acetate (ICA) for its applicability and protective properties in the heart, (ii) to analyze the role of PHD2 in cardiac fibroblasts via an inducible fibroblast-specific PHD2 knock out mouse, as well as (iii) to examine the morphological and functional responses of fibroblasts to hypoxia in vitro. I could show that L929 fibroblasts respond to hypoxia with striking morphological changes including an enlargement of cell area and volume, increased focal contact assembly and a dramatic reorganization of the actin cytoskeleton with prominent $\beta$-actin enriched circular stress fibers. These hypoxic adaptions are associated with enhanced cell spreading as well as reduction in migration properties. Furthermore, it could be shown that the maintenance of p-cofilin levels is dependent on HIF$1 \alpha$ which subsequently affects the actin filament arrangement and may cause the observed increase in cell area and reduction in migration under hypoxic conditions.

To study the role of HIF-1 $\alpha$ in fibroblastic properties in vivo a tamoxifen-inducible fibroblastspecific PHD2 knock out mouse was generated and Cre-mediated DNA recombination of Phd2 loxP sites could be detected, but lacks PHD2 knock out efficacy on mRNA and protein level.

I could show that the PHD inhibitor ICA leads to a rapid and strong HIF- $1 \alpha$ and HIF-2 $\alpha$ accumulation in the heart and to the induction of HIF target genes which subsequently exert acute cardio-protective effects in MI. ICA treatment significantly reduced total infarct size after MI. This effect was seen not only after pre-conditional treatment, but also after postconditional application of ICA. This indicates that there is a therapeutic time window for the 
treatment of ischemic diseases with systemic PHD inhibitors as a useful tool for clinical approaches.

Summing up, I could show that hypoxia and specifically HIF-1 $\alpha$ greatly affects fibroblastic properties and functions and that a transient HIF-1 $\alpha$ stabilization via small molecule PHD inhibitors is a suitable approach to induce cytoprotection in case of ischemia. 


\section{Introduction}

\subsection{Hypoxia}

Oxygen is essential for cell homeostasis. In the alveoli of the lungs the erythrocytes are enriched with oxygen, a process referred to as oxygenation of the hemoglobin. Via blood flow cells are supplied with oxygen to produce energy by ATP generation. If the oxygen demand of cells is higher than the availability hypoxia develops. An impaired oxygen delivery not only occurs in diseased states, but also under physiological conditions. Physiologically reduced oxygen concentrations ranging from $1 \%$ to $5 \% \quad \mathrm{O}_{2}$ are important for proper mammalian embryonic development (Chen et al., 1999; Okazaki and Maltepe, 2006). Hypoxia also occurs when ascending to higher altitude, where the low oxygen partial pressure can lead to high altitude illness in unacclimatized persons (Hackett and Roach, 2001). Physiologically induced hypoxia also develops during endurance sports when the oxygen demand of the muscles exceeds the oxygen delivery by the cardiovascular system leading to anaerobic energy metabolism. Besides physiological hypoxia, limited oxygen supply to tissues can occur in several disease conditions like cardiovascular or chronic lung diseases, stroke, cancer and anemia. Cellular responses to hypoxia are mediated by the transcription factors hypoxia-inducible factor (HIF), which regulate the transcription of several genes involved in adaption to cellular or systemic hypoxic conditions (Wenger, 2002, and references therein). These are genes which are involved in processes like erythropoiesis, angiogenesis and energy metabolism and thus enable survival in a low-oxygen environment (Semenza, 2002).

\subsection{The Hypoxia inducible Factor (HIF)}

Hypoxia inducible factors act as the master regulators to mediate adaptional genetic responses of cells under hypoxic conditions.

\subsubsection{Structure and regulation of HIF}

$\mathrm{HIF}$ is a heterodimeric protein consisting of an oxygen dependend labile $120 \mathrm{kDa} \alpha$-subunit and an oxygen-insensitive stable 91-94 kDa $\beta$-subunit. Both subunits belong to the PERARNT-SIM (PAS) protein family of the basic helix-loop-helix (bHLH) transcription factors (Wang et al., 1995). The amino-terminal domain consists of the bHLH and PAS domains which are required for contacting the DNA in the major groove and for heterodimerization of 
the HIF $\alpha$ and HIF $\beta$ subunits, respectively. The dimer specifically binds to hypoxia responsive elements (HREs) of target genes to induce gene expression (Jiang et al., 1996).

In human and rodent cells three HIF $\alpha$ subunits HIF-1 $\alpha$, HIF- $2 \alpha$ and HIF-3 $\alpha$ exist. All three subunits are able to dimerize with the ubiquitously expressed HIF-1 $\beta$ subunit. Whereas HIF$1 \alpha$ is ubiquitously expressed, HIF- $2 \alpha$ and HIF- $3 \alpha$ show more restricted tissue expression patterns with a higher HIF-2 $\alpha$ expression in lung, brain and endothelial cells (Tian et al., 1997; Ema et al., 1997; Chavez et al., 2006). HIF-3 $\alpha$ was reported to be expressed in alveolar epithelial cells, kidney and vasculature (Hara et al., 2001; Li et al., 2006; Augstein et al., 2011). HIFs play a fundamental role during embryogenic development as a knockout of HIF$1 \alpha$ and HIF-2 $\alpha$ leads to embryonic lethal phenotypes. HIF- $1 \alpha$ is required for normal vascularization and cephalic mesenchymal cell survival and knock out animals show cardiovascular malformations and open neural tube defects (Iyer et al., 1998). HIF-2 $\alpha$ knock out embryos die due to bradycardia and vascular disorganization (Tian et al., 1998; Peng et al., 2000).

HIF- $1 \alpha$ and HIF-2 $\alpha$ share the most common similarities concerning structure, regulation and DNA binding (Tian et al., 1997). Both contain two transactivation domains, the N-terminal transactivation domain (N-TAD) and the C-terminal transactivation domain (C-TAD) (Pugh et al., 1997; O'Rourke et al., 1999) (Figure 1). The N-TAD contains the oxygen-dependent degradation (ODD) domain which is hydroxylated at the two proline residues Pro402 and Pro564 by prolyl-4-hydroxylase enzymes (PHDs) under normoxic conditions (Ivan et al., 2001; Jaakola et al., 2001). The hydroxylated proline is recognized by the E3 ubiquitin ligase von Hippel-Lindau protein (pVHL), which leads to polyubiquitination and subsequent proteasomal degradation of HIF-1 $\alpha$ (Maxwell et al., 1999). The protein levels of HIF-1 $\alpha$ under normoxic conditions are tightly regulated with a short half-life of 5-8 min (Berra et al., 2001).

In addition to the modification of proline residues, HIF- $1 \alpha$ and HIF- $2 \alpha$ are hydroxylated by factor inhibiting HIF (FIH) at the asparaginyl residues Asn803 and Asn851, respectively. The asparagine hydroxylation interferes with the recruitment of the transcriptional coactivator CREB binding protein $\mathrm{CBP} / \mathrm{p} 300$. The $\mathrm{CPB} / \mathrm{p} 300$ cofactor is a histone acetyltransferase. Histone acetylation leads to increased transcriptional activity by 'opening' the genomic locus (Lando et al., 2002). Furthermore, the heat shock protein 90 (HSP90) can form a stable association with $\mathrm{HIF} \alpha$ by interacting with its PAS B domain (Minet et al., 1999; Katschinski et al., 2002). 


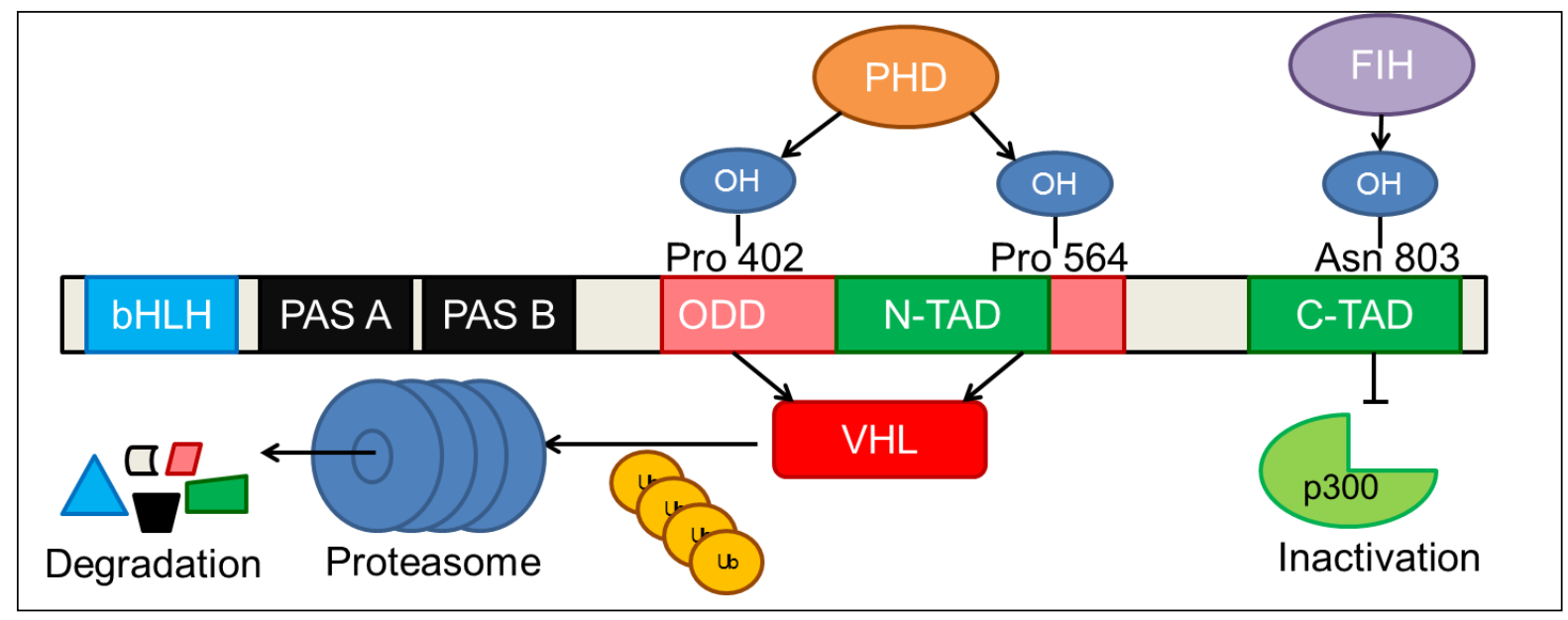

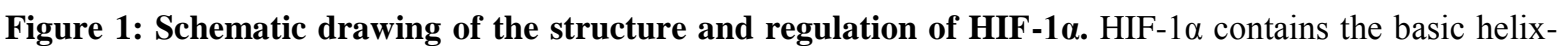
loop-helix (bHLH) domain for DNA binding and PER-ARNT-SIM (PAS) domains for dimerization with HIF$1 \beta$. The oxygen-dependent degradation domain (ODD) which is partially located within the N-terminal transactivation domain (N-TAD) is hydroxylated at the two proline residues Pro402 and Pro564 by proly-4hydroxylase enzymes (PHDs) in normoxia. Hydroxylated HIF-1 $\alpha$ is recognized by the von Hippel-Lindau (pVHL) E3 ubiquitin ligase and is targeted for proteasomal degradation. The C-terminal transactivation domain (C-TAD) can be hydroxylated by factor inhibiting HIF (FIH) at Asn803. This hydroxylation interferes with the recruitment of the transcriptional co-activator $\mathrm{p} 300$.

HIF-3 $\alpha$ shows a high similarity to HIF- $1 \alpha$ and HIF- $2 \alpha$ regarding the bHLH and PAS domains, but lacks the C-TAD (Gu et al., 1998). A HIF-3 $\alpha$ splice variant termed inhibitory PAS (IPAS) was identified in mice, which due to its lack in the transactivation domain, acts as negative regulator of the HIF-1/2 pathway (Makino et al., 2001 and 2002).

\subsubsection{HIF activation and target genes}

Hypoxia causes HIF-1 $\alpha$ stabilization. The subsequent nuclear import of HIF- $1 \alpha$ is facilitated by unmasking its C-terminal bipartite nuclear localization signal (NLS) via destabilization of the HIFa/HSP90 complex (Gradin et al., 1996; Kallio et al., 1998; Luo and Shibuya, 2001). Nuclear import is mediated by the interaction of the NLS with importins. Importins 4 and 7

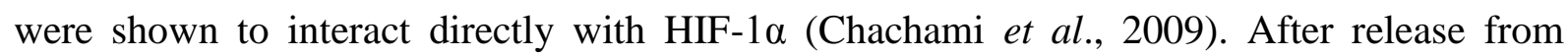
importins in the nucleus HIF-1 $\alpha$ dimerizes with HIF-1 $\beta$ through intermolecular interactions of their bHLH and PAS domains. The C-TAD of HIF-1 $\alpha$ is activated and the transcriptional coactivator $\mathrm{CBP} / \mathrm{p} 300$ recruited (Gradin et al., 2002). The transcriptional active HIF-1 complex recognizes HREs that contain the DNA consensus sequence RCGTG to induce the expression of HIF target genes (Semenza et al., 1996). To date more than 200 HIF target genes are known which are involved in adaptional physiological responses including angiogenesis, erythropoiesis and glycolysis. They include the vascular endothelial growth factor (VEGF), the most potent promoter for neoangiogenesis in hypoxic tissues (Liu et al., 1995). It increases capillary density and thus leads to an improved tissue oxygenation (Ferrara 
and Gerber, 2001). In addition to VEGF the production of erythropoietin (EPO) is also increased and stimulates erythropoiesis (Beck et al., 1993). Besides this, HIF-1 also upregulates a number of molecules like the inducible nitric oxide synthase (iNOS) and the heme oxygenase-1 (HO-1) which synthesize nitric oxide (NO) and carbon monoxide (CO) respectively, and thus modulate the vascular tone (Lee et al., 1997; Melillo et al., 1997). Under hypoxic conditions the limited oxygen supply causes a switch to anaerobic glycolysis to maintain cellular ATP production. To achieve this, several glycolytic enzymes like aldolase A, enolase 1, lactate dehydrogenase A, phosphofructokinase L, and phosphoglycerate kinase 1 and the glucose transporter 1 (GLUT-1) are upregulated by HIF-1 (Wenger, 2000, and references therein; Minchenko et al., 2002). These enzymes and transporters lead to an increased glucose uptake as well as an enhanced anaerobic ATP synthesis. The transmembrane carbonic anhydrase IX is induced by HIF-1 to regulate the $\mathrm{pH}$ by converting the arising protons and bicarbonate to carbon dioxide (Wykoff et al., 2000).

\subsection{Prolyl-4-hydoxylase domain enzymes}

Prolyl-4-hydoxylase domain enzymes (PHDs) are known to hydroxylate the HIF $\alpha$ subunit in an oxygen-, iron- and 2-oxoglutarate (2OG) dependent manner. This strict dependency on oxygen sets the PHDs up to function as cellular oxygen sensors. Three isoforms, PHD1, PHD2 and PHD3 are known. Although all three family members are able to hydroxylate HIF $\alpha$, PHD2 appears to be the main oxygen sensor in normoxia (Berra et al., 2003).

PHD1-3 are expressed ubiquitously with high expression levels of PHD1 in the testis and hormone responsive tissues (Lieb et al., 2002). PHD3 is abundant in the heart and skeletal muscle as well as in the placenta (Lieb et al., 2002). PHD2 is constitutively expressed in all tissues (Berra et al., 2003).

The expression of PHD2 and PHD3 is hypoxic inducible as both contain HREs within their promoter regions. This regulation serves as a negative feedback loop and enables the rapid degradation of HIF $\alpha$ during reoxygenation (Metzen et al., 2003; Schofield and Ratcliffe, 2004). The expression of PHD1 is not hypoxia inducible; however PHD1 can be induced in human breast cancer cells by estrogen (Seth et al., 2002).

The three PHDs exhibit different cell localization patterns. Whereas PHD1 was shown to be exclusively present in the nucleus, PHD2 is mainly localized in the cytoplasm, and PHD3 can be found in both cell compartments with cytoplasmic predominance (Metzen et al., 2003; Steinhoff et al., 2009). 


\subsubsection{PHD activity}

PHDs hydroxylate two critical prolines within a strongly conserved LXXLAP motif within the ODD of HIF-1 $\alpha,-2 \alpha$ or $-3 \alpha$ subunits (Huang et al., 2002). Whereas PHD1 and PHD2 recognize the two critical proline residues 402 and 564 in human HIF-1 $\alpha$, PHD3 hydroxylates with a higher preference proline 564 (Epstein et al., 2001; Hirsilä et al., 2003).

PHDs fulfill the requirements to function as oxygen sensors in eukaryotic cells, because their $\mathrm{Km}$ values are $230-250 \mu \mathrm{M}$ and thus slightly above the concentration of dissolved $\mathrm{O}_{2}$ in air (Hirsilä et al., 2003). This leads to highly sensitive changes in PHD activity in response to decreases in tissue oxygen availability.

At the catalytic site of PHD enzymes iron is non-covalently ligated by two histidines and one aspartic residue. These protein ligands form a 'facial triad' that occupies three of six possible iron coordination sites (Schofield and Ratcliffe, 2004). 2OG is ligated to $\mathrm{Fe}^{2+}$ through its 1caboxylate and 2-oxo goups (Figure 2) at the two further coordination sites. The remaining coordination site is occupied by one labile water molecule which is readily displaced by the HIF $\alpha$ substrate. This displacement leads to oxygen binding and activation of the enzyme. The uncoordinated oxygen of the bound dioxygen attacks the ketone carbonyl group of the $2 \mathrm{OG}$ forming a bicyclic Fe(IV)-peroxyhemiketal complex. This complex undergoes decarboxylation concomitantly with the formation of an oxo-ferryl $(\mathrm{Fe}(\mathrm{IV})=\mathrm{O})$ intermediate and the release of $\mathrm{CO}_{2}$. The highly reactive intermediate attacks the HIF $\alpha$ proline residues to withdraw a hydrogen atom and then introduces the hydroxyl radical. After release of the hydroxylated HIF $\alpha$ ODD succinate is also separated from the complex and the free iron coordination sites are again occupied by water molecules (Schofield and Ratcliffe, 2004; Smirnova et al., 2012).

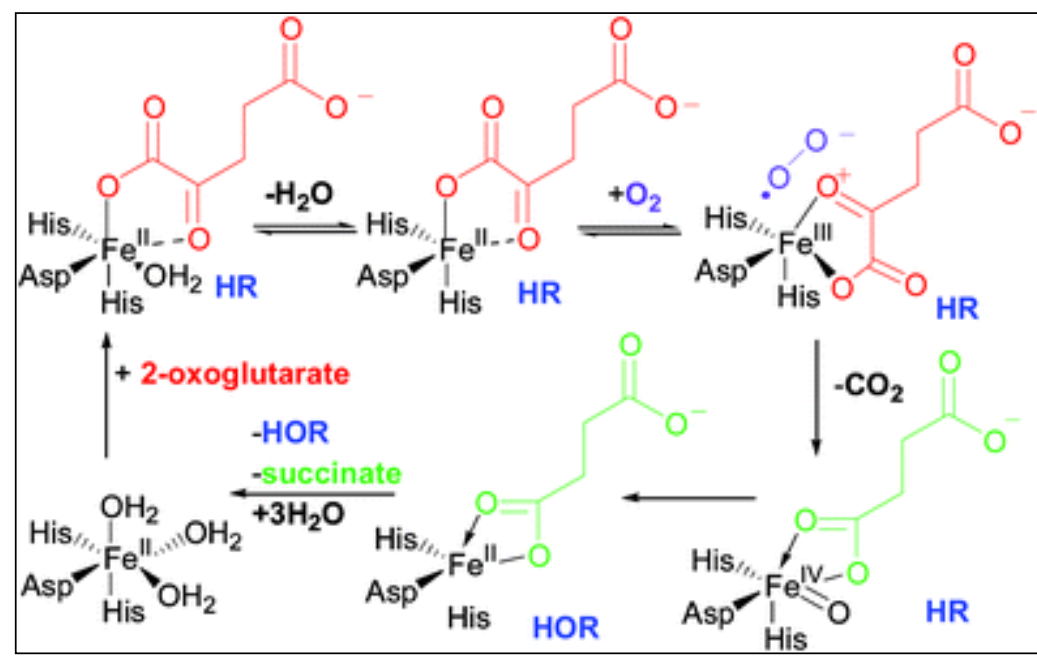

Figure 2: Outline of the catalytic cycle of PHDs. The PHDs form an enzyme-Fe ${ }^{2+}$-2-oxoglutarate (red) complex able to bind the substrate HIF $\alpha$ (HR; blue) by the release of water. They transfer one of the oxygen atoms (purple) onto the HIF $\alpha$ proline residues (HR to $\mathrm{HOR}$ ) and the second oxygen atom reacts with 2-oxoglutarate via oxidative decarboxylation to give succinate (green) and carbon dioxide (taken from Banerji et al., 2005). 
The PHDs might require in addition ascorbate for their full catalytic activity as an alternative oxygen acceptor in uncoupled decarboxylation cycles as it has been described for collagen PHDs (Myllylä et al., 1984). However, it has been reported that ascorbate might be dispensable for HIFa hydroxylation and glutathione could substitute for ascorbate in vivo (Nytko et al., 2011).

\subsubsection{PHD in vivo functions}

To gain deeper insight into in vivo functions of the PHDs several knock out mice were generated and characterized. Ubiquitous PHD2 knock out mice are not viable as PHD2 knock out embryos die between E12.5 and E14.5 because of early cardiac and placenta defects. These mice present severe heart defects including thinner ventricular compact layer, poorly developed trabecula, open interventricular septum and enlarged atria. The placentas of these animals show a reduced vascularization in the irregularly formed labyrinth, an abnormal distribution of giant cells and widespread penetration of the labyrinth by spongiotrophoblasts (Takeda et al., 2006; Minamishima et al., 2008). In contrast to this, PHD1 knock out mice do not present any obvious phenotype under basal conditions (Aragonés et al., 2008). However, the skeletal muscles of PHD1 knock out animals are protected against lethal ischemia due to metabolic adaption towards oxygen conservation. PHD3 knock out mice are viable, but PHD3 was reported to regulate neuronal apoptosis as well as adrenal medulla morphology and sympathoadrenal development. Thus, the sympathoadrenal system was described to be dysfunctional in PHD3 knock out mice with reduced innervation of target organs and dysregulated responses, including reduced catecholamine secretion and reduced systemic blood pressure (Bishop et al., 2008).

\subsection{PHD inhibitors}

Inhibition of PHD enzymes might partly induce a protective effect by stabilizing HIF $\alpha$ in normoxia. Several PHD inhibitors have been described for in vitro and in vivo applications and have been tested in clinical and pre-clinical trials for their tissue protection potential (Katschinski, 2009). Inhibition of the enzymatic activity of PHDs can be achieved by the usage of competitive substrate analogs, iron chelators like desferrioxamine (DFO), or iron replacement by transition metal ions like cobalt, nickel and manganese (Epstein et al., 2001; Schofield and Ratcliffe, 2004). Additionally, it was found that the endogenous 2-oxoacids pyruvate and oxaloacetate can both act as competitive inhibitors of 2OG-dependent 
oxygenases (Tuderman et al., 1977). 2OG-substrate analogs such as dihydroxybenzoate (DHB) and dimethyloxalylglycine (DMOG) bind in a similar fashion like 2OG to the PHDs. These 2OG-substrate analogs also displace the water molecule, however due to their structure they cannot be oxidized which will result in uncoupled reactions (Smirnova et al., 2012). Non-selective oxoglutarate analogs such as N-oxalyl-glycine and DMOG were used in different applications in vitro (Jaakkola et al., 2001; Epstein et al., 2001), but these agents are likely not suitable enough for the clinical use because they inhibit many 2-OG-dependent dioxygenases besides PHD1-3 (Ivan et al., 2002).

As PHDs exhibit isoform-specific functions in vivo, it is important to use or develop PHD isoform-specific inhibitors to induce distinct HIF $\alpha$ actions and to reduce unwanted side effects. Several structurally diverse small molecule inhibitors were developed and tested regarding their PHD enzyme inhibiting properties. Isoquinoline based inhibitors and 4Hydroxy-2-oxo-1,2-dihydroquinoline glycinamide analogs (4HQs) seem to be more selective for PHDs than the non-selective oxoglutarate analogs N-oxalyl-glycine and DMOG. While DMOG inhibits besides to PHDs also FIH, the isoquinoline analogs and 4HQs inhibition properties are almost restricted to PHDs. PHD isoform specificity could also be improved by varying side chains. Furthermore, isoquinoline analogs and $4 \mathrm{HQs}$ were reported to be more potent in stabilizing HIFa than the non-selective PHD inhibitors (Stubbs et al., 2009; Chowdhury et al., 2013). Therefore, these PHD inhibitors seem to be more suitable for clinical use. These substances were successfully used in in vivo experiments to stimulate erythropoiesis (Safran et al., 2006; Hsieh et al., 2007) as well as to exert tissue protective effects in ischemic diseases in the kidney, heart and brain (Philipp et al., 2006; Baranova et al., 2007; Rosenberger et al., 2008; Bao et al., 2010).

\subsection{Ischemic heart disease}

Ischemic heart disease is one of the leading causes of mortality worldwide (Mathers and Loncar, 2006). It is in most cases age dependent, with a prevalence of $2.3 \%$ in persons younger than 50 years versus $15.1 \%$ in those with an age over 60 (Gösswald et al., 2013). Ischemia occurs in the heart e.g. when an atherosclerotic plaque in the wall of a major coronary artery blocks the blood perfusion. This leads to inadequate oxygen and nutrient delivery to the heart tissue. This shortage of $\mathrm{O}_{2}$ and nutrient supply can cause cell death and necrosis of the ischemic tissue after prolonged arterial occlusion and subsequently myocardial infarction (MI). An early response to myocardial ischemia is the increase of HIF-1 $\alpha$ levels as 
observed in biopsy specimens obtained from ischemic or infarcted human myocardium (Lee et al., 2000). In addition to this, the tissue undergoes after the acute infarction complex remodeling processes including changes in cell metabolism, matrix production by fibroblasts and myocyte replication (Williams and Benjamin, 2000). This myocardial remodeling after ischemia can also lead to tissue stiffness, dilatation and ventricular dysfunction, disability and death (Pfeffer et al., 1990).

\subsection{Animal models to mimic myocardial infarction}

Transient myocardial ischemia is due to an imbalance between coronary perfusion as well as oxygen and nutrient demand resulting in a state of myocardial impairment. Tissue viability can be preserved by reperfusion within 20 minutes. Severe and prolonged ischemia however leads to irreversible injury and subsequent necrosis (Braunwald and Kloner, 1985). As a murine in vivo model, the surgical ligation of the left anterior descending artery (LAD) is well accepted to resemble MI (Patten et al., 1998). The LAD appears to be the major supplier of blood and nutrients to the left ventricle, whereby it courses either as a single major vessel to the apex or it bifurcates into two major vessels (Michael et al., 1995). After ligation of the LAD no further blood flow is permitted into the apex of the left ventricle resulting in an ischemic area, while the surrounding myocardial tissue is almost not affected. The size of the ischemic myocardium as well as viable areas within the infarction can be determined by using Evan's blue/2,3,5-triphenyltetrazolium chloride (TTC) staining (Bohl et al., 2009). Furthermore, the heart function and cardiac remodeling after MI can be evaluated in living animals by echocardiography.

\subsection{The cardio protective role of HIF-1 $\alpha$ in the heart}

It was shown that hearts exposed to short episodes of ischemia and reperfusion (i.e. $5 \mathrm{~min}$ ) were protected against injury caused by a subsequent prolonged episode of ischemiareperfusion (30 $\mathrm{min}$ ). This phenomenon is also known as ischemic preconditioning (IPC) (Murry et al., 1986). The protection exhibits two phases, the first directly after reperfusion which lasts for several hours and the second which starts $24 \mathrm{~h}$ after the stimulus and lasts for several days (Murry et al., 1986; Kuzuya et al., 1993; Marber et al., 1993). In contrast, hearts directly subjected to prolonged ischemia-reperfusion without IPC showed dramatically increased infarct sizes (Liu et al., 1991). In the early phase it is postulated that IPC induces HIF-1 dependent CD39 and CD73 expression in vascular endothelial cells. These integral 
membrane proteins hydrolyze ATP to adenosine an obligatory mediator of acute cardioprotection (Liu et al., 1991; Semenza, 2014). In addition to this, it was shown that HIF1 is first induced in the infarct surrounding tissue, shortly thereafter also in the non-infarcted myocardium (Jürgensen et al., 2004). As HIF-1 induces hundreds adaptive genes upon ischemia it probably plays an important role in IPC.

Cardioprotective effects of the HIF pathway have also been reported in the setting of acute MI. Genetically modified mouse models in which HIF-1 $\alpha$ is stabilized in cardiomyocytes show improved cardiac function and reduced infarct size after MI (Kido et al., 2005; Hölscher et al., 2011). Beneficial effects after MI were also reported for the injection of small hairpin RNA targeting PHD2 (Huang et al., 2008). And also the treatment of mice with PHD inhibitors like cobalt chloride, DFO, DMOG and GSK360 is protective in the case of MI (Xi et al., 2004; Dendorfer et al., 2005; Eckle et al., 2008; Bao et al., 2010). The underlying mechanisms are not understood in detail, however increased capillary area, metabolic reprogramming towards glucose consumption and altered calcium handling have been discussed to be involved in HIF-dependent cardioprotection.

On the other hand, long-term activation of HIF-1 and its associated pathways may actively contribute to heart failure (Hölscher et al., 2012).

\subsection{The role of fibroblasts in the heart}

Besides cardiomyocytes, which occupy approximately $75 \%$ of the normal myocardial tissue volume and $30-40 \%$ of cell numbers, the majority of the remaining cells are predominantly fibroblasts (Vliegen et al., 1991; Camelliti et al., 2005). Fibroblasts are defined as cells of mesenchymal origin that produce a variety of extracellular matrix (ECM) components, including multiple collagens, as well as fibronectin (Souders et al., 2009). They contribute to cardiac development, cell signaling and electro-mechanical properties of the myocardium (Camelliti et al., 2005). The content of fibroblasts in the heart increases during normal development and aging (Anversa et al., 1986). In diseased states like myocardial ischemia, fibroblasts play an important role in cardiac tissue remodeling. This is due to their ability to secrete and breakdown the ECM. They infiltrate the damaged tissue within hours after myocardial infarction with a maximum density after one week (Camelliti et al., 2005). Fibroblasts can differentiate into myofibroblasts that are specialized cells which possess a more contractile and synthetic phenotype than fibroblasts. Due to the expression of contractile proteins like $\alpha$-smooth muscle actin ( $\alpha$-SMA) and the assembly of fibronexus they can 
generate force which is applied to the surrounding extracellular matrix (Tomasek et al., 2002; Gabbiani et al., 2003). Myofibroblasts deposit increasing amounts of ECM in order to preserve tissue integrity resulting in myocardial scar formation (Cleutjens et al., 1995). However, excessive ECM production may also cause impaired cellular communication and electrical propagation in the heart (Kohl et al., 2005). Besides the role of fibroblasts in ECM deposition, they also express matrix metalloproteinases (MMPs) and humoral factors (e.g. TGF- $\beta$, angiotensin II and TNF- $\alpha$ ) resulting in inflammatory cell infiltration and cytokine production that further enhances fibroblast infiltration, proliferation and differentiation (Tao et al., 2004).

\subsection{The role of the actin cytoskeleton in fibroblastic properties}

Infiltration of fibroblasts into an ischemic tissue like the infarcted heart is a complex process. The most important step for the migration of fibroblasts is the rearrangement of the actin cytoskeleton, yet not much is known about hypoxia-induced effects on the cytoskeleton based fibroblast architecture and function.

The actin cytoskeleton mediates a variety of biological functions like cell morphology, polarity, motility, cell division and intracellular transport. Vertebrates express six actin isoforms, including $\alpha$-skeletal, $\alpha$-cardiac, $\alpha$ - and $\gamma$-smooth muscle, and the two cytoplasmic $\beta$ and $\gamma$-actins. They differ by only a few amino acids (Vandekerckhove and Weber, 1978; Herman, 1993).

Actin exists as globular G-actin monomers which can assemble into long filamentous F-actin polymers that are polar helical structures. G-actin contains a $\mathrm{Mg}^{2+}$-ion complexed with either ATP or ADP. The assembly into F-actin is accompanied with the hydrolysis of ATP to ADP and Pi. Monomer assembly is the dominant reaction at the fast growing (i.e. barbed) ends of actin filaments, whereas filament disassembly prevails at the slow growing (i.e. pointed) end (Wegner, 1976; Wegner and Isenberg 1983). The actin microfilaments, which form a threedimensional cytoskeletal network throughout the cell, are shaping the cell morphology via continuous remodeling (Winder, 2003). Besides this, the continuous turnover of the actin cytoskeleton is essential for the migration of fibroblasts which goes along with phases of protrusion and contraction as a cyclical process. Every step of this cycle critically depends on the timely assembly, disassembly, and reorganization of actin filaments as well as contractile actomyosin structures (Horwitz and Parsons, 1999). These actomyosin structures are termed stress fibers and are composed of bi-polar bundles of 10-30 actin filaments, which are 
crosslinked by $\alpha$-actinin and myosin (Tojkander et al., 2012). They are often anchored to focal adhesions to connect the ECM to the cytoskeleton and can be divided in dorsal and ventral stress fibers, as well as in transverse arcs with distinct functions. Whereas highly motile cells contain few, thin and dynamic stress fibers, thick and relative stable actin stress fibers are prominent in stationary cells as they may inhibit cell migration (Burridge, 1981; Pellegrin and Mellor, 2007).

The mechanisms of actin dynamics are mainly controlled by members of the Rho family of small GTPases which includes over 20 different members (Heasman and Ridley, 2008). The RhoGTPases RhoA, Rac and Cdc42 are the best characterized family members (Hall, 1998). RhoA plays an important role in the assembly of stress fibers and is therefore required for generating contractile forces (Ridley and Hall, 1992). Besides this, Rac plays a fundamental role in actin polymerization leadig to lamellipodium and membrane ruffle formation (Ridley et al., 1992). Cdc42 has been shown to act as a key regulator for cell polarity and filopodium formation (Nobes and Hall, 1995, 1999). These processes including actin polymerization, stress fiber- and focal adhesion formation are mainly controlled by Rho through effectors such as the Rho associated kinase ROCK. ROCK regulates the actin cytoskeleton turnover by modulating the activity of actin-binding proteins (Jaffe and Hall, 2005). One actin-binding and severing protein is cofilin. Its activity was shown to be regulated by RhoA/ROCK/LIMdomain kinase-dependent phosphorylation to regulate F-actin formation (Ohashi et al., 2000). Furthermore, cofilin is also important for the maintenance of a polarized cytoskeleton that is indispensable for directional cell migration (Dawe et al., 2003).

\subsection{Aim of this study}

Since oxygen-dependent gene expression is involved in adaptive cellular mechanisms and angiogenesis, manipulation of the HIF pathway via interfering with PHD activity is an attractive strategy for tissue protection (Katschinski, 2009). In line, cardiomyocyte-specific HIF-1 $\alpha$ stabilization has been reported to be protective against acute ischemia (Kido et al., 2005; Hyvärinen et al., 2010; Moslehi et al., 2010; Hölscher et al., 2011) and PHD enzymes have been identified as drugable targets to affect hypoxia-induced signaling in the heart. One aim of this thesis was to analyze the PHD inhibitor ICA with regard to its cardioprotective effects and to add to the understanding of the available time frame for the application of PHD inhibitors after MI. 
As cardiac fibroblasts play an important role in tissue remodeling after MI another objective of this work was to investigate the consequences of hypoxia and HIF $\alpha$-stabilization on fibroblast function. Overall this thesis should add to our understanding of cardio-protective therapeutic strategies by targeting PHD activities and stabilizing HIF $\alpha$. 


\section{Original Publications}

This chapter contains the following original publications which have been published before the submission date of this thesis.

\section{Hypoxia Modulates Fibroblastic Architecture, Adhesion and Migration: A Role for} HIF-1 $\alpha$ in Cofilin Regulation and Cytoplasmic Actin Distribution

Melanie Vogler*, Sabine Vogel*, Sabine Krull, Katja Farhat, Pia Leisering, Susanne Lutz, Christina M. Wuertz, Dörthe M. Katschinski, Anke Zieseniss

*both authors contributed equally

PLoS ONE 8.7 (2013): e69128

Pre- and post-conditional inhibition of prolyl-4-hydroxylase domain enzymes protects the heart from an ischemic insult

Melanie Vogler*, Anke Zieseniss*, Amke R. Hesse, Elif Levent, Malte Tiburcy, Eva Heinze, Nicolai Burzlaff, Gunnar Schley, Kai Uwe Eckardt, Carsten Willam, Dörthe M. Katschinski *both authors contributed equally

Pflügers Archiv - European Journal of Physiology (2015): DOI 10.1007/s00424-014-1667-z 


\subsection{Hypoxia Modulates Fibroblastic Architecture, Adhesion and Migration: A Role for HIF-1 $\alpha$ in Cofilin Regulation and Cytoplasmic Actin Distribution}

Fibroblasts play a fundamental role during embryonic development, wound healing and tissue remodeling. These processes are often associated with reduced oxygen supply leading to a hypoxic environment of the cells (Chen et al., 1999; Tandara and Mustoe, 2004). Because not much is known about the effect of hypoxia on fibroblastic properties, I analyzed and described its effect on cell architecture and function of L929 fibroblasts in the following publication. The cell area and volume, spreading and migration properties and also the composition of the actin cytoskeleton were analyzed and compared between cells cultivated under hypoxic $\left(1 \% \mathrm{O}_{2}\right)$ and normoxic $\left(20 \% \mathrm{O}_{2}\right)$ conditions. I observed striking morphological changes in hypoxia including an increase in cell area, enhanced cell spreading, and a changed focal contact assembly as well as a reduced migration and changed actin isoform distribution in hypoxia. As cells respond to hypoxia by the stabilization of HIF-1 $\alpha$, I established HIF-1 $\alpha$ knock down clones to examine its effect in the observed fibroblastic properties. In this publication I show an important role for HIF-1 $\alpha$ in the cytoskeleton-related architecture and functional changes.

\subsubsection{Declaration of my contribution}

The experiments were conceived and designed by Prof. Dr. Dörthe M. Katschinski, Prof Dr. rer. nat. Susanne Lutz and Dr. rer. nat. Anke Zieseniss. The experimental part was mainly performed by me including data analysis (cell culture, fluorescence staining for the cytoplasmic actin isoforms and confocal microscopy, cell area analysis, flow cytometry analysis, single cell migration, scratch assay, protein extraction and immunoblot analysis for HIF-1 $\alpha, \beta$-tubulin, vinculin and integrin- $\beta 1$ ) kindly supported by Dr. rer. nat. Sabine Vogel. The draft of the manuscript was written by Prof. Dr. Dörthe M. Katschinski and Dr. rer. nat. Anke Zieseniss. I wrote parts of the Material and Methods sections and proposed modifications for the publication. 


\title{
Hypoxia Modulates Fibroblastic Architecture, Adhesion and Migration: A Role for HIF-1 $\alpha$ in Cofilin Regulation and Cytoplasmic Actin Distribution
}

\author{
Melanie Vogler $^{19}$, Sabine Vogel ${ }^{19}$, Sabine Krull ${ }^{1}$, Katja Farhat ${ }^{1}$, Pia Leisering ${ }^{1}$, Susanne Lutz ${ }^{2}$, \\ Christina M. Wuertz ${ }^{2}$, Dörthe M. Katschinski ${ }^{1}$, Anke Zieseniss ${ }^{1 *}$
}

1 Institute of Cardiovascular Physiology, University Medical Center, Georg-August-University Goettingen, Goettingen, Germany, 2 Institute of Pharmacology, University Medical Center, Georg-August-University Goettingen, Goettingen, Germany

\begin{abstract}
Cells can adapt to hypoxia by various mechanisms. Yet, hypoxia-induced effects on the cytoskeleton-based cell architecture and functions are largely unknown. Here we present a comprehensive analysis of the architecture and function of L929 fibroblasts under hypoxic conditions $\left(1 \% \mathrm{O}_{2}\right)$. Cells cultivated in hypoxia showed striking morphological differences as compared to cells cultivated under normoxic conditions $\left(20 \% \mathrm{O}_{2}\right)$. These changes include an enlargement of cell area and volume, increased numbers of focal contacts and loss of cell polarization. Furthermore the $\beta$ - and $\gamma$-actin distribution is greatly altered. These hypoxic adjustments are associated with enhanced cell spreading and a decline of cell motility in wound closure and single cell motility assays. As the hypoxia-inducible factor- $1 \alpha$ (HIF-1 $\alpha$ ) is stabilised in hypoxia and plays a pivotal role in the transcriptional response to changes in oxygen availability we used an shRNA-approach to examine the role of HIF-1 $\alpha$ in cytoskeleton-related architecture and functions. We show that the observed increase in cell area, actin filament rearrangement, decrease of single cell migration in hypoxia and the maintenance of $p$-cofilin levels is dependent on HIF-1 $\alpha$ stabilisation.

Citation: Vogler M, Vogel S, Krull S, Farhat K, Leisering P, et al. (2013) Hypoxia Modulates Fibroblastic Architecture, Adhesion and Migration: A Role for HIF-1 $\alpha$ in Cofilin Regulation and Cytoplasmic Actin Distribution. PLoS ONE 8(7): e69128. doi:10.1371/journal.pone.0069128

Editor: Surinder K. Batra, University of Nebraska Medical Center, United States of America

Received March 7, 2013; Accepted June 4, 2013; Published July 18, 2013

Copyright: (c) 2013 Vogler et al. This is an open-access article distributed under the terms of the Creative Commons Attribution License, which permits unrestricted use, distribution, and reproduction in any medium, provided the original author and source are credited.

Funding: A.Z. is a Heidenreich von Siebold fellow (http://www.med.uni-goettingen.de/de/content/forschung/182.html). The funders had no role in study design, data collection and analysis, decision to publish, or preparation of the manuscript.

Competing Interests: The authors have declared that no competing interests exist.

*E-mail: anke.zieseniss@med.uni-goettingen.de

9 These authors contributed equally to this work.
\end{abstract}

\section{Introduction}

Reduced oxygen availability (hypoxia) is necessary for proper embryonic and fetal development for cells and tissues [1,2]. Cells also have to face hypoxia under pathological conditions like cardiovascular or chronic lung diseases, stroke and cancer. Moreover during wound healing, vascular injury leads to hypoxic tissue areas through loss in perfusion. Under all these circumstances fibroblasts are one of the cell types found within or migrating into the hypoxic environment. They are pivotal to embryogenesis, tissue repair and tissue remodelling. For example, they play a significant role in pathological hypoxic conditions such as myocardial scar formation after infarction [3], intestinal [4] and cutaneous wound healing. Literature shows heterogeneous effects of hypoxia on fibroblasts: Acute hypoxia can enhance human dermal fibroblasts migration and thus play a positive role in early skin wound healing [5-7]. Human pulmonary artery adventitial fibroblasts show an increase in migration [8], however, there is also a recent report demonstrating a reduced migration of dermal fibroblasts under hypoxic conditions [9]. These differences in migration are likely attributable to differences in the experimental setup, e.g. the supply of growth factors [7] and the origin of the cells.

The actin cytoskeleton is fundamental to cell locomotion and changes in migration are associated with dynamic cytoskeleton reorganization. Interestingly it has been shown in different cell types that hypoxia influences members of the Rho family of GTPases [10-14], which are master regulators of the actin cytoskeleton $[15,16]$. Besides cell motility the actin cytoskeleton governs many other cellular activities like cytokinesis, endocytosis, cell adhesion and cell shape [17-20]. Even though some studies have investigated fibroblasts under hypoxic conditions none of them have in depth focused on the morphological consequences of hypoxia on fibroblasts and the associated functional effects. Given the importance of fibroblasts in many tissues in normal and pathological conditions we set out to study the hypoxic adjustments of L929 fibroblasts and found striking changes in cell shape, attachment and motility. These changes are partly related to the hypoxic reorganisation of cytoplasmic actins which depends on the stabilisation of the hypoxia-inducible factor- $1 \alpha$ (HIF- $1 \alpha)$.

\section{Results}

Hypoxia Changes Cell Morphology and Focal Contact Assembly

As a first step in investigating the effects of hypoxia on cell architecture L929 fibroblasts were cultivated in normoxic $(20 \%$ 
$\left.\mathrm{O}_{2}\right)$ and hypoxic $\left(1 \% \mathrm{O}_{2}\right)$ conditions. Cells cultivated in hypoxia for 24 hrs showed striking morphological changes compared to normoxic control cells (Fig. 1A). Under hypoxic conditions the cell area significantly increased compared to normoxic conditions. To address the question whether the increase in L929 cell area is due to flattening and spreading of the cells or is accompanied by an increase in cell volume the cells were analysed by flow cytometry (Fig. 1B). Measurements of forward-angle light scatter (FSC) showed that the enlarged cell area under hypoxic conditions goes along with a gain in cell volume. To analyse whether this change in cell morphology under hypoxic conditions also correlates with a change in focal adhesions the cells were immunostained for vinculin, a characteristic focal contact protein and focal contacts were quantified (Fig. 1C). 24 hrs of hypoxic incubation led to a significantly increased average number of vinculin positive focal contacts. In line with this result we also observed the accumulation of $\beta 1$-integrin at the cell surface using flow cytometry (Fig. 1D).

\section{Advanced Early Cell Spreading and Delayed Cell Migration of L929 Cells in Hypoxia}

As integrins initiate the formation of focal adhesions the consequence of their higher number in hypoxia on the early stages of cell attachment and spreading behaviour was analysed. Cells grown under normoxic or hypoxic conditions were suspended, replated, cultured and allowed to attach for $20 \mathrm{~min}$, then fixed and stained with phalloidin-FITC. Cells were grouped into three categories: category $\mathrm{A}$, round cells, weakly adhered; category $\mathrm{B}$, weakly adhered cells in the course of spreading; category C, flat cells, well spread. Examples of each category are shown in Figure 2A. Compared with cells grown under normoxic conditions hypoxia was found to considerably enhance early cell spreading of L929 cells and notably more hypoxic cells were found in the group of flat, well spread cells whereas the normoxic cells were barely spread.

The observed changes in early cell spreading prompted us to investigate the influence of hypoxia on L929 cell migration as both processes depend on the cell attachment. A L929 monolayer was scratched with a sterile pipet tip and wound closure was analysed. We observed a marked reduction in the overall speed of wound closure in hypoxic cells. Whereas the normoxic L929 cells almost closed the wound within $30 \mathrm{hrs}$, the hypoxic cells were markedly delayed (Fig. 2B). Cell proliferation of L929 cells in hypoxia was hold up compared to normoxic conditions. In normoxia L929 cells had a doubling time of $10.69 \pm 0.03783 \mathrm{hrs}$ whereas in hypoxia the doubling time was $12.17 \pm 0.1974 \mathrm{hrs}$. Thus, to further validate the hypoxic effect on cell migration a single cell motility assay was performed. For this purpose cells were seeded at very low density to minimize the effect of cell-cell contacts and individual moving cells, excluding those undergoing mitosis, were analysed over a $360 \mathrm{~min}$ period under normoxic and hypoxic conditions. Consistent with our findings from the scratch assay hypoxic cells displayed a significant reduction in single cell random migration (Fig. 2C). In summary, our results from both, the scratch assay and the single cell migration assay clearly show that hypoxia causes decreased cell migration of L929 cells.

\section{Hypoxia Changes the Organization of Cytoplasmic Actins}

As cell spreading and cell migration depend on actin polymerization and actin networks, we determined the actin stress fiber complement of L929 cells kept in both conditions, and analysed the subcellular distribution of the $\beta$ - and $\gamma$-actin isoforms. Using highly specific antibodies [21], immunofluorescence staining and confocal microscopy we found the expected, almost uniform distribution of $\beta$ - and $\gamma$-cytoplasmic actin and a partial overlap of both actin isoforms in L929 cells under normoxic conditions (Fig. 3A). However, this subcellular pattern changed in hypoxia (Fig. 3B). There was a partial segregation of $\beta$ - and $\gamma$ - cytoplasmic actin between different forms of F-actin bundles. In hypoxia $\gamma$ cytoplasmic actin was preferentially located within fibres at the periphery of the cell whereas in many cells $\beta$-cytoplasmic actin accumulated in circular bundles. A differential distribution of both actin isoforms is in accordance with previous reports describing the localization pattern of cytoplasmic $\beta$ - and $\gamma$-actin in stationary and moving cells [21]. However, it was never reported before that hypoxia induces the actin isoform redistribution.

\section{The Hypoxia-inducible Factor- $1 \alpha$ Regulates Cell Area Increase Under Hypoxia}

HIF-1 is the main transcription factor involved in the cellular response to decreased oxygen availability [22] (Fig. 4A). It is a heterodimeric complex consisting of the stable $\beta$-subunit and the $\alpha$-subunit that is rapidly degraded in normoxia [23]. This degradation is controlled by the prolyl-4-hydroxylase domain enzymes (PHDs) which, in the presence of oxygen, hydroxylate HIF- $1 \alpha$ and thus target it for proteasomal degradation [24,25] Inhibition of the PHDs results in the stabilisation of HIF- $1 \alpha$ under normoxic conditions and the subsequent expression of HIF-1 target genes that are involved in metabolic adaptation, cell survival, angiogenesis etc. [26].

To gain further insight into the interrelationship between HIF-1 and the observed morphological changes in L929 cells we inhibited the enzymatic activity of the PHDs using the oxoglutarate analog dimethyloxalylglycine (DMOG) [27]. As expected we observed a normoxic stabilisation of HIF- $1 \alpha$ in DMOG-treated L929 cells, which was comparable to the stabilisation of HIF-1 $\alpha$ in hypoxia (Fig. 4B). This was correlated with a significant increase in cell area indicating that this morphological change either depends on PHD-activity or on the stabilisation of HIF-l $\alpha$ (Fig. 4C). To discriminate between these possibilities, we used an shRNA approach and established the HIF- $1 \alpha$ L929 knock down cell lines L929 HIF- $1 \alpha$ clone 1 (c1) and L929 HIF-1 $\alpha$ clone 2 (c2) (Fig. 4D). Simultaneously L929 cells that stably express a non-target control shRNA (shC) were generated to serve as controls. Under hypoxic conditions L929 cells and shC cells showed a strong stabilisation of HIF-1 $\alpha$. This effect was greatly reduced in both HIF- $1 \alpha$ knock down cell clones $\mathrm{cl}$ and $\mathrm{c} 2$ as seen in Western Blot analysis (Fig. 4D). Hypoxia caused an increase in cell area in the shC cells (Fig. 4E). Remarkably, this increase in cell area was completely abolished in both of the HIF$1 \alpha$ knock down cell clones (Fig. 4E). However in flow cytometry the cells still showed a rightward shift of the forward-angle light scatter indicating an increase of cell volume (Fig. 4F). In summary, our data indicate that the change in cell area in hypoxia is HIF- $1 \alpha$ dependent, while the change in cell volume is not regulated by HIF- $1 \alpha$.

\section{Focal Contact Formation, Enhanced Spreading and Sheet} Migration of L929 Cells in Hypoxia is Independent of HIF$1 \alpha$

Having observed that the hypoxic changes of cell shape are HIF- $1 \alpha$ dependent, we were interested in the functional significance of HIF- $1 \alpha$ in the context of focal contact formation and cell spreading. Similar to the wild type (wt) L929 cells the number of vinculin-positive focal contacts increased in hypoxia in shC cells (Fig. 5A). A comparable effect was also seen in both of the HIF-1 $\alpha$ knock down cell clones $\mathrm{cl}$ and $\mathrm{c} 2$. This increase in focal contacts in the control and knock down cell clones was corroborated by flow 
A
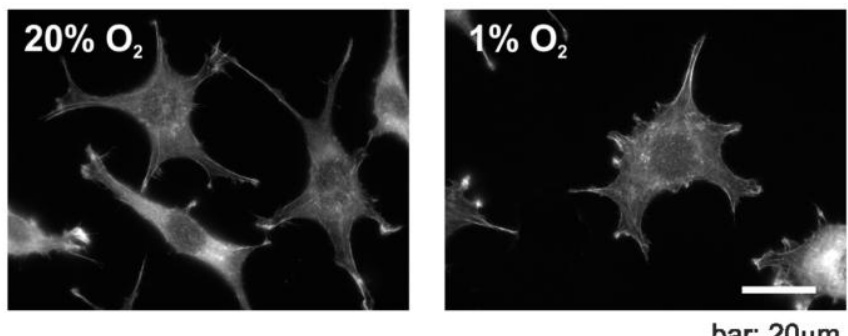

B

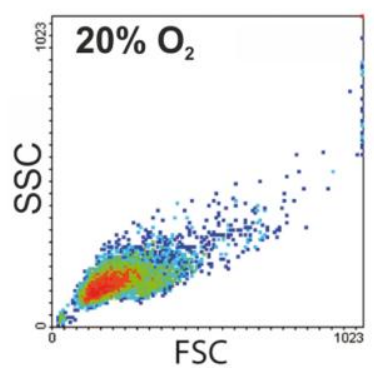

C
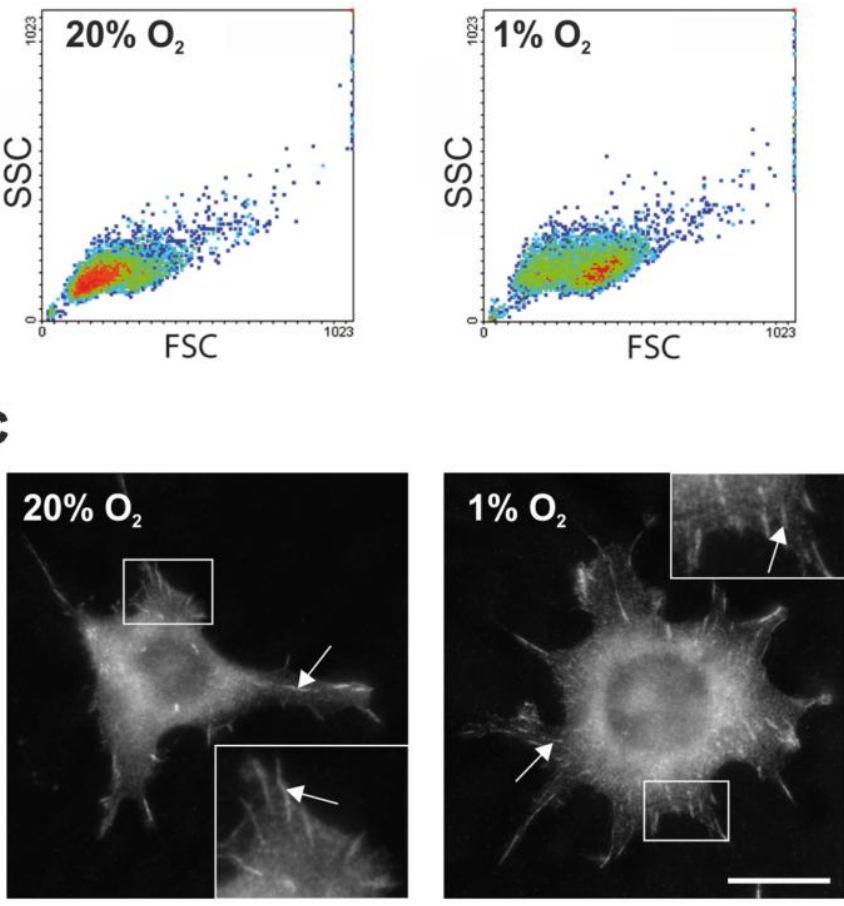

bar: $20 \mu \mathrm{m}$
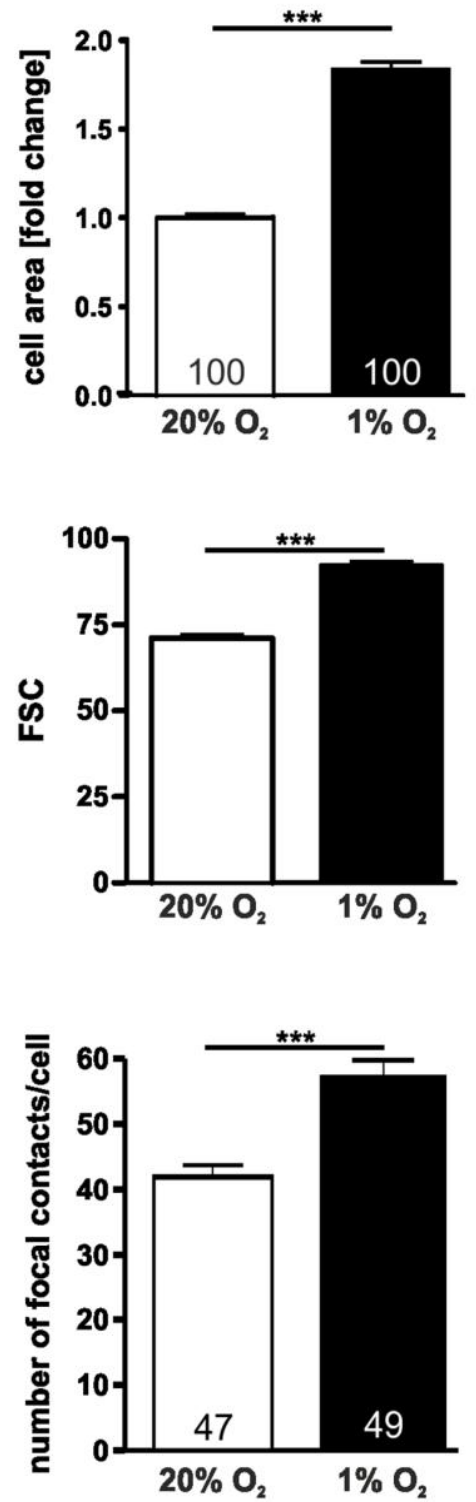

D

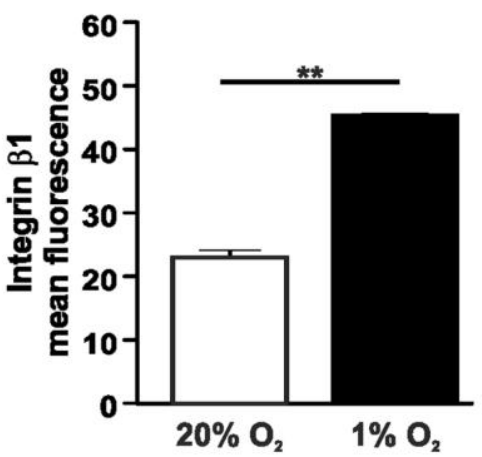

Figure 1. Hypoxia changes cell size and focal contact number. (A) Hypoxia increases the cell area of L929 fibroblasts. Cells were incubated in normoxic $\left(20 \% \mathrm{O}_{2}\right)$ or hypoxic conditions $\left(1 \% \mathrm{O}_{2}\right)$ for 24 hrs fixed and stained with phalloidin-FITC. The cell area of single cells was measured and was 
calculated as fold change compared to $20 \% \mathrm{O}_{2}$. (B) Flow cytometry analysis of cell volume after incubation in normoxia and hypoxia for 24 hrs. Cells were harvested after 24 hrs. Single cell suspension was prepared by enzymatic digestion. (C) Immunofluorescence images of vinculin in L929 cells. Focal contacts were counted after 24 hrs of hypoxic or normoxic incubation. Note the increase in vinculin positive focal contacts in hypoxia. Arrows point to exemplary focal contacts. (D) Flow cytometry analysis of L929 cells after incubation for 24 hrs in normoxia and hypoxia stained with integrin $\beta 1$ antibodies. Numbers within the bars indicate the number of cells analysed. ${ }^{* *} p<0.01,{ }^{* * *} p<0.001$. Bars represent mean values \pm SEM. doi:10.1371/journal.pone.0069128.g001

cytometry data which show an increase in $\beta 1$-integrin at the cell surface (Fig. 5B). However, total vinculin and $\beta 1$-integrin protein levels were not changed in hypoxia compared to normoxia (Fig. 5C). Furthermore, we examined the spreading of L929 cells in the absence of HIF-1 $\alpha$ (Fig. 5D) and did not find any marked changes in the spreading capability. In wt, shC and the HIF- $1 \alpha$ knock down cell clones the spreading kinetics increased in hypoxia.

In cell wounding assays the migration behaviour of $\operatorname{shHIF-1} \alpha \mathrm{cl}$ and shHIF- $1 \alpha$ c 2 resembled that of shC cells under normoxic conditions (Fig. 6A). The proliferation of all three cell lines was also comparable (generation time shC: $11.62 \pm 0.1458 \mathrm{hrs}$; gener- ation time shHIF-l $\alpha$ cl:11.13 $\pm 0.2628 \mathrm{hrs;}$ generation time shHIF- $1 \alpha$ c2:10.92 \pm 0.4984 hrs). However, under hypoxic conditions wound closure in the HIF-1 $\alpha$ knock down clones $\mathrm{cl}$ and $\mathrm{c} 2$ was even more delayed than in the shC cells (Fig. 6A). The generation times were prolonged compared to normoxic conditions but were comparable between cell types (generation time shC: $14.41 \pm 0.03036 \mathrm{hrs}$; generation time shHIF-1 $\alpha$ $\mathrm{cl}: 13.25 \pm 0.06483 \mathrm{hrs} ; \quad$ generation time shHIF-l $\alpha$ c2: $13.27 \pm 0.2580 \mathrm{hrs}$.
A cell category

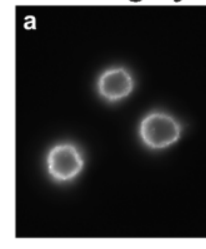

B

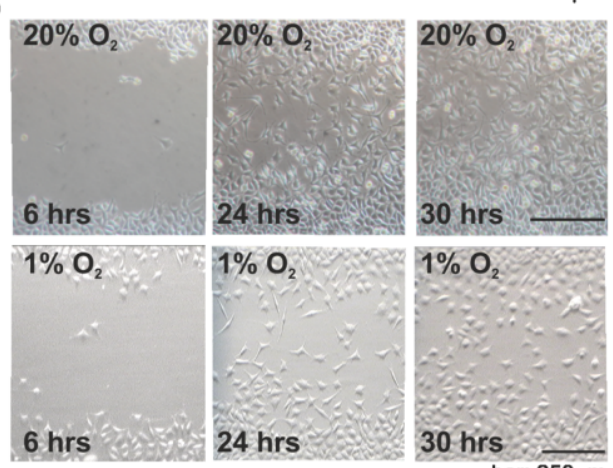

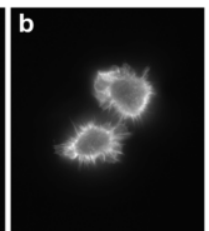

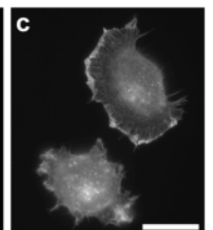

ar:20um

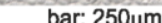

$20 \% \mathrm{O}_{2}$
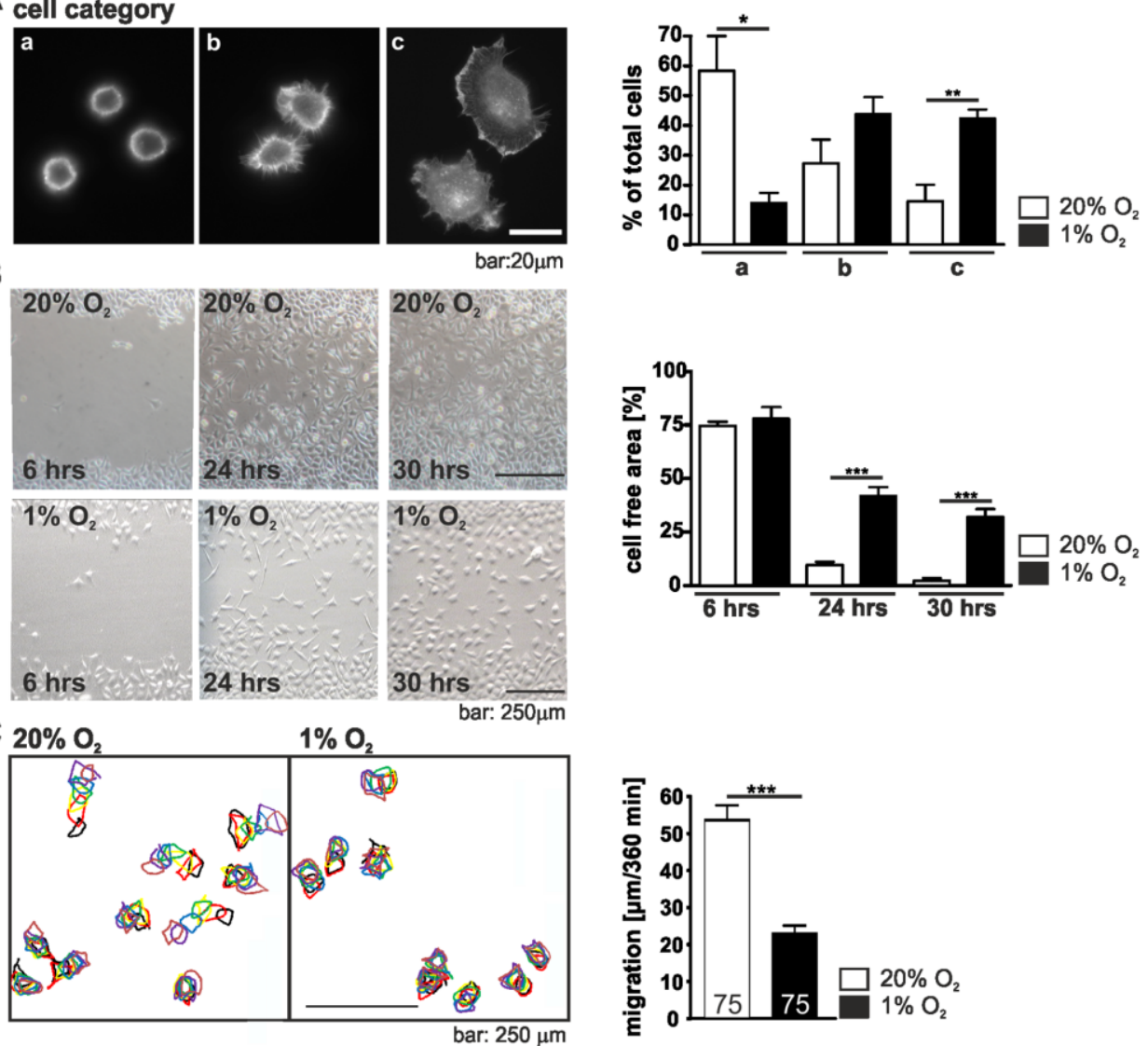

Figure 2. Hypoxia changes cell spreading and migration. (A) Spreading of L 929 cells in normoxia and hypoxia. $L 929$ cells were incubated under normoxic $\left(20 \% \mathrm{O}_{2}\right)$ or hypoxic conditions $\left(1 \% \mathrm{O}_{2}\right)$, trypsinized and replated for 20 min. Cells were fixed, stained with phalloidin-FITC and divided into three categories (a: round, barely spread; b: in the course of spreading; c: well spread). The percentage of cells in each category was determined. Note that L929 fibroblasts spread faster under hypoxic conditions. (B) Scratch wound healing assays under normoxic and hypoxic conditions. The cell monolayer was scratched with a sterile pipette tip. Images were taken $6,12,30$ hrs after wounding and the cell-free area was determined. Note that L929 fibroblasts in hypoxia migrate slower into the scratch. (C) Single cell migration of L929 fibroblasts. After 24 hrs of normoxic and hypoxic incubation bright field images of the cells were taken over a period of 360 min. Images were superimposed and the path of the cells was reconstructed by monitoring the cells at each timepoint (going from black to brown). Note that single cell migration is slower under hypoxic conditions. Numbers within the bars indicate the number of cells analysed. ${ }^{*} p<0.05,{ }^{* *} p<0.01,{ }^{* * *} p<0.001$. Bars represent mean values \pm SEM.

doi:10.1371/journal.pone.0069128.g002 

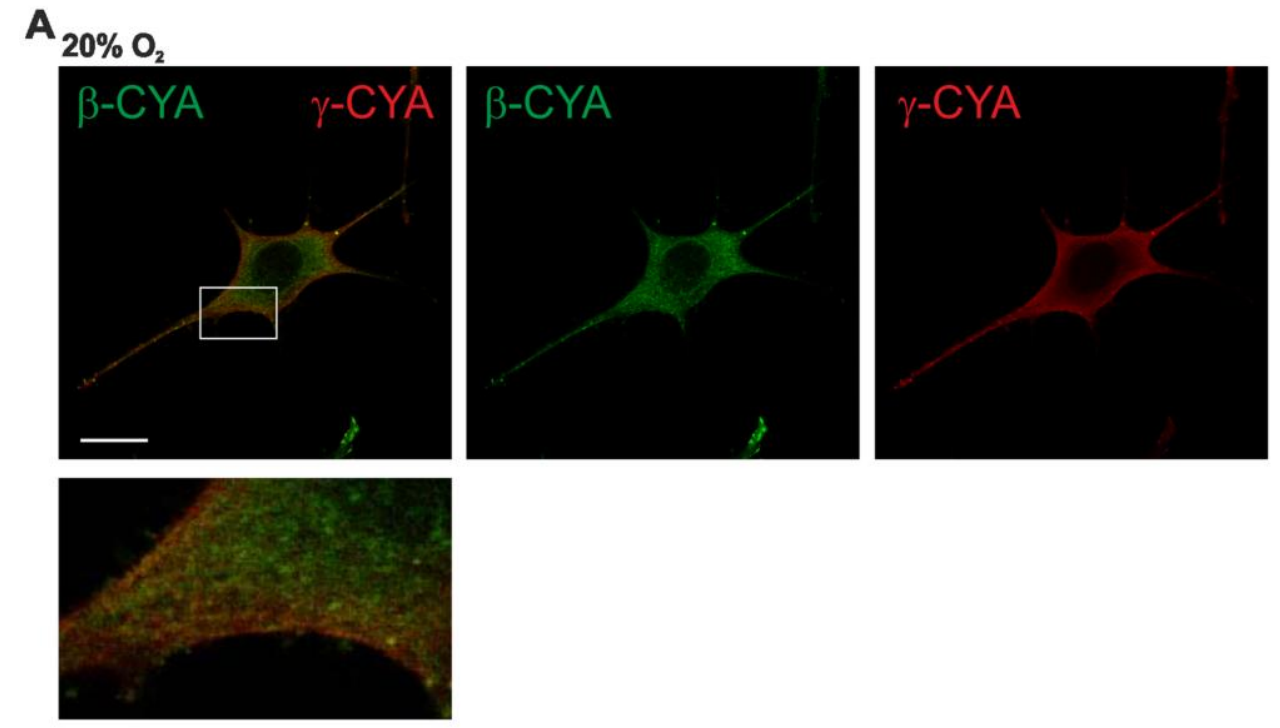

B
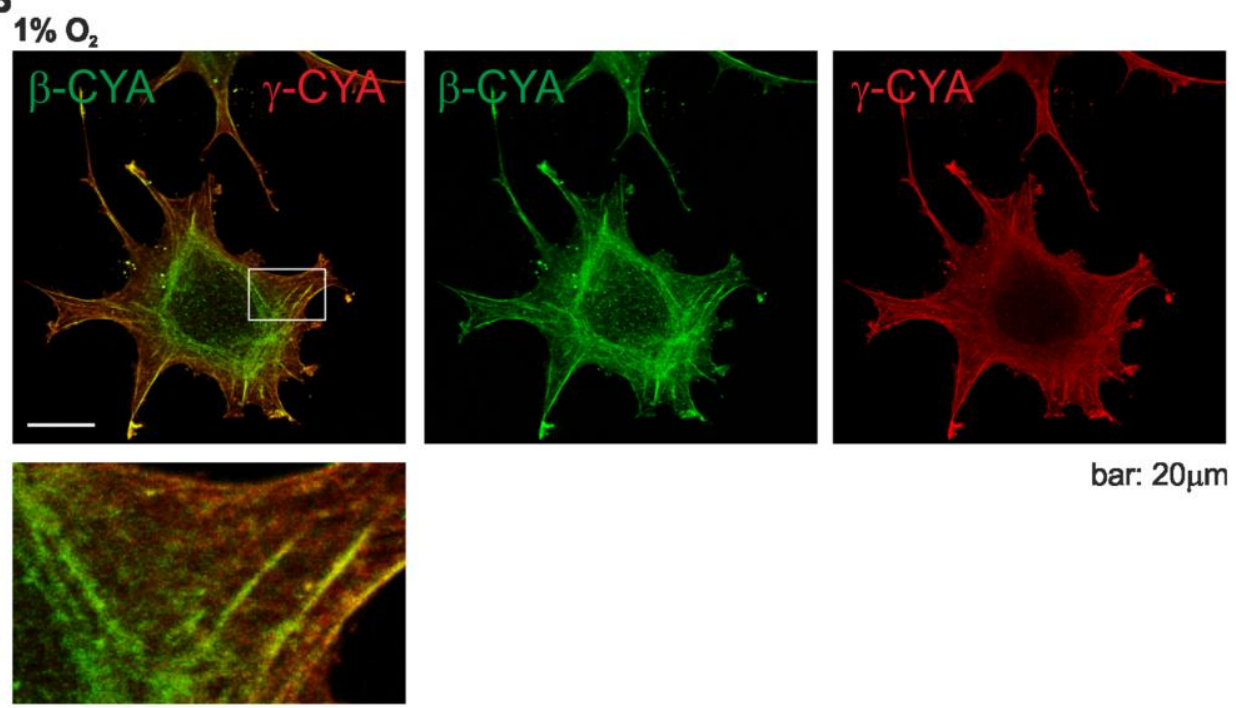

bar: $20 \mu \mathrm{m}$

Figure 3. Hypoxia induces the reorganisation of the actin cytoskeleton. $\beta$ - and $\gamma$-actin distribution in L929 fibroblasts in normoxia (A) and in hypoxia (B). Cells were grown for 24 hrs in normoxic or hypoxic conditions and subsequently stained for $\beta$-actin and $\gamma$-actin. Under normoxic conditions both actin isoforms colocalize. In contrast, under hypoxic conditions the cells develop ring-like actin bundles in the cell center, which are greatly enriched with $\beta$-actin, while $\gamma$-actin is enriched at the cell periphery.

doi:10.1371/journal.pone.0069128.g003

Single Cell Migration and Actin Remodelling of L929 Cells in Hypoxia Depend on HIF- $1 \alpha$

In single cell migration experiments both HIF- $1 \alpha$ shRNA clones $\mathrm{cl}$ and $\mathrm{c} 2$ showed a slight decrease in migration under normoxic conditions when compared to the shRNA control clone. However, hypoxia did not change the migration of the HIF- $1 \alpha$ knock down clones whereas the migration of shC cells was significantly reduced (Fig. 6B). These results point to a different role of HIF-1 $\alpha$ in sheet migration as seen in wounding assays and single cell migration under hypoxic conditions.

Remarkably, when we analysed the distribution of cytoplasmic $\beta$ - and $\gamma$-actins in the HIF- $1 \alpha$ knock down L929 cell clones we did not see differences between cells under hypoxic or normoxic conditions. The shC cells showed a redistribution of $\beta$ - and $\gamma$ actins in hypoxia similar to wt L929 cells (Fig. 7).

\section{Cofilin Phosphorylation Depends on HIF-1 $\alpha$ Expression}

Actin dynamics are modulated by cofilin, an actin-binding and severing protein. Cofilin activity is regulated via phosphorylation. LIM kinase dependent phosphorylation inactivates cofilin and thus promotes F-actin assembly, whereas dephosphorylated cofilin is active. This results in severing of actin filaments and sequestering of actin monomers from the pointed end of the filament [28]. Elevated cofilin phosphorylation was observed in hypoxic cells 


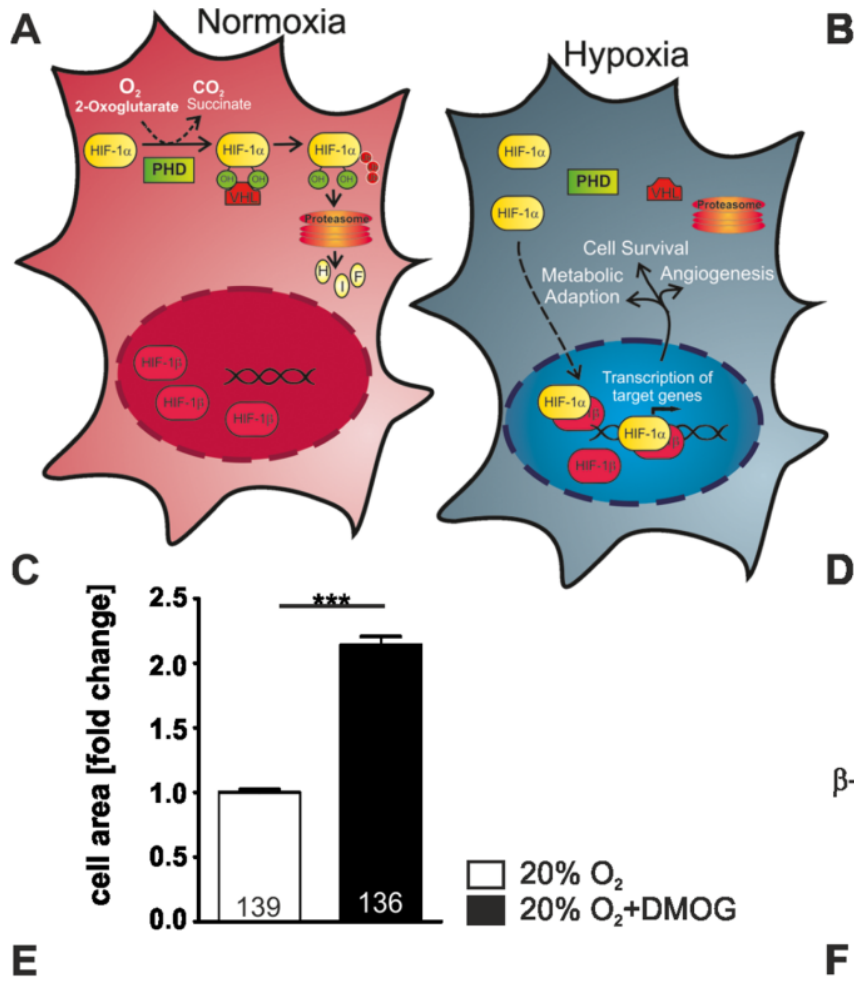

B

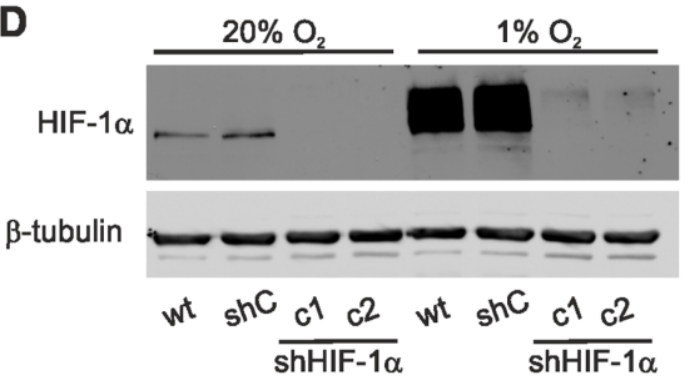

$\mathbf{E}$

$\mathbf{F}$
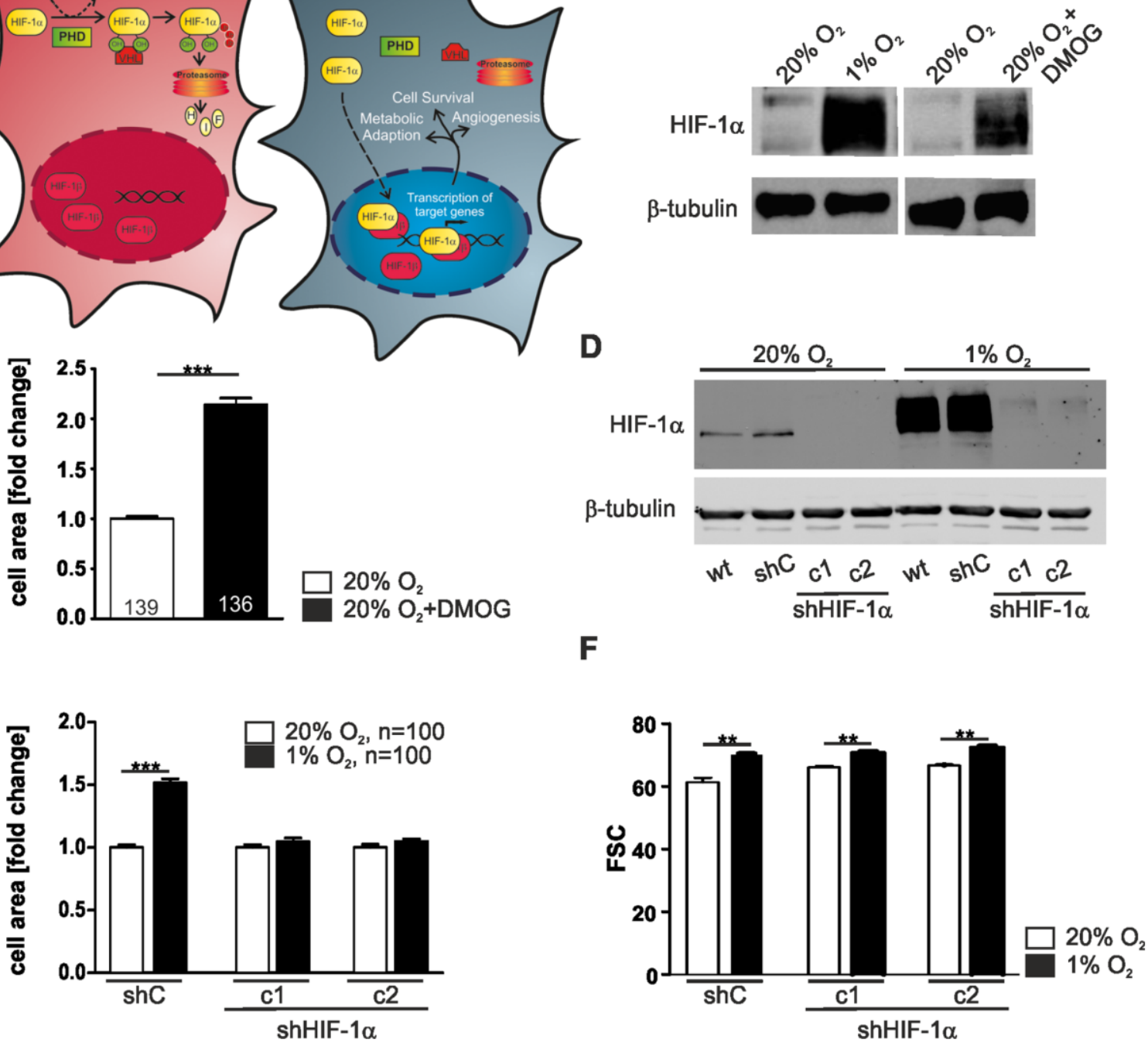

Figure 4. HIF-1 $\alpha$ stabilisation regulates cell area. (A) Schematic drawing of HIF-1 and its regulation in normoxia and hypoxia. The stability of the HIF-1 $\alpha$ subunit is regulated by prolyl-4-hydroxylase domain (PHD) enzymes in an oxygen dependent manner. Following hydroxylation of the critical prolyl residues under normoxic conditions, the ubiquitin ligase von Hippel-Lindau tumor suppressor protein (pVHL) recognises HIF-1 $\alpha$ subunits and targets them for rapid ubiquitination and proteasomal degradation under normoxic conditions. Hypoxia impairs the hydroxylation, which results in HIF-1 $\alpha$ stabilisation, nuclear accumulation, heterodimerisation with HIF-1 $\beta$ and subsequent hypoxia-inducible gene expression. (B) Inhibition of PHDs by DMOG causes HIF-1 $\alpha$ stabilisation under normoxic conditions. L929 cells were treated with 1 mM DMOG for 48 hrs and total extracts were analysed by immunoblot with the respective antibodies. (C) The cell area of DMOG treated cells increased significantly. The cell area of single cells was measured and was calculated as fold change compared to $20 \% \mathrm{O}_{2}$. (D) Two HIF-1 $\alpha$ knock down cell clones (c1, c2) and a non-target control shRNA cell clone (shC) were obtained via stable transduction of specific sh-plasmids. The HIF-1 $\alpha$ knock down was verified in western blot experiments of cell lysates from cells incubated at $20 \% \mathrm{O}_{2}$ or $1 \% \mathrm{O}_{2}$. $\beta$-tubulin was used as a loading control. (E) HIF-1 $\alpha$ knock down cell clones ( 1 , c2) do not respond to hypoxia with an increase in cell area. The cell area of single cells was measured and was calculated as fold change compared to the cell clone cultivated at $20 \% \mathrm{O}_{2}$. (F) Flow cytometry analysis of cell volume after incubation in normoxia and hypoxia. shC, c1 and c2 cells were harvested after 24 hrs of normoxic $\left(20 \% \mathrm{O}_{2}\right)$ or hypoxic $\left(1 \% \mathrm{O}_{2}\right)$ incubation. Single cell suspension was prepared by enzymatic digestion. Note that hypoxia increases the cell volume independently of the HIF-1 $\alpha$ knock down.

doi:10.1371/journal.pone.0069128.g004

$[29,30]$ and tissues [31]. This led us to investigate the expression and phosphorylation status of cofilin in L929 cells by Western blot. In wt and shC cells the phosphorylation of cofilin was slightly elevated in hypoxia (Fig. 8). In the HIF-1 $\alpha$ knock down cells we noted a marked reduction in cofilin phosphorylation as compared to wt and shC cells. This decrease was seen under normoxic and hypoxic conditions with no obvious changes in total cofilin protein levels. Hence, these data provide evidence for a direct link between 
A

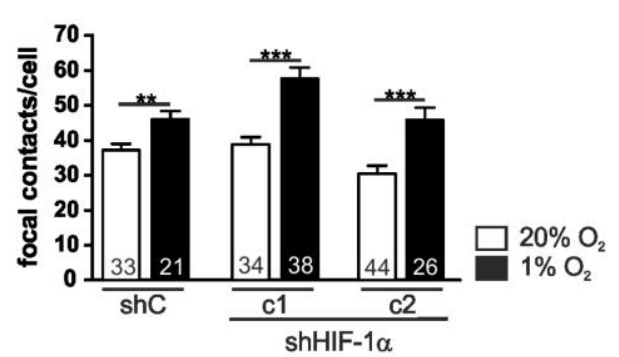

C

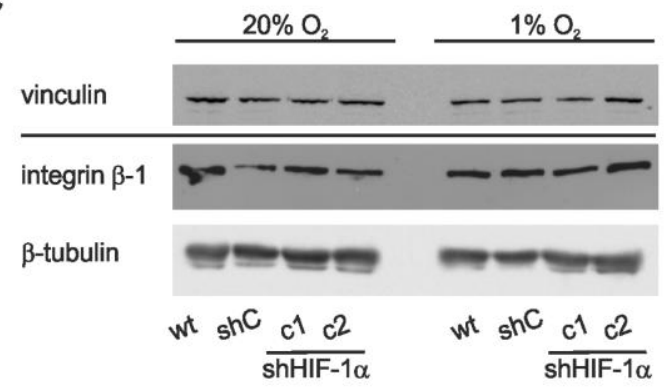

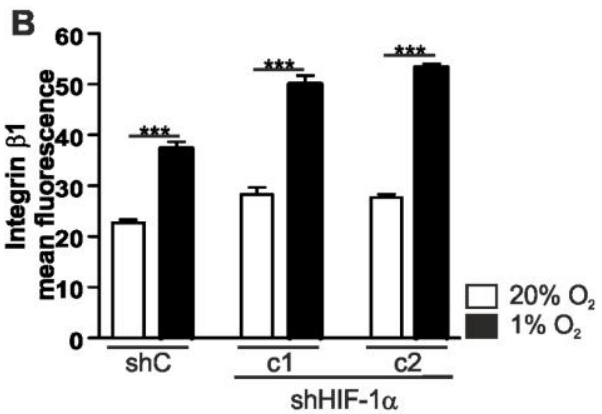

D

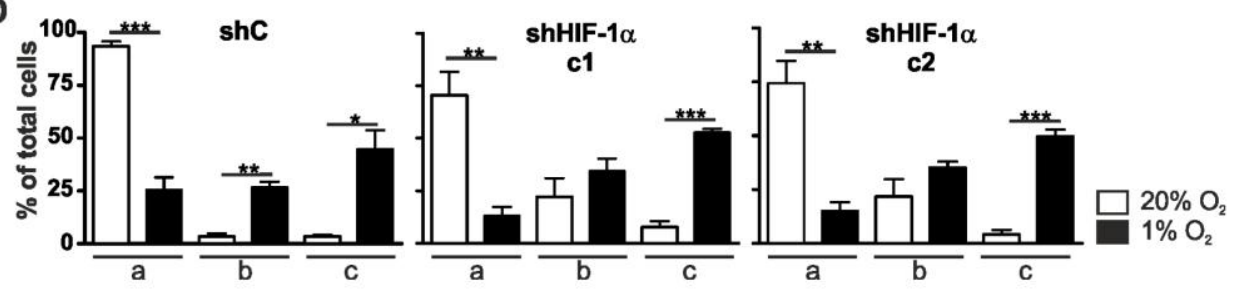

Figure 5. Depletion of HIF-1 $\alpha$ does not affect the number of focal contacts and cell spreading. (A) Two HIF- $1 \alpha$ knock down cell clones (c1, c2) and a non-target control shRNA cell clone (shC) were stained for vinculin 24 hrs after normoxic $\left(20 \% \mathrm{O}_{2}\right)$ or hypoxic $\left(1 \% \mathrm{O}_{2}\right)$ incubation. Counting vinculin positive focal contacts showed a higher number of focal contacts in hypoxia in all three cell lines. (B) Flow cytometry analysis of the HIF-1 $\alpha$ knock down cell clones $\mathrm{c} 1$ and $\mathrm{c} 2$ and the non-target control shRNA cell clone (shC) after 24 hrs of normoxia or hypoxia stained with integrin $\beta 1$ antibodies. (C) Wt, shC, and the HIF-1 $\alpha$ knock down cell clones $\mathrm{c} 1$ and $\mathrm{c} 2$ cells were lysed after 24 hrs of normoxia $\left(20 \% \mathrm{O}_{2}\right)$ or hypoxia $\left(1 \% \mathrm{O}_{2}\right)$. Cell extracts were analysed by Western blots. Note that vinculin and integrin $\beta 1$ levels are not changed in hypoxia. (D) Cell spreading of the HIF-1 $\alpha$ knock down cell clones $\mathrm{c} 1$ and $\mathrm{c} 2$ and the non-target control shRNA (shC) cell clone in normoxia and hypoxia. Cells were incubated at $20 \% \mathrm{O}_{2}$ and $1 \% \mathrm{O}_{2}$ trypsinised and replated for $20 \mathrm{~min}$. Cells were fixed and stained with phalloidin-FITC and divided into three categories (a: round, barely spread; b: in the course of spreading; c: well spread). The percentage of cells in each category was determined. All three cell lines spread faster under hypoxic conditions. Numbers within the bars indicate the number of cells analysed. ${ }^{* *} p<0.01,{ }^{* * *} p<0.001$. Bars represent mean values \pm SEM. doi:10.1371/journal.pone.0069128.g005

HIF- $1 \alpha$ expression and cofilin phosphorylation that may be pivotal for the hypoxia induced changes in L929 fibroblast morphology and function as described above.

\section{Discussion}

Fibroblasts encounter hypoxic environments in physiological and pathological conditions e.g. development, cardiovascular diseases and wound healing. However little is known about the morphological and functional consequences of hypoxia on fibroblasts so far. In the current study, we demonstrate that hypoxia strikingly changes cell area, cell volume, cell adhesion and motility in L929 fibroblasts. With the exception of the changes in cell volume and adhesion these phenomena can be accounted for by the stabilisation of HIF- $1 \alpha$. We can link HIF- $1 \alpha$ stabilisation to $\mathrm{p}$-cofilin levels with a rearrangement of cytoplasmic $\beta$-actin and changes in L929 cell morphology and function (Fig. 9).
Our studies show an increase in L929 fibroblasts cell volume in hypoxia. This increase is independent of HIF- $1 \alpha$ stabilisation as it was also seen after knock down of HIF- $1 \alpha$. Increases in cell volume of cerebral microvascular endothelial cell monolayers and of astrocytes in hypoxic conditions have been reported in previous studies $[32,33]$ and have been found to be partially dependent on $\mathrm{Na}-\mathrm{K}-\mathrm{Cl}$ cotransporter and $\mathrm{Na} / \mathrm{H}$ exchange activity. Parallel to an increase in cell volume we noticed an increase in cell area of L929 fibroblasts under hypoxic conditions. As hypoxia is known to induce changes in the cytoskeleton, e.g. the exposure of endothelial cells to hypoxia causes a shift in filamentous actin from a web like structure to parallel stress fibres [34], we speculated that a change in cell morphology might depend on cytoplasmic actin rearrangement. Monitoring the distribution of actin isoforms we found that under normoxic conditions both $\beta$ - and $\gamma$-cytoplasmic actin partly colocalised, while hypoxia provoked a reorganization of the cytoplasmic actin network with enhanced formation of $\beta$ - 
A

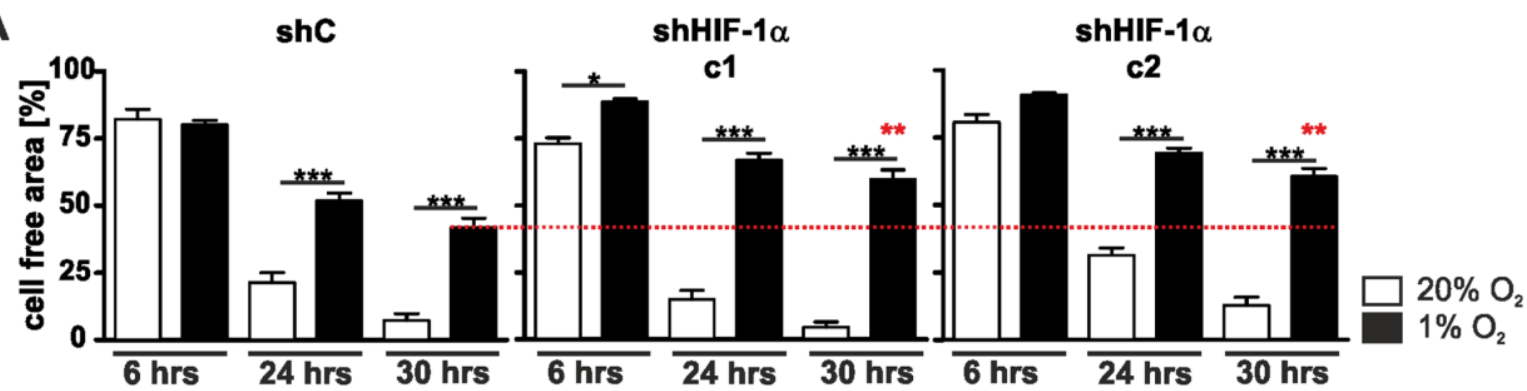

B
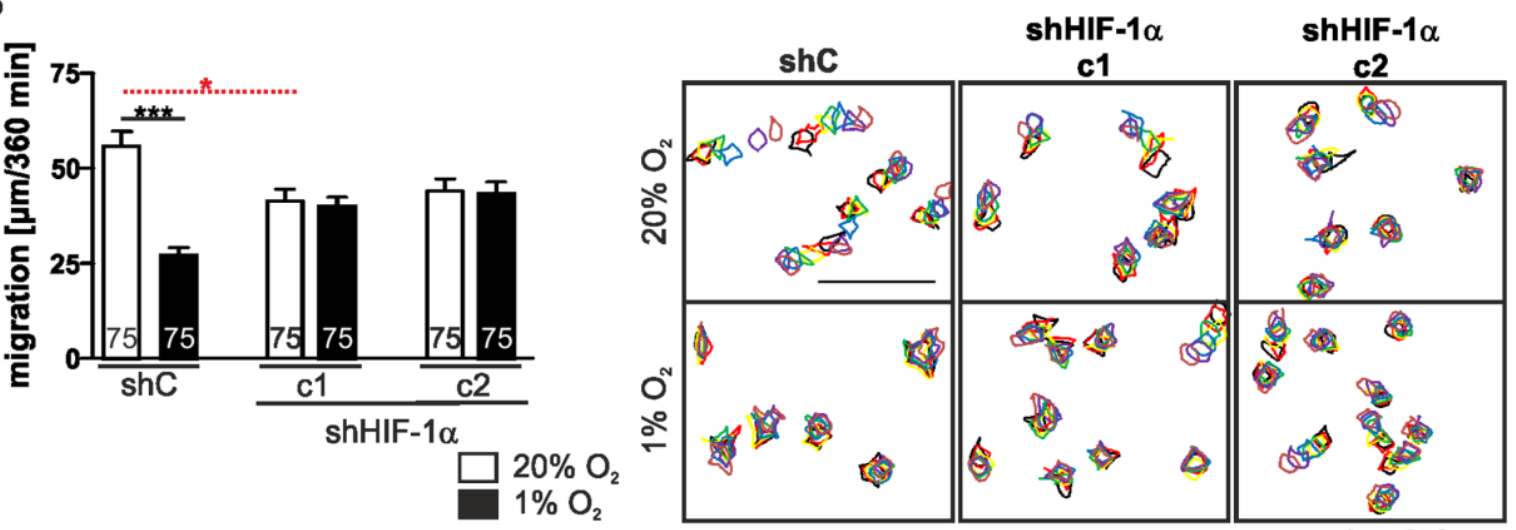

bar: $250 \mu \mathrm{m}$

Figure 6. Depletion of HIF-1 $\alpha$ alters cell motility. (A) Wounding assay of the HIF-1 $\alpha$ knock down cell clones $\mathrm{c} 1$ and $\mathrm{c} 2$ and the non-target control shRNA (shC) cell clone in normoxia and hypoxia. Cells were grown in normoxia and hypoxia and experimental wounds were caused by scratching cell monolayers with a pipet tip. Images were taken at the indicated time points and the cell free area was determined. Hypoxia delayed wound healing. Note that knocking down HIF-1 $\alpha$ slowed wound closure down even more (dashed red line). (B) Single cell migration of the HIF-1 $\alpha$ knock down cell clones $\mathrm{c} 1$ and $\mathrm{c} 2$ and the shC cells. Cells were incubated at $20 \% \mathrm{O}_{2}$ and $1 \% \mathrm{O}_{2}$ for 24 hrs. Images were taken over a time period of $360 \mathrm{~min}$ and cell movement was analysed. shC cells showed a reduced migration under hypoxic condition, however this effect was not seen in the HIF- $1 \alpha$ knock down clones $c 1$ and $c 2$. Numbers within the bars indicate the number of cells analysed. ${ }^{* *} p<0.01,{ }^{* * *} p<0.001$. Bars represent mean values \pm SEM.

doi:10.1371/journal.pone.0069128.g006

cytoplasmic actin containing stress fibres around the cell centre and with $\gamma$-cytoplasmic actin enriched in a meshwork at the periphery of the cell. As the intrinsic polarity of the cytoskeletal components is required for directed movement, these findings suggest that the formation of circular $\beta$-cytoplasmic actin bundles may be causative for the reduced single cell migration of L929 cells in hypoxia. The cytoplasmic actin rearrangement was dependent on HIF- $1 \alpha$ stabilisation and was not observed in shHIF- $1 \alpha$ knockdown L929 cells. It is coherent that shHIF-l $\alpha$ knock down fibroblasts did not show an increase in cell area and a further reduction in single cell migration in hypoxia.

In hypoxia we also observed the accumulation of integrins and vinculin containing focal contacts. The most obvious roles for focal contacts involve their ability to dynamically connect the cell membrane with the substratum and thus allow cells to attach, detach and move. As a consequence of hypoxia cell spreading of L929 cells was altered and significantly faster compared to normoxic conditions. This is in line with the observation that the accumulation of $\beta 1$-integrin at the cell surface of HeLa cells results in more efficient cell spreading [35] and that increasing vinculin expression in 3T3 cells also increased the formation of focal contacts and enhanced cell spreading [36]. On the other hand, an increase in vinculin containing focal contacts has been shown to suppress cell motility in wound closure experiments and to reduce individual cell locomotion [36]. This finding provides another possible explanation for the observed effect of hypoxia on cell migration. HIF- $1 \alpha$ depletion did not influence $\beta 1$-integrin accumulation or focal contact number in hypoxia. Neither did it reverse the hypoxic cell adhesion phenotype implying that these are at least in part HIF- $1 \alpha$ independent effects. However the impaired wound healing under hypoxic conditions was even further reduced after HIF- $1 \alpha$ knock down. Taken together our data show that HIF-l $\alpha$ is involved in L929 cell migration in wound healing experiments as well as in single cell migration. Nevertheless, depending on the migration mode (single cell migration versus "sheet migration" in wound healing experiments), the underlying mechanisms seem to differ and it is feasible that multiple pathways are involved.

The dynamic control of the actin cytoskeleton is essential for cell migration and is mediated by RhoGTPases which control a multitude of actin-binding proteins [17,37]. For instance RhoROCK and Rac-PAK signalling pathways activate LIM-kinase that in turn can phosphorylate and inhibit the actin filament severing protein cofilin [28]. This results in a reorganisation of the actin cytoskeleton. The importance of cofilin in remodeling processes and the maintenance of a polarised cytoskeleton, which is a prerequisite for directional cell migration, has been shown in several studies and the phosphorylation and inactivation of cofilin 
Hypoxia Induces Changes in Fibroblastic Function

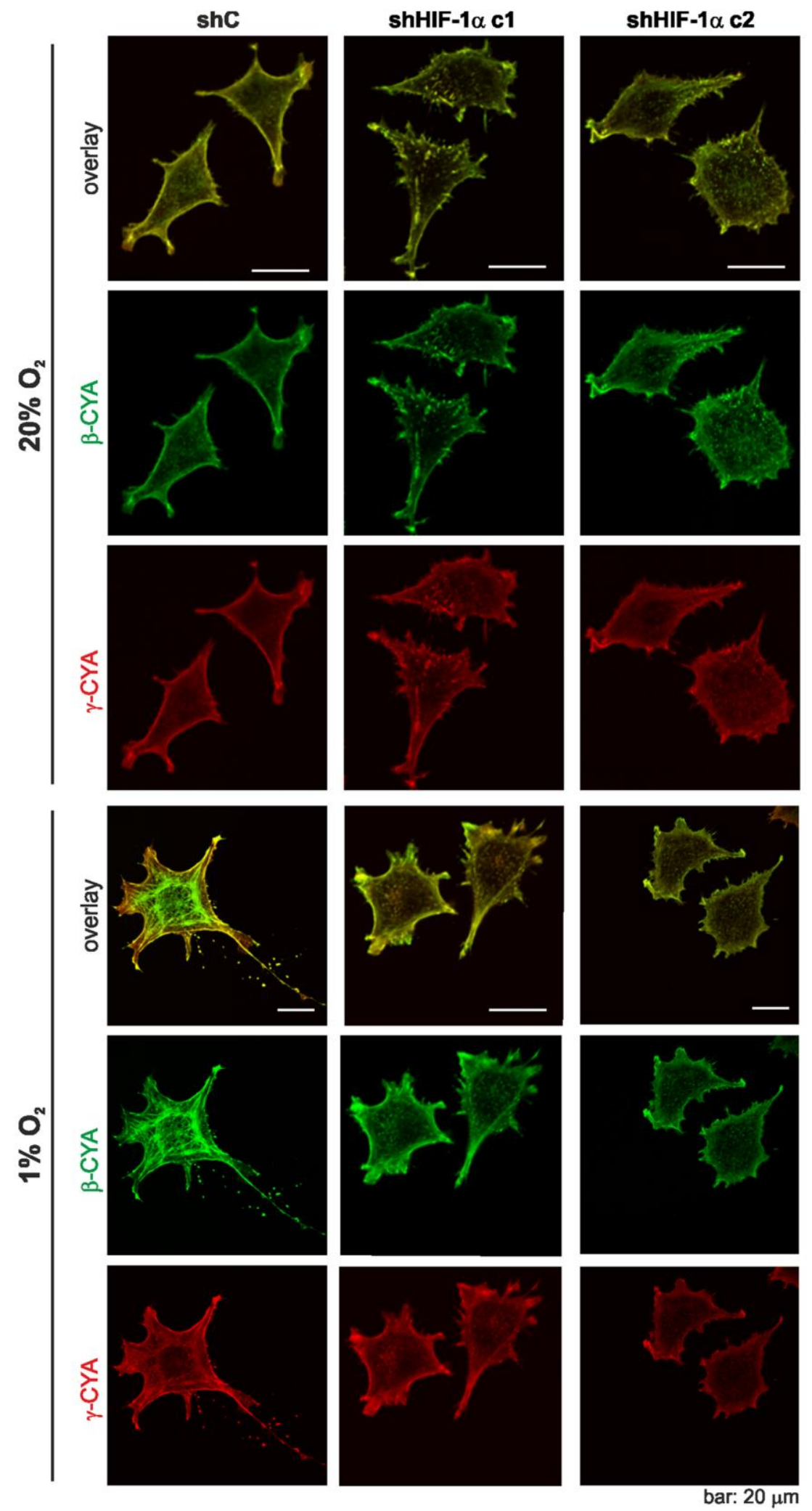


Figure 7. HIF-1 $\alpha$ knock down affects cytoplasmic actin reorganisation in hypoxia. ShC cells, and the HIF- $1 \alpha$ knock down cell clones $\mathrm{c} 1$ and c2 cells were incubated at $20 \%$ and $1 \% \mathrm{O}_{2}$ for $24 \mathrm{hrs}$ and stained for $\beta$-actin and $\gamma$-actin. Whereas the shC cells display an actin isoform redistribution in hypoxia no obvious actin reorganisation is seen in $\mathrm{c} 1$ and $\mathrm{c} 2$ cells. doi:10.1371/journal.pone.0069128.g007

are necessary for motility to occur $[38,39]$. In stably transfected HIF- $1 \alpha$ knock down L929 cells we noticed a massive decrease in p-cofilin levels with no obvious change in total cofilin. Consistent with the assumption that cofilin phosphorylation and dephosphorylation reactions control actin dynamics and are important for actin-based motility [40], cell migration was impaired in a monolayer wounding assay in hypoxia and single cell migration assays in normoxia. Hypoxic inhibition of fibroblast migration may contribute to the regulation of fibroblasts in wound healing as the accumulation of fibroblasts is an important factor of tissue repair after injury.

As the reorganisation of the actin cytoskeleton has been associated with a plethora of cellular functions including cell morphology, cell spreading and motility, the mechanisms by which actin dynamics are regulated are diverse. We show that a switch of L929 fibroblasts from normoxia to hypoxia induces changes in the actin cytoskeleton, mainly the redistribution of $\beta$-cytoplasmic actin, which goes along with an increase in cell area and volume, enhanced cell spreading and reduced cell locomotion. The increase in cell area and the reduction of migration are related to HIF- $1 \alpha$ stabilisation and $p$-cofilin levels. While cofilin phosphorylation has been linked to hypoxia before, here we show a direct involvement of HIF-1 $\alpha$ stabilisation on p-cofilin levels. Taken together, our results bring new insights into the influence of hypoxia on cell function, linking the HIF-signalling pathway to actin dynamics.

\section{Materials and Methods}

Cell Culture and Treatments

L929 fibrosarcoma cells (ATCC \# CCL-1), derived from mouse, were cultivated in high glucose modified Eagles medium (Pan Biotech, Aidenbach, Germany) containing 10\% fetal calf
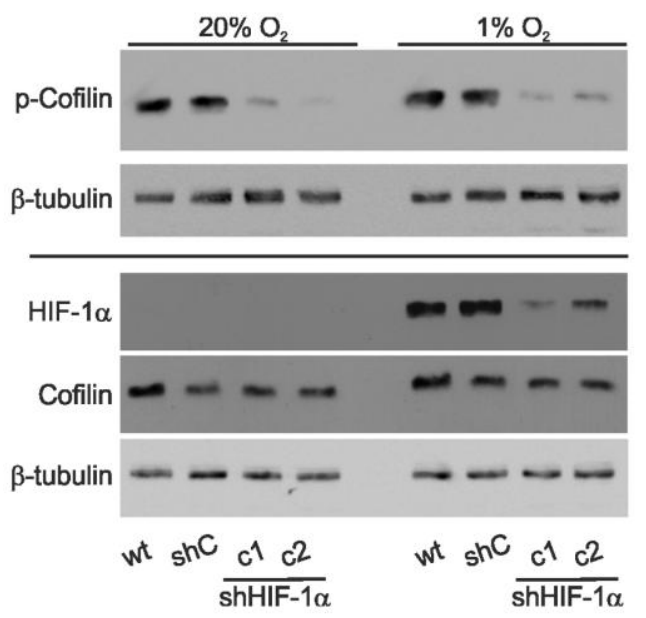

Figure 8. Cofilin phosphorylation is HIF-1 $\alpha$ dependent. Wt, shC, and the HIF-1 $\alpha$ knock down cell clones $\mathrm{c} 1$ and $\mathrm{c} 2$ cells were lysed after 24 hrs of normoxia $\left(20 \% \mathrm{O}_{2}\right)$ or hypoxia $\left(1 \% \mathrm{O}_{2}\right)$. Cell extracts were analysed by Western blots. Note that p-cofilin levels are reduced in $\mathrm{c} 2$ and $\mathrm{c} 2$ cells compared to wt and shC cells at $20 \% \mathrm{O}_{2}$ and $1 \% \mathrm{O}_{2}$. doi:10.1371/journal.pone.0069128.g008 serum (Biochrom, Berlin, Germany), 50 units/ml penicillin $\mathrm{G}$, and $50 \mu \mathrm{g} / \mathrm{ml}$ streptomycin (Pan Biotech). Cells were cultivated in a humidified $5 \% \mathrm{CO}_{2}, 95 \%$ air atmosphere at $37^{\circ} \mathrm{C}$. For hypoxic conditions, $\mathrm{O}_{2}$ levels were decreased to $1 \%$ with $\mathrm{N}_{2}$ in an in vivo 400 work station or SCITIVE work station (Ruskinn, Pencoed, UK). In some experiments cells were treated with $1 \mathrm{mM}$ DMOG (Alexis, Grünberg, Germany).

L929 HIF- $1 \alpha$ knock down clones were generated by lentiviral transduction with the pLKO.1-puro HIF- $1 \alpha$-shRNA expression vector (\#TRCN0000003810, Sigma-Aldrich, St. Louis, USA). For generating the shControl (shC) transfected cells, a pLKO.1-puro vector was used containing a non-targeting shRNA (\#SHC002, Sigma-Aldrich)

For lentiviral transduction, viral particles were produced in HEK293T cells using the ViralPower lentiviral expression system according to the manufacturers instructions (Life Technologies, Paisley, UK). Cells were treated with $20 \mu \mathrm{g} / \mathrm{ml}$ puromycin (Life Technologies) to select the cells with successfully integrated plasmid. Two shHIF- $1 \alpha$ subclones (cl and $\mathrm{c} 2$ ) and one shControl expressing clone were established.

\section{Cell Proliferation}

The growth rates of all cell lines were measured by plating $5 \times 10^{4}$ cells/well as three biological replicates. On days $1,2,3$, and 4 after plating, cells were dispersed by trypsin treatment and counted. The experiment was repeated three times.

\section{Fluorescence Staining}

Cells were grown on coverslips. For anti-vinculin (hVin-1, V9264; Sigma, Sigma-Aldrich, Steinheim, Germany) and phalloidin-Alexa Fluor 488 (Life Technologies) staining cells were fixed with $4 \%$ paraformaldehyde for $20 \mathrm{~min}$. Subsequently, cells were washed with PBS and incubated with $0.1 \%$ Triton $\mathrm{X}$ for $15 \mathrm{~min}$. $\beta$ - and $\gamma$-cytoplasmic actin were stained as described in Dugina et al., 2009. The following secondary antibodies were used: Texas red- conjugated goat anti-mouse (Santa Cruz Biotechnology, Heidelberg, Germany), TRITC-conjugated goat anti-mouse IgG2b and FITC-conjugated goat anti-mouse IgG1 (Southern Biochtechnology, Birmingham, AL, USA). Images were acquired using a confocal microscope (Zeiss SP2, Carl Zeiss, Göttingen, Germany) or an inverted microscope (Axio Observer D1, Carl Zeiss, Göttingen, Germany).

\section{Cell Area}

Single cells were analysed by bright field microscopy. Pictures were taken with an Olympus C-5060 Wide Zoom camera and cell area was analysed with ImageJ software.

\section{Cell Spreading Assay}

Cells were grown to $70 \%$ confluence. Subsequently cells were trysinized, replated, cultured and allowed to reattach. After $20 \mathrm{~min}$ cells were fixed and visualized with phalloidin-FITC staining.

\section{Flow Cytometry Analyses}

For flow cytometry analyses $4 \times 10^{4}$ cells per ml were seeded into 6 -wells as three biological replicates. Cells were detached and washed with FACS buffer containing $1.5 \%$ fetal calf serum 

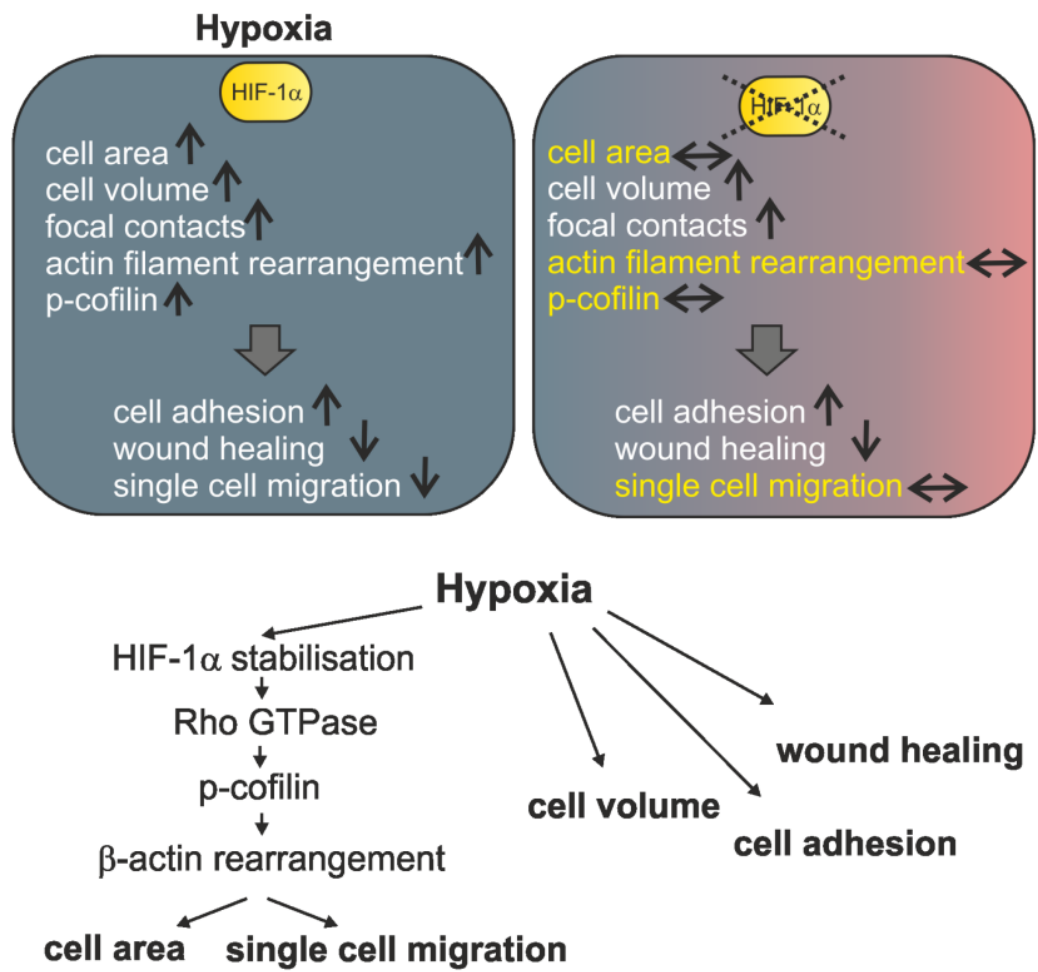

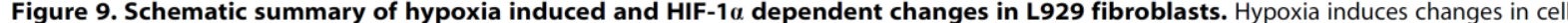
architecture and function. Some of these changes can be linked to stabilisation of HIF-1 1 . $\uparrow$, increase; $\downarrow$ decrease; $\leftrightarrow$, no change when compared to normoxia. HIF-1 $\alpha$ dependent effects, which are not seen in hypoxia after HIF-1 $\alpha$ knock down, are highlighted in yellow. doi:10.1371/journal.pone.0069128.g009

(Biochrom, Berlin, Germany), and 0.1\% sodium azide (Carl Roth GmbH+Co. KG, Karlsruhe, Germany) in PBS. Staining was performed with APC-conjugated anti-mouse $\beta 1$ integrin antibody (HM $\beta 1-1,102215$, BioLegend, London, UK) or IgG Isotype control (HTK888, 400911, BioLegend) for $20 \mathrm{~min}$ at $4^{\circ} \mathrm{C}$ according to manufacturer's recommendation. Cells were analysed using the BD FACSCanto flow cytometer system (Becton Dickinson GmbH, Heidelberg, Germany), BD FACSDiva and WinMDI2.9 software.

\section{Single Cell Migration}

For single cell migration experiments cells were seeded at $1 \times 10^{4}$ cells per $\mathrm{ml}$ and monitored by a NIKON AZ100 camera. Pictures were taken every $60 \mathrm{~min}$. Single cells were encircled and the pictures were overlaid which allowed us to follow the migration of the cells. Dividing cells were excluded.

\section{Scratch Assay}

For scratch assays, $1 \times 10^{5}$ cells per $\mathrm{ml}$ were seeded into 6 -wells as 6 biological replicates. Cells were grown until they reached almost $100 \%$ confluence. Using a sterile $200-\mu \mathrm{l}$ pipette tip, the cell layer was scratched in each well to create a cleared line. The scratch was photographed with an Olympus C-5060 Wide Zoom camera (in normoxia) or with a NIKON AZ100 microscope (in hypoxia) at different time points and the cell-free area was determined using ImageJ software.

\section{Protein Extraction and Immunoblot Analysis}

Cells were lysed in $400 \mathrm{mM} \mathrm{NaCl}, 1 \mathrm{mM}$ EDTA, $10 \mathrm{mM}$ Tris/ $\mathrm{HCl}, \mathrm{pH} 8.0$, and $0.1 \%$ TritonX100 including the protease inhibitor cocktail cOmplete Mini (Roche Applied Science, Mannheim, Germany). For p-cofilin and $\beta 1$-integrin detection cells were lysed in $8 \mathrm{M}$ urea and $1 \%$ CHAPS. Subsequently, lysates were treated with ultrasound (SONOPLUS HD 2070, Bandelin GmbH, Berlin, Germany). Protein concentrations were determined by the Bradford method using BSA as a standard. For immunoblot analysis, protein extracts were electrophoresed through sodium dodecyl sulfate (SDS)-polyacrylamide gels and electro-transferred onto nitrocellulose membranes (Amersham, Freiburg, Germany) by semi-dry blotting (PeqLab, Erlangen, Germany). For detection of specific proteins, the following primary and secondary antibodies were used: anti-HIF- $1 \alpha$ (NB100-479; Novus, Littleton, USA), anti- $\beta$-tubulin (Abcam, Cambridge, UK, ab6046), anti-cofilin (Abcam, ab42824), anti-p-cofilin (Santa Cruz Biotechnology, Heidelberg, Germany, sc-12912-R), anti- $\beta 1$-integrin (ab 5297, Abcam), anti-vinculin (hVin, Sigma-Aldrich), horseradish peroxidase (HRP)-labelled anti-mouse (Sc-2005, Santa Cruz) and HRP-labelled anti-rabbit (Sc-2004, Santa Cruz). Chemiluminescence detection of HRP was performed by incubation of the membranes with $100 \mathrm{mM}$ Tris- $\mathrm{HCl}, \mathrm{pH} 8.5,2.65 \mathrm{mM}$ $\mathrm{H}_{2} \mathrm{O}_{2}, 0.45 \mathrm{mM}$ luminol, and $0.625 \mathrm{mM}$ coumaric acid for $1 \mathrm{~min}$ followed by imaging using the LAS3000 system (Fuji) or Amersham Hyperfilm ECL (GE Healthcare, Muenchen, Germany) autoradiography films. 


\section{Statistical Analyses}

Results are expressed as mean \pm SEM. For statistical comparisons, results were analysed by unpaired Students $t$-test (Figs 1, 2; Fig. 4C, E, F Fig. 5A, B, C) and one-way ANOVA (Fig. 5D, F) followed by Bonferroni post hoc tests. Values of $\mathrm{p}<0.05{ }^{*}$ (*), $\mathrm{p}<0.01$ $(* *), \mathrm{p}<0.001{ }^{(* * *)}$ ) were considered statistically significant

\section{Acknowledgments}

We gratefully acknowledge Prof. Christine Chaponnier (Department of Pathology and Immunology, Faculty of Medicine, University of Geneva,

\section{References}

1. Simon MC, Keith B (2008) The role of oxygen availability in embryonic development and stem cell function. Nat Rev Mol Cell Biol 9: 285-296.

2. Chen EY, Fujinaga M, Giaccia AJ (1999) Hypoxic microenvironment within an embryo induces apoptosis and is essential for proper morphological development. Teratology 60: 215-225.

3. van den Borne SW, Diez J, Blankesteijn WM, Verjans J, Hofstra L, et al. (2010 Myocardial remodeling after infarction: the role of myofibroblasts. Nat Rer Cardiol 7: $30-37$.

4. Rieder F, Brenmoehl J, Leeb S, Scholmerich J, Rogler G (2007) Wound healing and fibrosis in intestinal disease. Gut 56: 130-139.

5. Tandara AA, Mustoe TA (2004) Oxygen in wound healing more than a nutrient. World J Surg 28: 294-300.

6. Mogford JE, Tawil N, Chen A, Gies D, Xia Y, et al. (2002) Effect of age and hypoxia on TGF $\beta$ I receptor expression and signal transduction in human hypoxia on TGF receptor expression and signal transduction in hi

7. Li W, Li Y, Guan S, Fan J, Cheng CF, et al. (2007) Extracellular heat shock protein-90 $\alpha$ : linking hypoxia to skin cell motility and wound healing. EMBO J 26: $1221-1233$

8. Eul B, Rose F, Krick S, Savai R, Goyal P, et al. (2006) Impact of HIF- $1 \alpha \alpha$ and $\mathrm{HIF}-2 \alpha$ on proliferation and migration of human pulmonary artery fibroblasts in hypoxia. FASEB J 20: 163-165.

9. Breit S, Bubel M, Pohlemann T, Oberringer M (2011) Erythropoietin ameliorates the reduced migration of human fibroblasts during in vitro hypoxia. J Physiol Biochem 67: 1-13.

10. Aslam M, Schluter KD, Rohrbach S, Rafiq A, Nazli S, et al. (2012) Hypoxia/ reoxygenation-induced endothelial barrier failure: Role of RhoA, Racl, and MLCK. J Physiol 591: 461-73.

11. Turcotte S, Desrosiers RR, Beliveau R (2003) HIF- $1 \alpha$ mRNA and protein upregulation involves Rho GTPase expression during hypoxia in renal cell carcinoma. J Cell Sci 116: 2247-2260.

12. Hayashi M, Sakata M, Takeda T, Tahara M, Yamamoto T, et al. (2005) Hypoxia up-regulates hypoxia-inducible factor- $1 \alpha$ expression through $\mathrm{RhoA}$ activation in trophoblast cells.J Clin Endocrinol Metab 90: 1712-1719.

13. Jin HG, Yamashita H, Nagano Y, Fukuba H, Hiji M, et al. (2006) Hypoxiainduced upregulation of endothelial small $\mathrm{G}$ protein RhoA and Rho-kinase/ ROCK2 inhibits eNOS expression. Neurosci Lett 408: 62-67.

14. Pacary E, Tixier E, Coulet F, Roussel S, Petit E, et al. (2007) Crosstalk between HIF-1 and ROCK pathways in neuronal differentiation of mesenchymal stem cells, neurospheres and in PC12 neurite outgrowth. Mol Cell Neurosci 35: 409 423

15. Hall A, Nobes CD (2000) Rho GTPases: molecular switches that control the organization and dynamics of the actin cytoskeleton. Philos Trans R Soc Lond B Biol Sci 355: 965-970.

16. de Curtis I, Meldolesi J (2012) Cell surface dvnamics - how Rho GTPase orchestrate the interplay between the plasma membrane and the cortical cytoskeleton. J Cell Sci 125: 4435-4444.

17. Pollard TD, Borisy GG (2003) Cellular motility driven by assembly and disassembly of actin filaments. Cell 112: 453 465

18. Engqvist-Goldstein AE, Drubin DG (2003) Actin assembly and endocytosis: from yeast to mammals. Annu Rev Cell Dev Biol 19: 287-332.

19. Parsons JT, Horwitz AR, Schwartz MA (2010) Cell adhesion: integrating cytoskeletal dynamics and cellular tension. Nat Rev Mol Cell Biol 11: 633-643.

Pollard TD (2010) Mechanics of cytokinesis in eukaryotes. Curr Opin Cell Biol 22: $50-56$.

21. Dugina V, Zwaenepoel I, Gabbiani G, Clement S, Chaponnier C (2009) Beta and gamma-cytoplasmic actins display distinct distribution and functional diversity. J Cell Sci 122: 2980-2988.
Switzerland) for providing $\beta$ - and $\gamma$-cytoplasmic actin antibodies and Prof. Brigitte M. Jockusch (Cell Biology, Zoological Institute, TU Braunschweig, Germany) for valuable discussions.

\section{Author Contributions}

Conceived and designed the experiments: DMK SL AZ. Performed the experiments: MV SV SK KF CMW PL AZ. Analyzed the data: MV SV KF CMW DMK AZ. Contributed reagents/materials/analysis tools: SL AZ. Wrote the paper: DMK AZ.

22. Semenza GL (1998) Hypoxia-inducible factor 1: master regulator of $\mathrm{O}$ homeostasis. Curr Opin Genet Dev 8: 588-594.

23. Semenza GL (2001) HIF-1, $\mathrm{O}_{2}$, and the 3 PHDs: how animal cells signal hypoxia to the nucleus. Cell 107: 1-3.

24. Ivan M, Kondo K, Yang H, Kim W, Valiando J, et al. (2001) HIF $\alpha$ targeted fo VHL-mediated destruction by proline hydroxylation: implications for $\mathrm{O}_{2}$ sensing. Science 292: 464468

25. Jaakkola P, Mole DR, Tian YM, Wilson MI, Gielbert J, et al. (2001) Targeting of HIF- $\alpha$ to the von Hippel-Lindau ubiquitylation complex by $\mathrm{O}_{2}$-regulated prolyl hydroxylation. Science 292: 468-472.

26. Epstein AC, Gleadle JM, McNeill LA, Hewitson KS, O'Rourke J, et al. (2001) $\mathrm{C}$. elegans EGL-9 and mammalian homologs define a family of dioxygenase that regulate HIF by prolyl hydroxylation. Cell 107: 43-54.

27. Mole DR, Schlemminger I, McNeill LA, Hewitson KS, Pugh CW, et al. (2003) 2-oxoglutarate analogue inhibitors of $\mathrm{HIF}$ prolyl hydroxylase. Bioorg $\mathrm{Med}$ Chem Lett 13: 2677-2680.

28. Bernstein BW. Bamburg JR (2010) ADF/cofilin: a functional node in cell biology. Trends Cell Biol 20: 187-195.

29. Vogel S, Wottawa M, Farhat K, Zieseniss A, Schnelle M, et al. (2010) Proly hydroxylase domain (PHD) 2 affects cell migration and F-actin formation via RhoA/rho-associated kinase-dependent cofilin phosphorylation. J Biol Chen 285: $33756-33763$.

30. Negash S, Narasimhan SR, Zhou W, Liu J, Wei FL, et al. (2009) Role of cGMPdependent protein kinase in regulation of pulmonary vascular smooth muscle cell adhesion and migration: effect of hypoxia. Am J Physiol Heart Circ Physiol 297: H304-312.

31. Veith C, Schmitt S, Veit F, Dahal BK, Wilhelm J, et al. (2012) Cofilin, hypoxia-regulated protein in murine lungs identified by 2-dimensional ge electrophoresis: The role of the cytoskeletal protein cofilin in pulmonary hypertension. Proteomics 13: 75-88.

32. Brillault J, Lam TI, Rutkowsky JM, Foroutan S, O’Donnell ME (2008) Hypoxia effects on cell volume and ion uptake of cerebral microvascular endothelial cells. Am J Physiol Cell Physiol 294: C88-96.

33. Rutkowsky JM, Wallace BK, Wise PM, O'Donnell ME (2011) Effects of estradiol on ischemic factor-induced astrocyte swelling and AQP4 protein abundance. Am J Physiol Cell Physiol 301: C204-212

34. Kayyali US, Pennella CM, Trujillo C, Villa O, Gaestel M, et al. (2002 Cytoskeletal changes in hypoxic pulmonary endothelial cells are dependent on MAPK-activated protein kinase MK2. J Biol Chem 277: 42596-42602.

35. Dunphy JL, Moravec R, Lv K, Lasell TK, Melancon P, et al. (2006) The Arf6 GEF GEP100/BRAG2 regulates cell adhesion by controlling endocytosis of betal integrins. Curr Biol 16: 315-320.

36. Rodriguez Fernandez JL, Geiger B, Salomon D, Ben-Ze'ev A 1992 Overexpression of vinculin suppresses cell motility in BALB/c 3T3 cells. Cell Motil Cytoskeleton 22: 127-134.

37. Ridley AJ, Schwartz MA, Burridge K, Firtel RA, Ginsberg MH, et al. (2003) Cell migration: integrating signals from front to back. Science 302: 1704-1709.

38. Dawe HR, Minamide LS, Bamburg JR, Cramer LP (2003) ADF/cofilin control cell polarity during fibroblast migration. Curr Biol 13: 252-257.

39. Nishita M, Aizawa H, Mizuno K (2002) Stromal cell-derived factor $1 \alpha$ activate LIM kinase 1 and induces cofilin phosphorylation for T-cell chemotaxis. Mo Cell Biol 22: 774-783.

40. Arber S, Barbayannis FA, Hanser H, Schneider C, Stanvon CA, et al. (1998 Regulation of actin dynamics through phosphorylation of cofilin by LIM-kinase. Nature 393: 805-809. 


\subsection{Pre- and post-conditional inhibition of prolyl-4-hydroxylase domain enzymes protects the heart from an ischemic insult}

In ischemic tissues the stabilization of HIF-1 $\alpha$ and the following transcription of hundreds of HIF target genes may exhibit tissue protective effects (Wenger, 2002, and references therein). Inhibition of PHD results in normoxic stabilization of HIF-1 $\alpha$ and has been shown to exert cardio-protective effects in genetically modified mouse models (Hölscher et al., 2011) Thus, there is a strong need to develop selective small molecule PHD inhibitors as a new therapeutic option for myocardial tissue protection during ischemia. Therefore, we analyzed in this study the isoquinoline analog 2-(1-chloro-4-hydroxyisoquinoline-3-carboxamido) acetate (ICA), a specific PHD inhibitor for its applicability and protective properties in the heart. ICA was tested for protective effects in acute MI induced by LAD ligation via pre- or post-conditional application. In the following publication I describe that ICA treatment leads to a rapid and strong HIF-1 $\alpha$ and HIF-2 $\alpha$ accumulation in heart muscle cells in vitro and in vivo and also to the induction of the known HIF target genes HO-1 and PHD3. It could be shown that ICA exerts acute cardio-protective effects in MI by a significantly reduced total infarct size. This effect was seen not only by pre-conditional treatment, but also after post-conditional application of ICA. This indicates that there is a therapeutic time window for the treatment with PHD inhibitors which could also be useful for acute clinical approaches.

\subsubsection{Declaration of my contribution}

The experiments were conceived and designed by Prof. Dr. Dörthe M. Katschinski and Dr. rer. nat. Anke Zieseniss. The animal experimentation was mainly performed by me including myocardial infarction, injection of ICA, echocardiography, collection of organs and blood as well as the corresponding analysis. Heart perfusion and Evan's blue/TTC staining was performed in collaboration with Dr. rer. nat. Anke Zieseniss who did the analysis of the total infarct size. The draft of the manuscript was mainly written by Prof. Dr. Dörthe M. Katschinski and Dr. rer. nat. Anke Zieseniss. I wrote parts of the Material and Methods section and proposed modifications for the manuscript. 


\title{
Pre- and post-conditional inhibition of prolyl-4-hydroxylase domain enzymes protects the heart from an ischemic insult
}

\author{
Melanie Vogler • Anke Zieseniss • Amke R. Hesse • Elif Levent • \\ Malte Tiburcy • Eva Heinze • Nicolai Burzlaff • Gunnar Schley • \\ Kai Uwe Eckardt • Carsten Willam • Dörthe M. Katschinski
}

Received: 4 September 2014 / Revised: 12 November 2014/Accepted: 2 December 2014

(C) Springer-Verlag Berlin Heidelberg 2015

\begin{abstract}
Several genetically modified mouse models implicated that prolyl-4-hydroxylase domain (PHD) enzymes are critical mediators for protecting tissues from an ischemic insult including myocardial infarction by affecting the stability and activation of hypoxia-inducible factor (HIF)-1 and HIF-2. Thus, the current efforts to develop small-molecule PHD inhibitors open a new therapeutic option for myocardial tissue protection during ischemia. Therefore, we aimed to investigate the applicability and efficacy of pharmacological HIF $\alpha$ stabilization by a small-molecule PHD inhibitor in the heart. We tested for protective effects in the acute phase of myocardial infarction after pre- or post-conditional application of the inhibitor. Application of the specific PHD inhibitor 2-(1chloro-4-hydroxyisoquinoline-3-carboxamido) acetate (ICA)
\end{abstract}

Melanie Vogler and Anke Zieseniss contributed equally.

M. Vogler • A. Zieseniss • A. R. Hesse • D. M. Katschinski $(\bowtie)$ Institute of Cardiovascular Physiology, University Medical Center, Georg-August-University Göttingen,

Humboldtallee 23, 37073 Göttingen, Germany

e-mail: doerthe.katschinski@med.uni.goettingen.de

E. Levent $\cdot$ M. Tiburcy

Institute of Pharmacology, University Medical Center,

Georg-August-University Göttingen, Göttingen, Germany

A. Zieseniss · A. R. Hesse · E. Levent $\cdot$ M. Tiburcy •

D. M. Katschinski

DZHK (German Center for Cardiovascular Research),

partner site Göttingen, Göttingen, Germany

E. Heinze $\cdot N$. Burzlaff

Inorganic Chemistry and Organometallic Chemistry,

Department of Chemistry and Pharmacy,

Friedrich-Alexander-University, Erlangen, Germany

G. Schley $\cdot$ K. U. Eckardt $\cdot$ C. Willam

Department of Nephrology and Hypertension,

Friedrich-Alexander-University, Erlangen, Germany resulted in HIF- $1 \alpha$ and HIF- $2 \alpha$ accumulation in heart muscle cells in vitro and in vivo. The rapid and robust responsiveness of cardiac tissue towards ICA was further confirmed by induction of the known HIF target genes heme oxygenase-1 and PHD3. Pre- and post-conditional treatment of mice undergoing myocardial infarction resulted in a significantly smaller infarct size. Tissue protection from ischemia after pre- or postconditional ICA treatment demonstrates that there is a therapeutic time window for the application of the PHD inhibitor (PHI) post-myocardial infarction, which might be exploited for acute medical interventions.

Keywords Ischemia $\cdot$ HIF · Prolyl-hydroxylase inhibitor . Hypoxia

\section{Introduction}

Myocardial infarction is a major cause for morbidity and mortality and often results in subsequent heart failure. Albeit many advances in prompt revascularization have been accomplished, only very few procedures for tissue protection to prevent further progressive heart dysfunction turned out to be successful. A promising procedure may represent ischemic precondition - and even remote preconditioning — which can prepare the heart muscle for an ischemic period of metabolic deficiency and cellular stress [13]. Previous studies demonstrated that ischemic preconditioning substantially relies on the activation of the transcription factor hypoxia-inducible factor (HIF) and that genetic deletion of HIF abrogates protective effects of preconditioning [6].

The heterodimeric transcription factor HIF is constitutively expressed, whereas the protein stability of the $\alpha$ subunits of HIF-1 or HIF-2 is oxygen-dependently regulated. In hypoxia, $\mathrm{HIF} \alpha$ levels accumulate and stimulate the hypoxia-inducible gene expression. This involves genes regulating glycolysis, 
Pflugers Arch - Eur J Physiol

glucose metabolism, angiogenesis, cell survival, etc. [31, 37]. An enzyme family of oxygen- and 2-oxoglutarate-dependent dioxygenases regulates the stability of $\mathrm{HIF} \alpha$ [18]. The prolyl4-hydroxylase domain (PHD) enzymes 1-3 hydroxylate $\mathrm{HIF} \alpha$ in a strictly oxygen-dependent manner, which marks the protein for ubiquitination and proteasomal degradation [19]. Both HIF $\alpha$ isoforms and in particular PHD2 and 3 are expressed in cardiomyocytes [29, 39]. Genetic inactivation of PHD2 in cardiomyocytes including conditional knockout or siRNA transfection led to HIF- $1 \alpha$ accumulation and increased ischemia tolerance of infarcted hearts $[15,17,25]$. Besides a decreased myocardial infarct size, an improved fractional shortening 3 weeks after the ischemic event could be observed in these mice [15].

In the meantime, new small-molecule PHD inhibitors (PHIs) were developed and successfully applied, e.g., in acute organ injuries, like ischemic or toxic kidney injury $[3,14,36]$. For the heart, a decreased myocardial infarct size was also reported after treating rats with the non-specific PHI dimethyloxalylglycine (DMOG) given $24 \mathrm{~h}$ before coronary occlusion [40] or ischemia reperfusion [10]. Since DMOG is a non-selective oxoglutarate analogue, it inhibits, besides the PHDs, also other 2-oxoglutarate-dependent dioxygenases including the collagen-modifying hydroxylases [8]. In fact, $\mathrm{N}$-oxalylglycine and its dimethyl ester analogue DMOG were described to inhibit prolyl-4hydroxylase activity before the PHD enzymes were even discovered [1]. Therefore, the data obtained with DMOG have to be interpreted with caution. Another study applied the newly developed PHI GSK360A for 28 days starting first at $48 \mathrm{~h}$ after left anterior descending artery (LAD) ligation. In this study, myocardial remodeling was improved and vascularity was better maintained [2]. In contrast, genetic chronic activation of HIF- $1 \alpha$ or HIF- $2 \alpha$ in the mouse heart resulted in heart failure mimicking ischemic cardiomyopathy [16, 23], which might limit long-term application of PHI. Just recently, Ong et al. reported that also short-term pre-conditional HIF $\alpha$ stabilization via application of GSK360A protects the heart from acute myocardial infarction [26]. In the clinical setting, application of a PHI in response to an ischemic event is more realistic compared to a pre-conditional application. Thus, we wondered how far short-term application of a specific HIF $\alpha$-stabilizing PHI leads to significant HIF activation in the heart and whether $\mathrm{HIF} \alpha$ stabilization may have effects on myocardial infarction outcome measures directly after infarction and in the post-infarction period. We applied 2-(1-chloro-4hydroxyisoquinoline-3-carboxamido) acetate (ICA), which has been chemically characterized before and has been successfully used in other acute ischemic models including kidney ischemia [30]. Characterization of ICA revealed a manifold higher affinity towards PHD2 compared to $\mathrm{N}$ oxalylglycine and a higher specificity towards the PHDs over the asparaginyl hydroxylase factor-inhibiting HIF (FIH) $[33,34]$. The tissue-protective effect of ICA was tested pre-conditionally or immediately post-conditionally after permanent ligation of the LAD in mice.

\section{Materials and methods}

ICA synthesis

ICA was obtained in a six-step synthesis as described earlier [30].

\section{Animal experimentation and echocardiography}

Animal experimentations were performed with male, 8-10week-old C57BL/6 mice (Jackson Laboratories). All protocols regarding animal experimentation were conducted according to the German animal protection law and approved by the responsible governmental authority (Niedersächsisches Landesamt für Verbraucherschutz und Lebensmittelsicherheit in Oldenburg; animal experimentation number 33.9-42502-04-10/0069) and conform to the Directive 2010/63/EU of the European Parliament. LAD ligations were performed by an investigator, who was blinded regarding the PHI treatment of the mice as described previously [15]. The measurement of infarct size was performed by an additional investigator, who was likewise blinded. Mice were anesthetized using $1.5 \%$ isoflurane (Forene, Abbott), applied by a blunt intubation cannula (intubation cannula, stainless steel with Y-adapter, 1.2-mm outer diameter, 30-mm length; Hugo Sachs Elektronik, Harvard Apparatus $\mathrm{GmbH}$ ) connected to a mechanical ventilator (MiniVent; Hugo Sachs Elektronik, Harvard Apparatus $\mathrm{GmbH}$ ). Anesthesia was considered adequate when the animal stayed still quietly, did not respond to external stimuli, and did not show the palpebral reflex. Pain management was controlled by intraperitoneal (i.p.) injection of $0.06 \mathrm{mg} / \mathrm{kg}$ body weight (BW) buprenorphine $1 \mathrm{~h}$ and daily treatment with $1.33 \mathrm{mg} / \mathrm{ml}$ metamizole in the drinking water starting 2 days before the surgery.

Mice received two doses of ICA ( $40 \mathrm{mg} / \mathrm{kg} \mathrm{BW})$ or vehicle i.p., either 6 and $1 \mathrm{~h}$ before myocardial infarction or 1 and $5 \mathrm{~h}$ after myocardial infarction. Two-dimensional images and Mmode tracings were recorded from the parasternal long axis view at midpapillary level (Vevo $2100^{\mathrm{TM}}$, MS400, Visual Sonics). Heart rate, end-diastolic area, end-systolic area as well as anterior and posterior wall thicknesses were determined. Fractional area shortening (FAS) of the left ventricle was defined as the (end-diastolic area-end-systolic area)/enddiastolic area. FAS was used as marker for cardiac function. During echocardiography, mice were anesthetized with $1 \%$ isoflurane. 


\section{Measurement of infarct size}

Six hours after LAD ligation, the mice were given heparin ( $250 \mathrm{IU})$, anesthetized with $2 \%$ isoflurane, and sacrificed by cervical dislocation. Subsequently, the hearts were excised. Total infarct size was determined by using Evans blue and 2,3,5-triphenyltetrazolium chloride (TTC) [15]. Briefly, the ascending aorta was cannulated with a 20 -gauge tubing adapter, and $1 \%$ Evans blue was perfused into the aorta and coronary arteries to delineate the total area at risk (AAR). The Evans blue dye was uniformly distributed to those areas of the myocardium, which were well perfused; hence, the area of the myocardium that was not stained with Evans blue was defined as the total AAR. The left ventricle was separated from the rest of the heart and sectioned into three transverse slices. Sections were incubated in $2 \%$ TTC for $20 \mathrm{~min}$ at $37^{\circ} \mathrm{C}$ to identify viable tissue, which appears in red compared to the white/pale area of necrosis (AON). Infarct quantification was performed on digital photographs (SMZ 1500, Nikon, Tokyo, Japan) using ImageJ (NIH, Bethesda, MD). AON and AAR were determined as the average percent area per slice and were then related to individual slice weight. Total infarct size was calculated as AON/total AAR.

Immunohistochemistry

Paraffin sections ( 2 to $4 \mu \mathrm{m}$ thick) were dewaxed in xylene and rehydrated in a series of ethanol washes. The following primary antibodies were used for immunodetection: polyclonal rabbit anti-HIF-1 $\alpha(1: 10,000$, Cayman Chemical), polyclonal rabbit anti-HIF-2 $\alpha$ (1:10,000; PM9 [38], a kind gift of P.H. Maxwell, University of Cambridge), polyclonal rabbit anti-PHD2 (1:10,000; Novus Biologicals), polyclonal rabbit anti-PHD3 (1:10,000, Novus Biologicals), polyclonal rabbit anti-heme oxygenase-1 (HO-1; 1:15,000, Enzo Life Sciences). A biotinylated secondary anti-rabbit antibody (1:1000, Dako) and a catalyzed signal amplification system (Dako) based on the streptavidin-biotin-peroxidase reaction were used for staining according to the manufacturer's instructions.

ODD-Luc engineered heart muscle

ODD-Luc engineered heart muscles (EHMs) were generated as described earlier [12]. In brief, EHMs were assembled from purified cardiomyocytes derived from a murine transgenic ODD-Luc embryonic stem cell line and mouse embryonic fibroblasts at a ratio of 70:30. Mouse embryonic fibroblasts were isolated from 13-16-day-old embryos of pregnant NMRI mice after $\mathrm{CO}_{2}$ euthanasia. ICA and a solvent control were added to the ODD-Luc EHMs after a 7-day differentiation process under mechanical loading.
Drug treatment was performed for 1 or $6 \mathrm{~h}$. Subsequently, EHMs were removed from the stretchers, transferred in luciferin (Caliper) solution (1 mg/ml in PBS), and incubated for $1 \mathrm{~min}$. The EHMs were subsequently placed on a 14.5$\mathrm{cm}$ cell culture dish, covered with a glass slide, and imaged in a light-tight chamber with a luminescence image analyzer (LAS-3000).

Red blood cell count, hemoglobin, and hematocrit

Red blood cell count, hemoglobin concentration, and hematocrit were determined using the CELL-DYN Sapphire hematology analyzer system (Abbot Laboratories).

\section{Statistical analysis}

Data are presented as mean \pm SEM. We determined statistical differences by two-tailed Student's $t$ test. A $p$ value less than 0.05 was considered statistically significant.

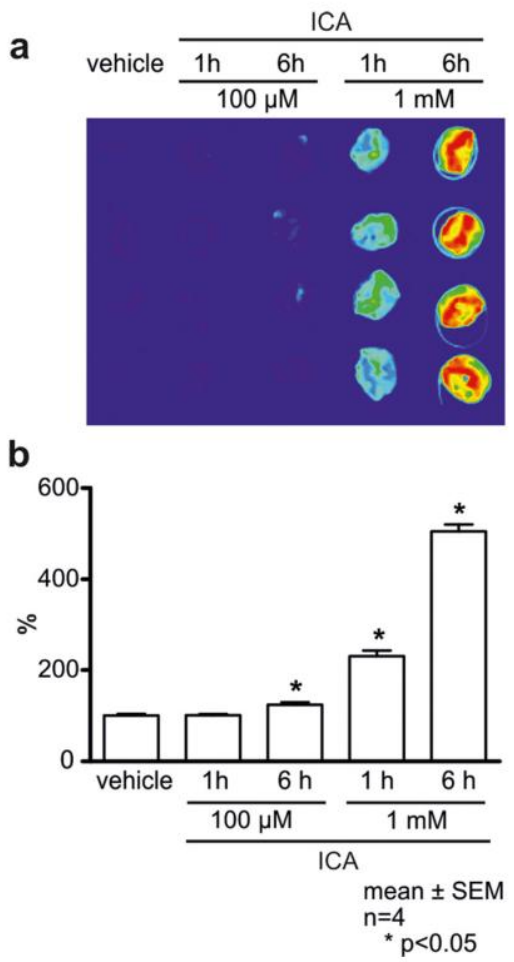

Fig. 1 ODD-Luc EHMs respond to ICA treatment with enhanced Luc signals. a ODD-Luc EHMs were incubated with $100 \mu \mathrm{M}, 1 \mathrm{mM}$ ICA or a vehicle control for 1 or $6 \mathrm{~h}$ as indicated. Color-coded image of the ODDLuc EHMs (blue is low, red is high Luc signal). b Luc signal intensity of vehicle- or ICA-treated ODD-Luc EHMs was quantified. $n=4$ EHMs per treatment group; shown are means \pm SEM, ${ }^{*} p<0.05$ 
Pflugers Arch - Eur J Physiol

Fig. 2 ICA treatment results in transient HIF- $1 \alpha$ and HIF- $2 \alpha$ stabilization. a HIF- $1 \alpha$ and HIF$2 \alpha$, immunohistochemistries of heart sections were performed under control conditions or 1, 6, and $24 \mathrm{~h}$ after ICA treatment (40-fold magnification). b Microscopy pictures of HIF- $1 \alpha$ and HIF- $2 \alpha$

immunohistochemistry of heart sections, which were obtained $6 \mathrm{~h}$ after ICA treatment (100-fold magnification). HIF- $1 \alpha$ and HIF$2 \alpha$ immunohistochemistries were repeated with samples from three independent animals.

Representative figures are shown
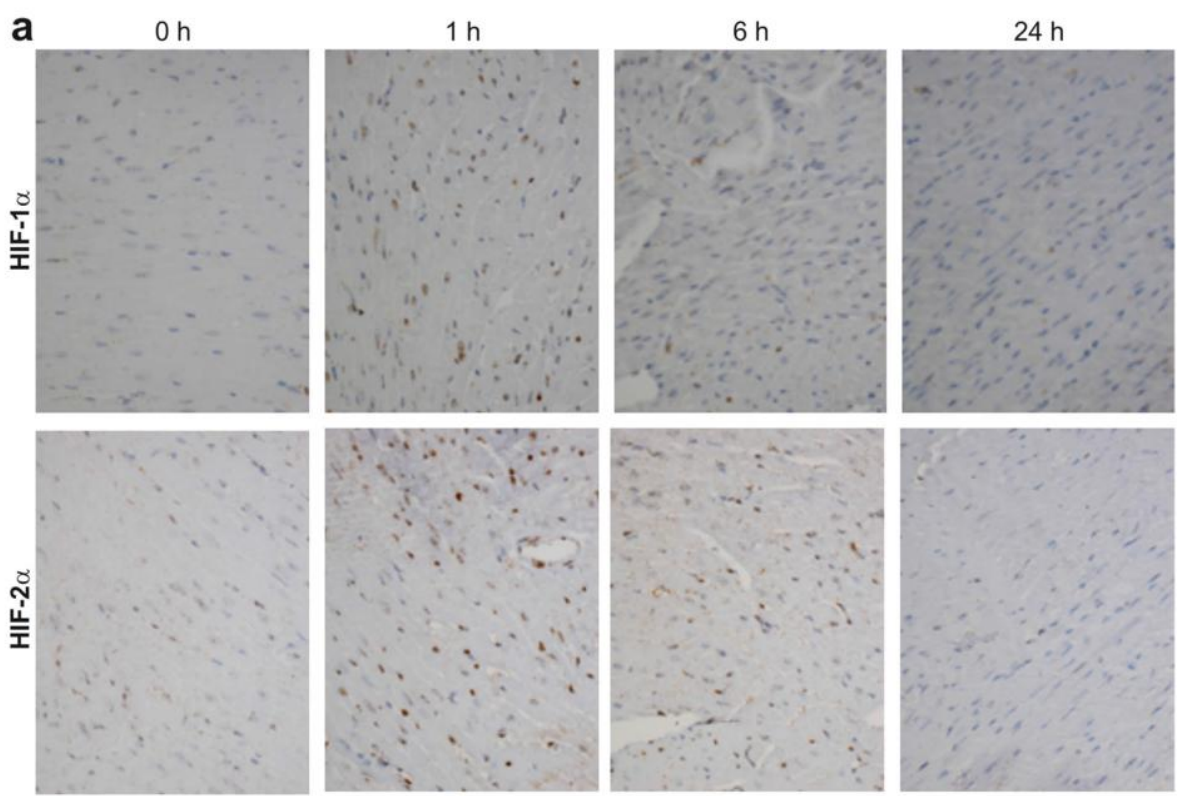

b
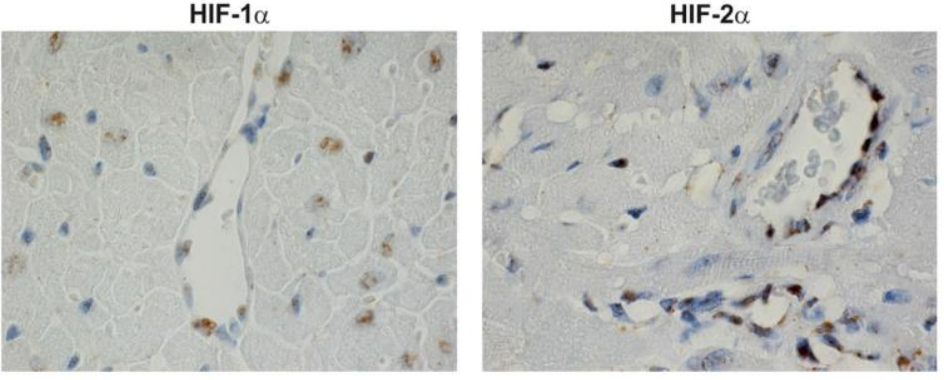

\section{Results}

ICA increases HIF $\alpha$ abundance and HIF target gene expression in cardiac tissue

We have previously established ODD-Luc hypoxia reporter cardiomyocytes, which express the oxygen-dependent degradation domain of HIF-1 $\alpha$ fused to the firefly luciferase under the control of the constitutively active CMV promoter [12]. These can be applied for generating EHMs, which are capable of monitoring sensitively and quantitatively the HIF response via bioluminescence in vitro. To analyze the efficacy for the induction of a HIF response after PHI treatment, ODD-Luc EHMs were generated and incubated with ICA for 1 and $6 \mathrm{~h}$ (Fig. 1a, b). Bioluminescence increased after PHI treatment, demonstrating that in cardiac tissue, ICA can robustly stimulate the HIF system. This was additionally verified by in vivo experiments with resting mice (Fig. 2a). Treatment of mice with ICA $(40 \mathrm{mg} / \mathrm{kg} \mathrm{BW})$, which was injected i.p. once, in vivo resulted in a transient HIF- $1 \alpha$ and HIF- $2 \alpha$ accumulation in the heart. Most interestingly, the HIF $\alpha$ induction was rapid but transient; $1 \mathrm{~h}$ after injection, a clear HIF$1 \alpha$ and HIF- $2 \alpha$ response was visible, which was even more pronounced at $6 \mathrm{~h}$ and was no longer visible at $24 \mathrm{~h}$ after treatment. HIF- $1 \alpha$ was seen predominantly in cardiomyocytes but also in some stromal cells, whereas HIF- $2 \alpha$ stabilization occurred predominantly in stromal cells which appeared morphologically to be endothelial cells in most cases (Fig. 2b). PHD3 and HO-1 are HIF target genes, which are upregulated as a consequence of HIF $\alpha$ stabilization and subsequent transcription activation of the HIF $\alpha / \beta$ complex. We could indeed see increased HO-1, PHD2, and PHD3 protein signals in the heart after ICA treatment, which persisted up to $24 \mathrm{~h}$ (Fig. 3). Whereas HO-1 was expressed predominantly in stromal cells, PHD2 and PHD3 were expressed ubiquitously. Compared to a strong induction of PHD3, PHD2 induction after ICA treatment was mild. Taken together, these data demonstrate that ICA is inducing a functional HIF program in the heart with elevated levels of $\mathrm{HIF} \alpha$ up to $6 \mathrm{~h}$ after a single injection of the PHI. 
Pflugers Arch - Eur J Physiol

Fig. 3 ICA treatment results in induction of HIF target genes. Heme oxygenase-1 (HO-1), PHD2, and PHD3

immunohistochemistries of heart sections were performed under control conditions or 1,6 , and $24 \mathrm{~h}$ after ICA treatment (40-fold magnification). HO-1, PHD2, and PHD3 immunohistochemistries were repeated with samples from three independent animals. Representative figures are shown
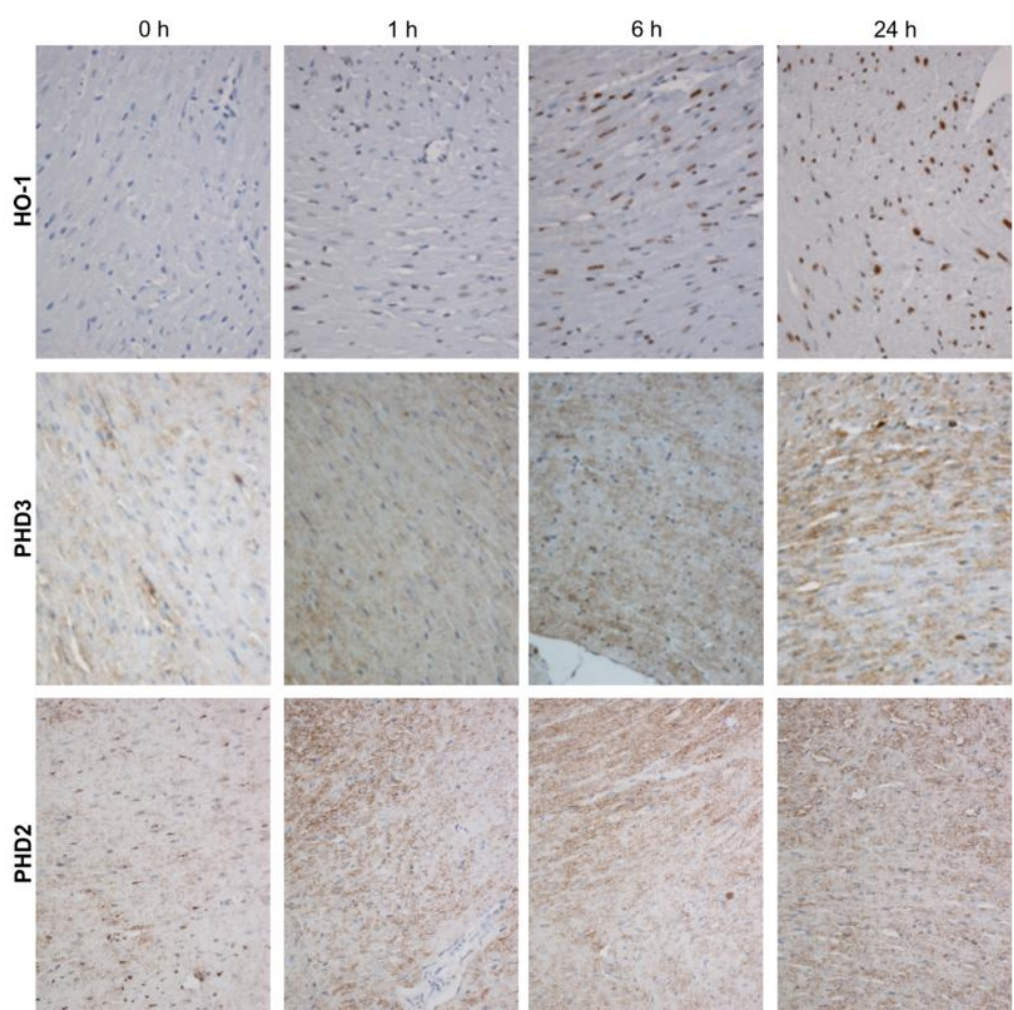

Short-term treatment with ICA affects neither cardiac function nor hematocrit in resting mice

Because PHIs induce erythropoietin synthesis, long-term application is linked to erythrocytosis, which may represent a new therapeutic option to treat renal anemia $[9,4]$. In case of cardiac tissue protection, it is, however, important that a HIF response in the heart can be achieved without affecting the erythrocyte concentration and hematocrit to prevent an increased afterload. In line with this, a short-term ICA treatment of two dosages separated by a 5 -h time interval failed to increase red blood cell count, hemoglobin concentration, and hematocrit (Fig. 4a-d). Additionally FAS, which is a marker for cardiac function as well as anterior and posterior wall thicknesses, which are markers for cardiac hypertrophy, were analyzed for up to 3 weeks (Fig. 4e-g). Neither cardiac function nor cardiac wall thickness was significantly altered by the PHI treatment.

Pre- and post-conditional ICA treatment decreases the myocardial infarct size after LAD ligation

Tissue protection from ischemia was demonstrated in genetically modified mice with constitutively high HIF-1 $\alpha$ levels $[15,21]$. These animals had a pre-conditional high HIF response, which protects the tissue from the subsequent insult. In line with these mouse models, a decrease in the total infarct size was seen $6 \mathrm{~h}$ after LAD ligation when resting mice were treated with ICA 6 and $1 \mathrm{~h}$ before LAD ligation (Fig. 5a-c). Pre-conditional application of a tissue-protective intervention is restricted to rare conditions of a planned ischemic procedure like transplantation etc. but is not useful for acute cardioprotection after myocardial infarction. Therefore, we next tested if post-conditional application of ICA 1 and $5 \mathrm{~h}$ after LAD ligation would affect the total infarct size likewise (Fig. 5d, e). Compared to the vehicle control, post-conditional application of ICA indeed significantly reduced the total infarct size, demonstrating that after the ischemic insult, there is a therapeutic time window. Cardiac function was severely impaired after LAD ligation, which is exemplified by a decreased FAS 7 and 14 days after surgery (Fig. 6). Tissue protection after treatment with ICA was translated into a partially better preserved heart function 14 days after LAD ligation.

\section{Discussion}

Activation of the HIF signaling pathway has a therapeutic potential for the treatment of ischemic diseases [27]. There are several reports demonstrating that treatment with known inhibitors of the PHD enzymes ameliorate a subsequent acute damage in models mimicking renal ischemia or stroke $[24,28$, 
Pflugers Arch - Eur J Physiol

Fig. 4 Cardiac function,

hematocrit, and erythrocyte and hemoglobin concentrations are not affected by short-term ICA treatment. a Schematic sketch showing the experimental time frame starting with the initial echocardiography. b Red blood cell concentration, $\mathbf{c}$ hemoglobin concentration, and $\mathbf{d}$ hematocrit of mice 21 days after ICA treatment and of vehicle-treated control animals. The numbers in the bars indicate the number of mice analyzed.

Echocardiographic measurements were performed before ICA treatments and serially 7,14 , and 21 days after treatments. e Fractional area shortening (FAS) and $\mathbf{f}$ anterior and posterior wall thicknesses were analyzed. $n=9$ 10 per treatment group; shown are means \pm SEM

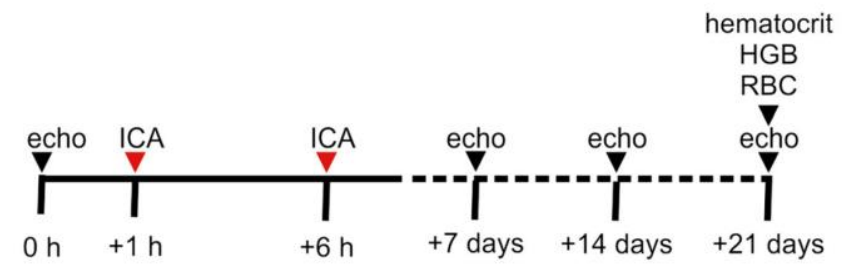

b

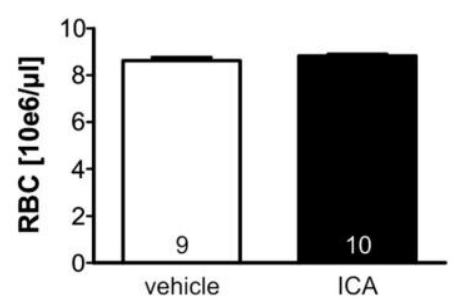

C

d
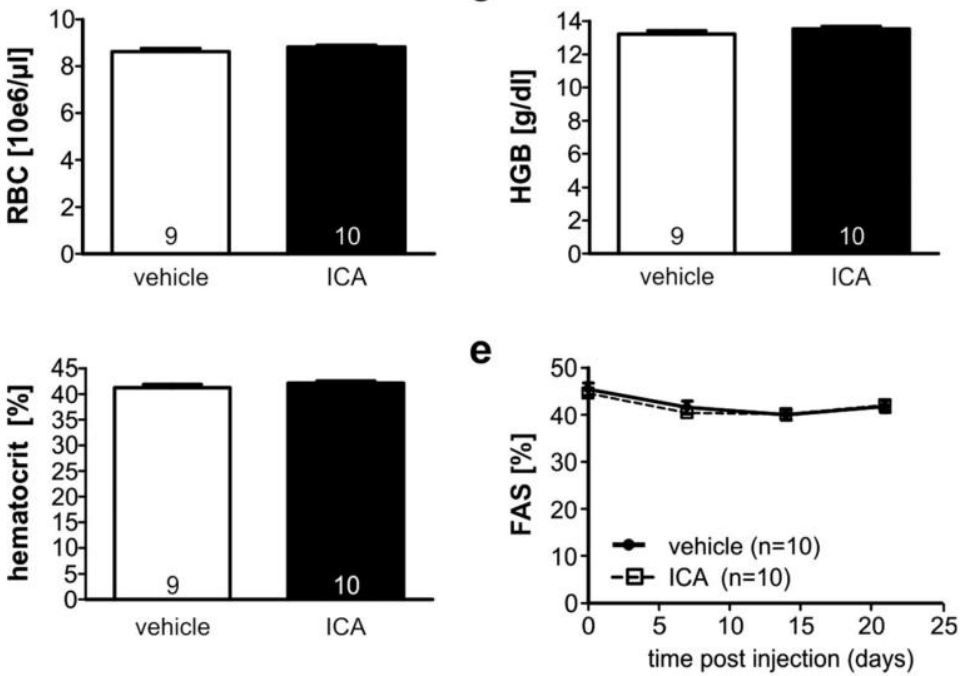

g

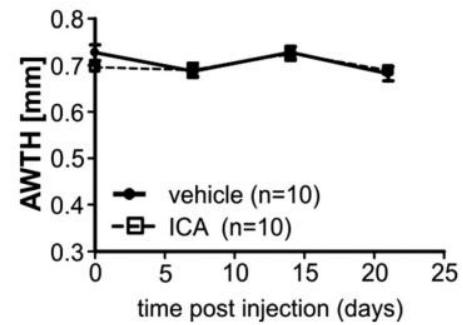

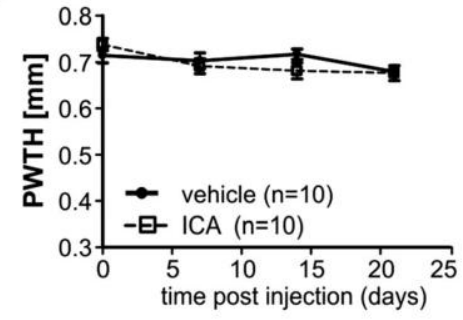

30, 32]. Genetic approaches have additionally supported the idea that HIF-1 $\alpha$ stabilization increases the tolerance towards hypoxia [22]. Regarding cardiac ischemia, previous studies suggest that chronic treatment with PHI after myocardial infarction improves cardiac function by supporting remodeling and increasing the vascularity in the peri-infarct region [2]. This effect was described in rats treated with the PHI GSK360A, which was given for 28 days starting first at $48 \mathrm{~h}$ after ligation of the LAD. Short-term protective effects of GSK360A on myocardial infarct size were seen after preconditional application [26]. Genetic HIF- $1 \alpha$ or HIF- $2 \alpha$ overexpression in the mouse heart demonstrates that chronic activation of HIF results in heart failure mimicking ischemic cardiomyopathy $[16,23]$. This effect might limit the possibility for a long-term treatment with PHIs and thus narrow the therapeutic time window. Additionally, cardio-selective PHD inhibitors are currently not available. Therefore, heart function after long-term treatment has to be analyzed in the context of hematological effects like increased hematocrit, which alters the mechanical load of the heart. In this regard, our data demonstrate most importantly that short-term preas well as post-conditional treatment of mice with the PHI ICA decreased the myocardial infarct size. The tissueprotective effect was achieved after treatment with the inhibitor done just twice over a period of $6 \mathrm{~h}$. ICA treatment was associated with a significant stabilization of HIF- $1 \alpha$ and HIF- $2 \alpha$ in the heart, which peaked transiently at $6 \mathrm{~h}$ after injection. Therefore, short-time treatment with a PHD inhibitor might be sufficient to stabilize HIF- $1 \alpha$ without affecting systemic hematocrit based on different pharmacokinetic 
Fig. 5 Protective effect of ICA in myocardial infarction. a Schematic sketch showing the experimental time frames of preand post-conditional ICA application. b Hearts of preconditionally treated mice were harvested $6 \mathrm{~h}$ after LAD ligation. The total infarct size was calculated based on Evans blue perfusion and TTC staining. $\mathbf{c}$ Representative mid-myocardial cross sections of stained left ventricles analyzed in $\mathbf{b}$ are shown. d Hearts of postconditionally treated mice were harvested $6 \mathrm{~h}$ after LAD ligation. The total infarct size was calculated based on Evans blue perfusion and TTC staining. e Representative mid-myocardial cross sections of stained left ventricles analyzed in $\mathbf{d}$ are shown. For visualization purposes, the stained areas in $\mathbf{c}$ and e were color marked (perfused area: blue outline; vital AAR: red outline; AON: grey outline). The numbers in the bars indicate the number of mice analyzed. $n=14-17$ per treatment group; shown are means \pm SEM, $* p<0.05$ a
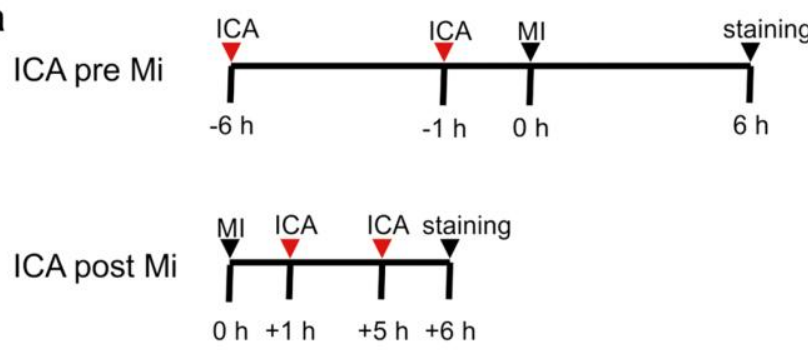

b

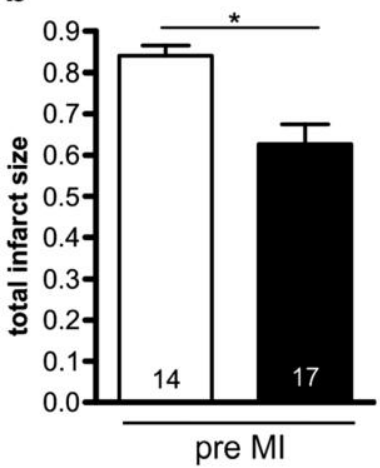

d

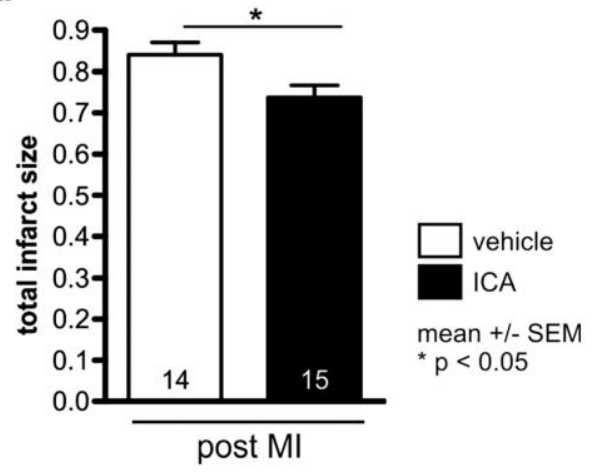

C
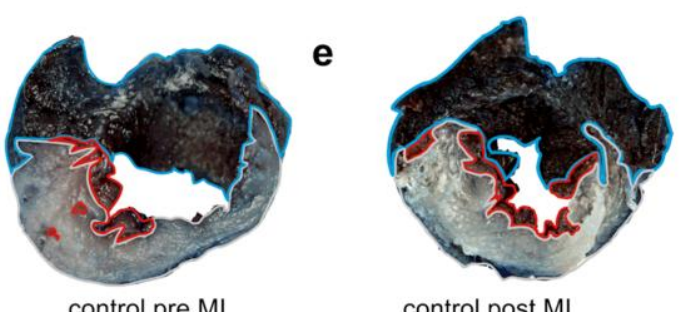

control post MI

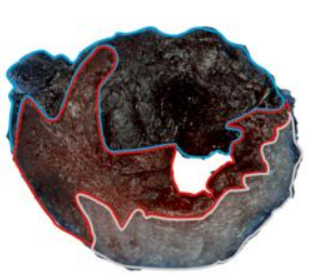

ICA pre MI

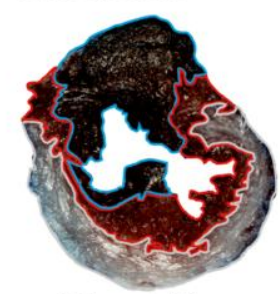

ICA post MI profiles of this small-molecule drug in the heart compared to the kidney. In this regard, it should be noted that the HIF $\alpha$ kinetic in the kidney after ICA treatment, which was reported previously, differed significantly from the kinetic seen in the heart. Whereas the response in the heart was transient, $\mathrm{HIF} \alpha$ accumulation in the kidney can be observed later and up to $72 \mathrm{~h}$ after ICA injection [30]. In this study, ICA induced HIF-1 $\alpha$ in all nephron segments with predominant high levels in the distal nephron. HIF- $2 \alpha$ was detectable additionally in interstitial and glomerular cells. This might at least in part explain that in renal ischemia, pre-conditional application but not post-conditional application, in sharp contrast to myocardial ischemia, resulted in tissue protection [35].

Although the net effect regarding tissue protection was similar in the pre- versus post-conditional ICA treatment conditions, the underlying mechanisms still might be different [11]. Cardioprotection initiated through ischemic preand post-conditioning has been associated with a myriad of cellular and subcellular adaptive responses including endogenous stimulation of adenosine receptors, iNOS and HO-1, activation of survival kinases, opening of ion channels, 
Pflugers Arch - Eur J Physiol

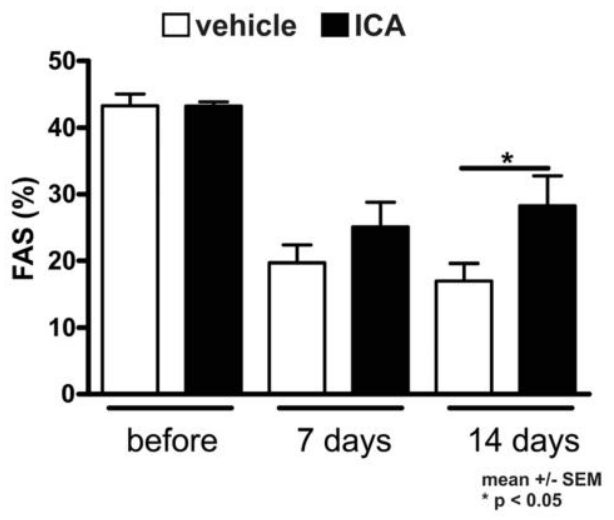

Fig. 6 Fractional area shortening is partially rescued after ICA treatment Mice were treated with ICA $(n=8)$ or with vehicle control (vehicle, $n=6)$ $6 \mathrm{~h}$ before undergoing LAD ligation. Before LAD ligation as well as 7 and 14 days after surgery, fractional area shortening (FAS) was determined by echocardiography. Shown are means \pm SEM, $* p<0.05$

attenuation of mitochondrial activity, etc. [5]. HIF itself as well as several of its target genes has been associated with ischemic pre- and post-conditioning [7]. Since ICA resulted in a clear stabilization of HIF- $1 \alpha, \mathrm{HIF}-2 \alpha$, and its target genes like HO-1 and PHD3, it is highly likely that the tissue-protective effect is mediated via HIF. The protective effect, however, is not necessarily limited to the stabilization of HIF $\alpha$ in the cardiomyocytes as suggested by the described cardiomyocyte-specific genetically modified mouse models. Interestingly, besides HIF-1 and HIF- $2 \alpha$ stabilization in cardiomyocytes after ICA treatment, HIF-2 $\alpha$ stabilization occurred additionally in endothelial cells, which may contribute to the observed protective effects. Cardioprotection by $\mathrm{HIF} \alpha$ stabilization in endothelial cells was previously demonstrated in a PHD2 hypomorph mouse model, which, in contrast to the described cardiomyocytespecific deletion of PHD2, has additionally significantly lower PHD2 protein levels in the cardiac endothelial cells [20]. Tie2 signaling in the endothelial cells contributed significantly to the ischemic cardioprotective effect in this mouse model.

After acute myocardial infarction, the heart undergoes a detailed remodeling process, which also involves the ischemic border zones. Heart function after ischemia is affected not only by the acute loss of tissue but also by a beneficial remodeling process. Cardiac fibroblasts are highly involved in adjusting heart structure and remodeling. Detailed followup studies involving this cell type need to be performed to clarify if inhibiting PHD activities also would beneficially support the remodeling process after infarction.

Taken together, our data demonstrate that post-myocardial infarction has a therapeutic time window, which might be used for acute tissue protection via post-conditional application of PHI.
Acknowledgments This work was supported by the Deutsche Forschungsgemeinschaft [M.V. is a fellow Ph.D. student of the IRTG1816] and an intramural grant from the University Erlangen Nürnberg (emerging field initiative: medicinal redox inorganic chemistry to N.B.)

Conflict of interest There is no conflict of interest to be declared.

\section{References}

1. Baader E, Tschank G, Baringhaus KH, Burghard H, Gunzler V (1994) Inhibition of prolyl 4-hydroxylase by oxalyl amino acid derivatives in vitro, in isolated microsomes and in embryonic chicken tissues. Biochem J 300:525-530

2. Bao W, Qin P, Needle S, Erickson-Miller CL, Duffy KJ, Ariazi JL, Zhao S, Olzinski AR, Behm DJ, Pipes GC, Jucker BM, Hu E, Lepore JJ, Willette RN (2010) Chronic inhibition of hypoxia-inducible factor prolyl 4-hydroxylase improves ventricular performance, remodeling, and vascularity after myocardial infarction in the rat. J Cardiovasc Pharmacol 56:147-155

3. Bernhardt WM, Campean V, Kany S, Jurgensen JS, Weidemann A, Warnecke C, Arend M, Klaus S, Gunzler V, Amann K, Willam C, Wiesener MS, Eckardt KU (2006) Preconditional activation of hypoxia-inducible factors ameliorates ischemic acute renal failure. $\mathrm{J}$ Am Soc Nephrol 17:1970-1978

4. Bernhardt WM, Wiesener MS, Scigalla P, Chou J, Schmieder RE, Gunzler V, Eckardt KU (2010) Inhibition of prolyl hydroxylases increases erythropoietin production in ESRD. J Am Soc Nephrol 21:2151-2156

5. Burley DS, Baxter GF (2009) Pharmacological targets revealed by myocardial postconditioning. Curr Opin Pharm 9:177-188

6. Cai Z, Zhong H, Bosch-Marce M, Fox-Talbot K, Wang L, Wei C, Trush MA, Semenza GL (2008) Complete loss of ischaemic preconditioning-induced cardioprotection in mice with partial deficiency of HIF-1 $\alpha$. Cardiovasc Res 77:463-470

7. Cai Z, Luo W, Zhan H, Semenza GL (2013) Hypoxia-inducible factor 1 is required for remote ischemic preconditioning of the heart. Proc Natl Acad Sci 110:17462-17467

8. Chowdhury R, Candela-Lena J, Chan MC, Greenald DJ, Yeoh KK, Tian YM, McDonough MA, Tumber A, Rose NR, Conejo-Garcia A, Demetriades M, Mathavan S, Kawamura A, Lee MK, van Eeden F, Pugh CW, Ratcliffe PJ, Schofield CJ (2013) Selective small molecule probes for the hypoxia inducible factor (HIF) prolyl hydroxylases. ACS Chem Biol 19:1488-1496

9. Duan LJ, Takeda K, Fong GH (2014) Hematological, hepatic, and retinal phenotypes in mice deficient for prolyl hydroxylase domain proteins in the liver. Am J Pathol 184:1240-1250

10. Eckle T, Kohler D, Lehmann R, El Kasmi K, Eltzschig HK (2008) Hypoxia-inducible factor- 1 is central to cardioprotection: a new paradigm for ischemic preconditioning. Circulation 118:166-175

11. Hausenloy DJ, Yellon DM (2006) Survival kinases in ischemic preconditioning and postconditioning. Cardiovase Res 70:240-253

12. Hesse AR, Levent E, Zieseniss A, Tiburcy M, Zimmermann WH, Katschinski DM (2014) Lights on for HIF-1 $\alpha$ : genetically enhanced mouse cardiomyocytes for heart tissue imaging. Cell Physiol Biochem 34:455-462

13. Heusch G (2013) Cardioprotection: chances and challenges of its translation to the clinic. Lancet 381:166-175

14. Hill P, Shukla D, Tran MG, Aragones J, Cook HT, Carmeliet P, Maxwell PH (2008) Inhibition of hypoxia inducible factor hydroxylases protects against renal ischemia-reperfusion injury. J Am Soc Nephrol 19:39-46 
15. Hölscher M, Silter M, Krull S, von Ahlen M, Hesse A, Schwartz P, Wielockx B, Breier G, Katschinski DM, Zieseniss A (2011) Cardiomyocyte-specific prolyl-4-hydroxylase domain 2 knock out protects from acute myocardial ischemic injury. J Biol Chem 286: 11185-11194

16. Hölscher M, Schäfer K, Krull S, Farhat K, Hesse A, Silter M, Lin Y, Pichler BJ, Thistlethwaite P, El-Armouche A, Maier LS, Katschinski DM, Zieseniss A (2012) Unfavourable consequences of chronic cardiac HIF-1 $\alpha$ stabilization. Cardiovasc Res 94:77-86

17. Hyvarinen J, Hassinen IE, Sormunen R, Maki JM, Kivirikko KI, Koivunen P, Myllyharju J (2010) Hearts of hypoxia-inducible factor prolyl 4-hydroxylase-2 hypomorphic mice show protection against acute ischemia-reperfusion injury. J Biol Chem 285:4202342032

18. Ivan M, Haberberger T, Gervasi DC, Michelson KS, Gunzler V, Kondo K, Yang H, Sorokina I, Conaway RC, Conaway JW, Kaelin WG Jr (2002) Biochemical purification and pharmacological inhibition of a mammalian prolyl hydroxylase acting on hypoxia-inducible factor. Proc Natl Acad Sci 99:13459-13464

19. Jaakkola P, Mole DR, Tian YM, Wilson MI, Gielbert J, Gaskell SJ, von Kriegsheim A, Hebestreit HF, Mukherji M, Schofield CJ, Maxwell PH, Pugh CW, Ratcliffe PJ (2001) Targeting of HIF- $\alpha$ to the von Hippel-Lindau ubiquitylation complex by $\mathrm{O}_{2}$-regulated prolyl hydroxylation. Science 292:468-472

20. Kerkela R, Karsikas S, Szabo Z, Serpi R, Magga J, Gao E, Alitalo K, Anisimov A, Sormunen R, Pietila I, Vainio L, Koch WJ, Kivirikko KI, Myllyharju J, Koivunen P (2013) Activation of hypoxia response in endothelial cells contributes to ischemic cardioprotection. Mol Cell Biol 33:3321-3329

21. Kido M, Du L, Sullivan CC, Li X, Deutsch R, Jamieson SW, Thistlethwaite PA (2005) Hypoxia-inducible factor la reduces infarction and attenuates progression of cardiac dysfunction after myocardial infarction in the mouse. J Am Coll Cardiol 46:2116-2124

22. Kunze R, Zhou W, Veltkamp R, Wielockx B, Breier G, Marti HH (2012) Neuron-specific prolyl-4-hydroxylase domain 2 knockout reduces brain injury after transient cerebral ischemia. Stroke 43: 2748-2756

23. Moslehi J, Minamishima YA, Shi J, Neuberg D, Charytan DM, Padera RF, Signoretti S, Liao R, Kaelin WG Jr (2010) Loss of hypoxia-inducible factor prolyl hydroxylase activity in cardiomyocytes phenocopies ischemic cardiomyopathy. Circulation 122:1004-1016

24. Nagel S, Papadakis M, Chen R, Hoyte LC, Brooks KJ, Gallichan D, Sibson NR, Pugh C, Buchan AM (2011) Neuroprotection by dimethyloxalylglycine following permanent and transient focal cerebral ischemia in rats. J Cereb Blood Flow Metab 31:132-143

25. Natarajan R, Salloum FN, Fisher BJ, Kukreja RC, Fowler AA 3rd (2006) Hypoxia inducible factor-1 activation by prolyl 4 hydroxylase-2 gene silencing attenuates myocardial ischemia reperfusion injury. Circ Res 98:133-140

26. Ong SG, Lee WH, Theodorou L, Kodo K, Lim SY, Shukla DH, Briston T, Kiriakidis S, Ashcroft M, Davidson SM, Maxwell PH, Yellon DM, Hausenloy DJ (2014) HIF-1 reduces ischaemiareperfusion injury in the heart by targeting the mitochondrial permeability transition pore. Cardiovasc Res. doi:10.1093/cvr/cvul 72
27. Rabinowitz MH (2013) Inhibition of hypoxia-inducible factor prolyl hydroxylase domain oxygen sensors: tricking the body into mounting orchestrated survival and repair responses. J Med Chem 56:93699402

28. Reischl S, Li L, Walkinshaw G, Flippin LA, Marti HH, Kunze R (2014) Inhibition of HIF prolyl-4-hydroxylases by FG-4497 reduces brain tissue injury and edema formation during ischemic stroke. PLoS One 9:e84767

29. Rohrbach S, Simm A, Pregla R, Franke C, Katschinski DM (2005) Age-dependent increase of prolyl-4-hydroxylase domain (PHD) 3 expression in human and mouse heart. Biogerontology 6:165-171

30. Schley G, Klanke B, Schodel J, Kroning S, Turkoglu G, Beyer A, Hagos Y, Amann K, Burckhardt BC, Burzlaff N, Eckardt KU, Willam C (2012) Selective stabilization of HIF-1 $\alpha$ in renal tubular cells by 2-oxoglutarate analogues. Am J Pathol 181:1595-1606

31. Schödel J, Mole DR, Ratcliffe PJ (2013) Pan-genomic binding of hypoxia-inducible transcription factors. Biol Chem 394:507-517

32. Siddiq A, Ayoub IA, Chavez JC, Aminova L, Shah S, LaManna JC, Patton SM, Connor JR, Cherny RA, Volitakis I, Bush AI, Langsetmo I, Seeley T, Gunzler V, Ratan RR (2005) Hypoxia-inducible factor prolyl 4-hydroxylase inhibition. A target for neuroprotection in the central nervous system. J Biol Chem 280:41732-41743

33. Stubbs CJ, Loenarz C, Mecinovic J, Yeoh KK, Hindley N, Lienard BM, Sobott F, Schofield CJ, Flashman E (2009) Application of a proteolysis/mass spectrometry method for investigating the effects of inhibitors on hydroxylase structure. J Med Chem 52:2799-2805

34. Tian YM, Yeoh KK, Lee MK, Eriksson T, Kessler BM, Kramer HB, Edelmann MJ, Willam C, Pugh CW, Schofield CJ, Ratcliffe PJ (2011) Differential sensitivity of hypoxia inducible factor hydroxylation sites to hypoxia and hydroxylase inhibitors. J Biol Chem 286:13041-13051

35. Wang Z, Schley G, Turkoglu G, Burzlaff N, Amann KU, Willam C, Eckardt KU, Bernhardt WM (2012) The protective effect of prolylhydroxylase inhibition against renal ischaemia requires application prior to ischaemia but is superior to EPO treatment. Nephrol Dial Transplant 27:929-936

36. Weidemann A, Bernhardt WM, Klanke B, Daniel C, Buchholz B Campean V, Amann K, Warnecke C, Wiesener MS, Eckardt KU, Willam C (2008) HIF activation protects from acute kidney injury. J Am Soc Nephrol 19:486-494

37. Wenger RH, Stiehl DP, Camenisch G (2005) Integration of oxygen signaling at the consensus HRE. Sci STKE:re12

38. Wiesener MS, Turley H, Allen WE, Willam C, Eckardt KU, Talks KL, Wood SM, Gatter KC, Harris AL, Pugh CW, Ratcliffe PJ, Maxwell PH (1998) Induction of endothelial PAS domain protein-1 by hypoxia: characterization and comparison with hypoxia-inducible factor-1 $\alpha$. Blood 92:2260-2268

39. Willam C, Maxwell PH, Nichols L, Lygate C, Tian YM, Bernhardt W, Wiesener M, Ratcliffe PJ, Eckardt KU, Pugh CW (2006) HIF prolyl hydroxylases in the rat; organ distribution and changes in expression following hypoxia and coronary artery ligation. $\mathrm{J}$ Mol Med Cardiol 41:68-77

40. Zhao HX, Wang XL, Wang YH, Wu Y, Li XY, Lv XP, Zhao ZQ, Zhao RR, Liu HR (2010) Attenuation of myocardial injury by postconditioning: role of hypoxia inducible factor-1a. Basic Res Cardiol 105:109-118 


\section{Unpublished data}

In this chapter I describe unpublished data regarding the establishment of an inducible, fibroblast-specific PHD2 conditional knock out mouse model using the Cre-loxP system.

\subsection{Establishment of fibroblast-specific PHD2 knock out mice}

\subsubsection{Abstract}

Since oxygen-dependent gene expression is involved in several adaptive mechanisms at the cellular and systemic level, manipulation of the HIF pathway by interfering with PHD activity is an attractive strategy for tissue protection (Katschinski, 2009). In line, cardiomyocyte specific HIF-1 $\alpha$ stabilization has been reported to be protective in acute ischemia (Kido et al., 2005; Hölscher et al., 2011). Besides cardiomyocytes, which account for 30-40\% of cardiac cells, the majority of the remaining cells are fibroblasts (Vliegen et al., 1991; Souders et al., 2009). They fulfill several important functions during heart development and in the normal cardiac homeostasis as well as in tissue remodeling involving fibrosis after myocardial infarction (Camelliti et al., 2005). Given the important role of fibroblasts in the healthy and diseased heart, it is important to take fibroblast function into account when considering the HIF pathway for treatment strategies. Thus, I set out to generate an inducible, fibroblastspecific PHD2 knock out mouse. For this purpose, Phd $2^{\text {floxflox }}$ mice were crossed with mice which express an inducible Cre-recombinase under the control of the Coll $\alpha 2$ promoter and treated with different tamoxifen (TAM) administration protocols. The PHD2 knock out efficacy was analyzed on genomic DNA (gDNA), messenger RNA (mRNA), and protein level in tissue specimens or isolated primary fibroblasts. Via all administration routes I could observe DNA recombination, however hardly any PHD2 knock out was detected on mRNA and protein level. This reveals an insufficient recombination activity which may be caused by a low promotor activity and subsequently incomplete activation of the Cre-recombinase.

\subsubsection{Introduction}

When the oxygen delivery is impaired cells respond to hypoxia by stabilisation of HIF $\alpha$, which is part of the heterodimeric transcription factor complex that regulates the transcription of genes affecting several adaptive processes, like angiogenesis, cellular metabolism and cell survival (Semenza, 2002). In normoxia PHDs hydroxylate HIF $\alpha$ and thus mark it for to ubiqitination and proteasomal degradation (Maxwell et al., 1999). Three isoforms, i.e. PHD1, 
PHD2 and PHD3 exist, which have the ability to hydroxylate the $\alpha$-subunit of HIF. Among those PHD2 can be regarded as the main oxygen sensor in normoxia (Appelhoff et al., 2004). Since oxygen-dependent gene expression is involved in several adaptive mechanisms, manipulation of the HIF pathway by interfering with PHD activity is an attractive strategy for tissue protection (Katschinski, 2009). It was shown that stabilization of HIF-1 $\alpha$ in cardiomyocyte-specific PHD2 knock out and HIF-1 $\alpha$ transgenic mice can exert tissue protective effects in acute myocardial infarction (Kido et al., 2005; Hölscher et al., 2011). In addition, protective effects were also observed by pharmaceutical inhibition of PHDs and subsequent HIF-1 $\alpha$ stabilization (Eckle et al., 2008; Bao et al., 2010; Vogler et al., 2015).

Besides cardiomyocytes, which account for 30-40\% of heart cells, the majority of the remaining cells are fibroblasts (Vliegen et al., 1991; Souders et al., 2009). They fulfill essential functions in cardiac development, cell signaling and electro-mechanical properties of the myocardium. They are also the main source of ECM proteins and are thus postulated to be important for the structural integrity of the heart and for the myocardial remodeling after infarction (Cleutjens et al., 1995; Camelliti et al., 2005).

The fibroblast population of the heart is fundamental for the performance of the normal and the diseased heart. When considering systemic PHD2 inhibition as therapeutic approach in case of myocardial ischemia it is important to understand the effects not only in cardiomyocytes, but also in fibroblasts. However, the contribution of PHD2 and the HIF pathway to cardiac fibroblast function in the ischemic heart is not understood. Thus, I set out to generate an inducible, fibroblast-specific PHD2 knock out mouse model by intercrossing $\operatorname{Tg}($ Colla2-cre/ERT $)$ deleter mice with $P h d 2^{\text {floxflox }}$ mice. The deleter mice express a fusion product involving the Cre-recombinase-domain and a mutated estrogen-receptor ligandbinding domain (ERT) under the control of a fibroblast-specific regulatory sequence from the proa2(I)collagen gene (Bou-Gharios et al., 1996). The Cre-recombinase is derived from the P1 bacteriophage and catalyzes the site specific recombination between two specific DNA recognition sites (LoxP-sites). These are palindromic sequences that were cloned into the PHD2 gene (Phd2 floxflox $)$ (Hölscher et al., 2011). The Cre-recombinase can be activated by the binding of 4-OHT, the active metabolite of TAM. This activation permits access of the Crerecombinase to the nucleus and subsequent excision of the DNA sequence flanked by the LoxP sequences. Several TAM administration protocols were described for the activation of the Cre-recombinase in different mouse models including animals that express the Crerecombinase under the control of the Col1 $\alpha 2$ promoter (Zheng et al., 2002; Hayashi and McMahon, 2002; Kiermayer et al., 2007; Denton et al., 2009). 
In this study I evaluated the PHD2 knock out efficacy in fibroblasts in vivo and in vitro using different TAM administration protocols and summarized their effects on gDNA, mRNA, and protein level.

\subsubsection{Materials and Methods}

Most chemicals and materials were obtained from Sigma-Aldrich, Hamburg, Germany or Carl Roth GmbH \& Co. KG, Karlsruhe, Germany, if not indicated differently in the text.

\section{$\underline{\text { Mice }}$}

Inducible, fibroblast-specific PHD2 knock out mice were generated by an intercross between

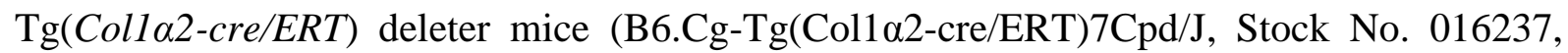
Jackson Laboratories, Bar Harbor, Maine, USA) with $P h d 2^{\text {floxfllox }}$ mice. The $P h d 2^{\text {floxflox }}$ mice were kindly provided by Prof. Dr. Breier and Dr. Wielockx, University Dresden, Germany. A detailed description of the $P h d 2^{\text {floxflox }}$ mice was reported elsewhere (Hölscher et al., 2011). In brief these mice carry two LoxP-sites flanking exons 2 and 3 of the PHD2 gene which encode for almost the entire catalytic domain of $P h d 2$. The $\operatorname{Tg}(\operatorname{Coll} \alpha 2$-cre/ERT $)$ deleter mice express the Cre-recombinase fused to a ERT ligand binding domain under the control of a fibroblastspecific regulatory sequence from the proa2(I)collagen gene (Bou-Gharios et al., 1996). Under basal conditions the inactive Cre-recombinase is located in the cytoplasm and becomes activated after binding of 4-OHT to the ERT leading to subsequent nuclear import and excision of the LoxP-flanked sequence. This leads to a frameshift mutation from exon 1 to 4 of the PHD2 gene and to a translational stop. All mice used in this report were born in a normal mendelian ratio. All protocols regarding animal experimentation were conducted according to the German animal protection laws and approved by the responsible governmental authority (Niedersächsisches Landesamt für Verbraucherschutz und Lebensmittelsicherheit in Oldenburg; animal experimentation number 33.9-42502-04$12 / 0833)$.

\section{$\underline{\text { Induction with TAM or 4-OHT }}$}

$10 \mathrm{mg}$ TAM (T5648) and $5 \mathrm{mg}$ 4-OHT (H6278, H7904) were dissolved in $500 \mu 1$ 100\% ethanol and vortexed (Vortex Genie 2TM; Schütt Labortechnik GmbH, Göttingen, Germany). $9.5 \mathrm{ml}$ conventional sunflower oil were added to gain final concentrations of $10 \mathrm{mg} / \mathrm{ml}$ TAM 
and $5 \mathrm{mg} / \mathrm{ml} \mathrm{4-OHT}$. Solutions were incubated for $1 \mathrm{~h}$ at RT under constant agitation. The suspensions were sonicated at 10\%-60\% power, cycle 9 (Sonopuls SH 70 G, BANDELIN electronic $\mathrm{GmbH} \& \mathrm{Co} . \mathrm{KG}$, Berlin, Germany) for 15-30 min, the vials were briefly vortexed every 5-10 min until the solution appeared clear. If necessary, the 4-OHT suspensions were incubated up to $1 \mathrm{~h}$ at $65^{\circ} \mathrm{C}$ to dissolve all the 4-OHT. The solutions were stored in light protected containers. TAM stocks were kept at $-20^{\circ} \mathrm{C}$, whereas $4-\mathrm{OHT}$ was used immediately. Experiments were performed with male and female mice at different ages from 7 days up to 8 weeks old as indicated in the text, as well as with pregnant mice at day 12 post-conception (PC). Activation of the Cre-recombinase was contemplated using different TAM administration protocols. Animals received either TAM containing chow of a soy free food base (TD.55125 and T.2016.12, Harlan Laboratories Inc, Rossdorf, Germany) for up to 7 weeks. In different attempts TAM was injected intraperitoneally (i.p.) (40 mg/kg, $200 \mathrm{mg} / \mathrm{kg}$ TAM, $50 \mathrm{mg} / \mathrm{kg}$ 4-OHT) using a 26-gauge needle with a $1 \mathrm{ml}$ syringe (B. Braun, Melsungen AG, Melsungen, Germany). Injections were performed either at single time points (in pregnant mice) or serially. For serial injections mice were treated either weekly for three consecutive weeks or daily for up to 10 consecutive days. Tissue harvest and isolation of primary fibroblasts were carried out 4 weeks after the last feeding with tamoxifen containing chow or injection of TAM.

\section{Echocardiography}

Non-invasive evaluation of the cardiovascular function was performed by echocardiography. Mice were anaesthetized with $2 \%$ isoflurane $\left(\right.$ Forene $^{\circledR}$, AbbVie Deutschland GmbH \& Co. KG, Ludwigshafen, Germany), depilated and fixed on a heating pad with ECG leads. Echocardiography was performed under anesthesia with $1 \%$ isoflurane. Two-dimensional images and M-mode tracings were recorded from the parasternal long axis view at midpapillary level (Vevo 2100TM, MS400; Visual Sonics, Toronto, Ontario, Canada). The heart rate, left ventricular enddiastolic diameter (LVEDD) and ensystolic diameter (LVESD) were determined. Fractional area shortening (FAS) of the left ventricle was defined as the LVEDD - LVESD divided by the LVEDD. The FAS was used as marker for cardiac function.

\section{$\underline{\text { Isolation and cultivation of primary fibroblasts }}$}

To determine the knock efficacy of PHD2 in primary murine fibroblasts in different tissues, fibroblasts were isolated from tail, skin, kidney and the heart. 
Tails were removed from the mice using sterile scissors and incubated for $60 \mathrm{~min}$ on ice in 20 ml DMEM (PAN-Biotech GmbH, Aidenbach, Germany) supplemented with 10\% FCS (PAN-Biotech GmbH), 1\% MEM-NEAA (PAN-Biotech GmbH) and 1\% penicillin/ streptomycin $(\mathrm{P} / \mathrm{S})(\mathrm{PAN}-\mathrm{Biotech} \mathrm{GmbH})$. After washing the tails in PBS containing $2 \% \mathrm{P} / \mathrm{S}$, they were dipped briefly in $70 \%$ ethanol and minced up using sterile scissors. Tissue was digested with $400 \mathrm{U} / \mathrm{ml}$ collagenase type II (\#C2-22; Biochrom AG, Berlin, Germany) added to the media and incubated while agitating at $37^{\circ} \mathrm{C}$ overnight. Cells were passed through a $70 \mu \mathrm{m}$ nylon cell strainer (\#22363548; Thermo Fisher Scientific Inc., Schwerte, Germany), centrifuged for $5 \mathrm{~min}$ at $1000 \mathrm{rpm}$ and seeded in cell culture dishes. The medium was changed after $2 \mathrm{~h}$.

Skin was shaved and disinfected with $70 \%$ ethanol. The tissue was cut into $4 \mathrm{~mm}^{2}$ squares using a sharp scalpel and placed into a sterile cell culture dish covered by a sterile cover slip. Medium (DMEM, 10\% FCS, 1\% MEM-NEAA, 1\% P/S) was added and changed every 3 days until the skin fibroblasts, which migrated out of the tissue became confluent.

Hearts and kidneys were harvested and washed in sterile PBS (137 mM NaCl, $2.7 \mathrm{mM} \mathrm{KCl}$, $10 \mathrm{mM} \mathrm{Na} 2 \mathrm{HPO}_{4}, 1.8 \mathrm{mM} \mathrm{KH} \mathrm{PO}_{4}$ ). The tissues were minced and digested at $37^{\circ} \mathrm{C}$ for $10 \mathrm{~min}$ while agitating in digestion buffer containing $137 \mathrm{mM} \mathrm{NaCl}, 5.4 \mathrm{mM} \mathrm{KCl}, 0.25 \mathrm{mM}$ $\mathrm{Na}_{2} \mathrm{HPO}_{4}, 0.44 \mathrm{mM} \mathrm{KH} \mathrm{PO}_{4}, 1.3 \mathrm{mM} \mathrm{CaCl}$, $1.0 \mathrm{mM} \mathrm{MgSO}_{4}, 4.2 \mathrm{mM} \mathrm{NaHCO} 3,0.1 \%$ trypsin and $100 \mathrm{U} / \mathrm{ml}$ collagenase type IV (\#C4-22; Biochrom AG). After precipitation of the cells for $1 \mathrm{~min}$ the first supernatant was discarded. The digestion-precipitation steps were repeated 4-5 times until the tissues were dissolved completely while supernatants were collected and spun down for $5 \mathrm{~min}$ at $1000 \mathrm{rpm}$ at $4^{\circ} \mathrm{C}$. Kidney fibroblasts were resuspended in DMEM, 10\% FCS, 1\% P/S, whereas DMEM/F-12, GlutaMAX ${ }^{\mathrm{TM}}$ (\#31331-028 Life Technologies GmbH, Darmstadt, Germany) supplemented with 10\% FCS, 1\% P/S and $100 \mu \mathrm{M}$ ascorbic acid was used for cardiac fibroblasts. Cells were plated and the medium was changed after $2 \mathrm{~h}$.

The isolated fibroblasts were cultivated under cell culture conditions at $37^{\circ} \mathrm{C}, 5 \% \mathrm{CO}_{2}$, $20 \% \mathrm{O}_{2}$ (Binder $\mathrm{GmbH}$, Tuttlingen, Germany).

\section{$\underline{\text { In vitro tamoxifen treatment and hypoxia }}$}

4-OHT was dissolved in ethanol to obtain a $1 \mathrm{mM}$ stock solution and stored in light protected tubes at $-20^{\circ} \mathrm{C}$. For in vitro induction experiments $1 \mu \mathrm{M} 4-\mathrm{OHT}$ was added to cultured fibroblasts and incubated for $72 \mathrm{~h}$ followed by $24 \mathrm{~h}$ without 4-OHT. Cells were additionally 
cultivated under hypoxic conditions at $1 \% \mathrm{O}_{2}$ (INVIVO $\mathrm{O}_{2}$, IUL Instruments $\mathrm{GmbH}$, Königswinter, Germany and Gas Mixer Q, Ruskinn Technology Ltd, Bridgend, UK).

\section{gDNA isolation and polymerase chain reaction}

The gDNA was isolated from murine tissue samples and primary fibroblasts by alkaline lysis in $0.2 \mathrm{mM}$ EDTA $25 \mathrm{mM} \mathrm{NaOH}$ for $1 \mathrm{~h}$ at $95^{\circ} \mathrm{C}$. After cooling for $10 \mathrm{~min}$ at $4^{\circ} \mathrm{C}$ the solution was neutralized with $40 \mathrm{mM}$ Tris $\mathrm{pH}$ 5.0. The dissolved gDNA was used for polymerase chain reactions (PCR) to either determine the mouse genotype or for evaluation of the PHD2 knock out efficacy after activation of the Cre-recombinase. By utilizing PCR the specific DNA regions are amplified in a three step process. In the first step the genomic double stranded DNA is denaturized, the second involves annealing of specific primers to the sequence of interest followed by subsequent elongation performed by a thermo stable DNA polymerase. The annealing temperature depends on the base composition and length of the used primers. Primers used for genotyping and PHD2 knock out analysis are listed in Table 1.

Table 1: Primers used for genotyping and PHD2 knock out analysis

\begin{tabular}{|l|l|l|}
\hline Primer name & Sequence & $\begin{array}{l}\text { Annealing } \\
\text { temperature }\end{array}$ \\
\hline Cre forward & 5'-GTTCGC AAGAACCTGATGGACA-3' $^{\prime}$ & $60^{\circ} \mathrm{C}$ \\
\hline Cre reverse & 5'-CTAGAGCCTGTTTTGCACGTTC-3' & $60^{\circ} \mathrm{C}$ \\
\hline PHD2 intron 1 forward & 5'-CTCACTGACCTACGCCGTGT-3 $^{\prime}$ & $61^{\circ} \mathrm{C}$ \\
\hline PHD2 exon 2 reverse & 5'-CGCATCTTCCATCTCCATTT-3' & $55^{\circ} \mathrm{C}$ \\
\hline PHD2 intron 3 reverse & 5'-ACCACCCCGTCTGACAATTC-3' & $56^{\circ} \mathrm{C}$ \\
\hline
\end{tabular}

PCR was performed in a total reaction volume of $25 \mu$ l containing $6.5 \mu \mathrm{l} \mathrm{H}_{2} \mathrm{O}, 5 \mu \mathrm{l}$ DNA template, $0.5 \mu \mathrm{l}$ forward primer $(20 \mathrm{pmol} / \mu \mathrm{l}), 0.5 \mu \mathrm{l}$ reverse primer $(20 \mathrm{pmol} / \mu \mathrm{l})$ and $12.5 \mu \mathrm{l}$ 2x PCR Mastermix (Thermo Fisher Scientific Inc.). The reaction was carried out in the Arktik Thermal Cycler (Thermo Fisher Scientific Inc.) with PCR cycling parameters as listed in Table 2.

Table 2: PCR cycling parameters for mice genotyping and PHD2 knock out analysis

\begin{tabular}{|c|c|c|c|c|c|c|}
\hline \multirow{2}{*}{ Step } & \multicolumn{3}{|c|}{ Genotyping PCR for Cre } & \multicolumn{3}{|c|}{$\begin{array}{l}\text { PHD2 genotyping /knock out } \\
\text { analysis }\end{array}$} \\
\hline & Time & Temperature & Cycles & Time & Temperature & Cycles \\
\hline Initial denaturation & $4 \mathrm{~min}$ & $94^{\circ} \mathrm{C}$ & 1 & $2 \mathrm{~min}$ & $94^{\circ} \mathrm{C}$ & 1 \\
\hline Denaturation & $30 \mathrm{sec}$ & $94^{\circ} \mathrm{C}$ & \multirow{3}{*}{30} & $30 \mathrm{sec}$ & $94^{\circ} \mathrm{C}$ & \multirow{3}{*}{$30 / 35$} \\
\hline Annealing & $30 \mathrm{sec}$ & $60^{\circ} \mathrm{C}$ & & $30 \mathrm{sec}$ & $56^{\circ} \mathrm{C}$ & \\
\hline Elongation & $75 \mathrm{sec}$ & $72^{\circ} \mathrm{C}$ & & $7 \mathrm{~min}$ & $72^{\circ} \mathrm{C}$ & \\
\hline Final elongation & $7 \mathrm{~min}$ & $72^{\circ} \mathrm{C}$ & 1 & $10 \mathrm{~min}$ & $72^{\circ} \mathrm{C}$ & 1 \\
\hline
\end{tabular}




\section{$\underline{\text { Agarose gel electrophoresis }}$}

Agarose gel electrophesis was used to separate and visualize DNA fragments of different sizes. Therefore agarose gels at concentrations of $1 \%$ or $2 \%$ were cast in $0.5 \mathrm{x}$ TBE buffer (44.5 mM Tris, $44.5 \mathrm{mM}$ boric acid, $1 \mathrm{mM}$ EDTA, $\mathrm{pH}$ 8.0) depending on the expected size of the amplified DNA fragments. To visualize the fragments Roti ${ }^{\circledR}$-Safe GelStain (Carl Roth $\mathrm{GmbH}+\mathrm{Co} . \mathrm{KG}$, Karlsruhe, Germany) was added to the liquid agarose gels according to the manufacturer's instructions. To load the samples on the gel $6 \mu 1$ OrangeG loading dye (30\% glycerin and $0.25 \%$ Orange $\mathrm{G}$ in water) were added to the reactions. In addition $5 \mu 1$ of either a $100 \mathrm{bp}$ or $1 \mathrm{~kb}$ molecular weight markers \#SM0322 and \#SM0311; Thermo Fisher Scientific Inc.) were used to determine the size of the separated DNA fragments. The agarose gel electrophesis was performed at $100 \mathrm{~V}$ for $1 \mathrm{~h}$. The DNA was visualized with an UVtransilluminator at $302 \mathrm{~nm}$ (Syngene, Cambridge, UK).

\section{$\underline{\text { mRNA isolation }}$}

To analyse the PHD2 knock out efficacy on mRNA level the cultured primary fibroblasts were washed with chilled PBS and lysed using TRIzol ${ }^{\circledR}$ Reagent (\#15596018, Ambion, Carlsbad, USA). The suspension was scraped off the cell culture dish and incubated 5 min at RT. $0.2 \mathrm{ml}$ chloroform were added per $1 \mathrm{ml}$ TRIzol ${ }^{\circledR}$ Reagent and vortexed. After incubation for $5 \mathrm{~min}$ at RT the samples were centrifuged at $12000 \mathrm{rpm}$ for $15 \mathrm{~min}$ at $4^{\circ} \mathrm{C}$ to separate the RNA containing aqueous phase from the phenol-chloroform phase. $0.5 \mathrm{ml}$ isopropanol per $1 \mathrm{ml} \mathrm{TRIzol}{ }^{\circledR}$ Reagent were added to the upper aqueous phase. After incubation at RT for 10 min the precipitated RNA was pelleted by centrifugation at $12000 \mathrm{rpm}$ for $10 \mathrm{~min}$ at $4^{\circ} \mathrm{C}$. The pellet was washed with $1 \mathrm{ml} 75 \%$ ethanol, vortexed and centrifuged again at $7500 \mathrm{rpm}$ for $5 \mathrm{~min}$ at $4^{\circ} \mathrm{C}$. The pellet was air dried for $10 \mathrm{~min}$ and resuspended in $15 \mu \mathrm{l}$ RNase-free water at $56^{\circ} \mathrm{C}$ for $10 \mathrm{~min}$. The RNA concentration and purity was determined by measuring the absorption at $260 \mathrm{~nm}$ and the ratio $260 \mathrm{~nm} / 280 \mathrm{~nm}$ using the SmartSpec ${ }^{\mathrm{TM}}$ Plus photometer (Bio-Rad, Munich, Germany).

\section{$\underline{\text { cDNA synthesis }}$}

Complementary DNA (cDNA) from mRNA templates was synthesised by using the First strand cDNA Synthesis Kit (\# K1612; Thermo Fisher Scientific Inc.). It contains the MMuLV reverse transcriptase which catalysis the reaction as well as Oligo (dT)18 primers, which selectively bind to the 3'-end of poly(A) RNA ensuring synthesis of cDNA only from 
poly(A) tailed mRNA. $2 \mu \mathrm{g}$ RNA were mixed with $1 \mu \mathrm{loligo}(\mathrm{dT}) 18$ primer $(0.5 \mu \mathrm{g} / \mu \mathrm{l})$ and RNAse-free water up to a volume of $11 \mu \mathrm{l}$. The mixture was gently mixed and incubated at $65^{\circ} \mathrm{C}$ for $5 \mathrm{~min}$. The samples were chilled on ice and subsequently $4 \mu 15 \mathrm{x}$ reaction buffer, $1 \mu \mathrm{l}$ RiboLock RNAse inhibitor (20 U/ $\mu \mathrm{l}), 2 \mu \mathrm{l} 10 \mathrm{mM}$ dNTP and $2 \mu \mathrm{l}$ M-MuLV reverse transcriptase $(20 \mathrm{U} / \mu \mathrm{l})$ were added to the reaction. cDNA synthesis was performed by incubation at $37^{\circ} \mathrm{C}$ for $60 \mathrm{~min}$. The reaction was stopped by incubating the samples at $70^{\circ} \mathrm{C}$ for $10 \mathrm{~min}$, which inactivates the M-MuLV reverse transcriptase.

\section{Quantitative real-time PCR}

Quantitative real-time PCR (qRT-PCR) allows the quantification of starting amounts of cDNA templates. With every amplification cycle fluorescent reporter molecules are linked to the PCR products and the intensity can be detected relative to the amount of the amplified product. The 2x SensiMix ${ }^{\mathrm{TM}}$ SYBR Low-ROX Kit (Bioline GmbH, Luckenwalde, Germany) was used in combination with a MX3000P light cycler (Stratagene/Agilent Technologies, Waldbronn, Germany). The fluorescent reporter molecule SYBR ${ }^{\circledR}$ Green I binds double stranded DNA and the resulting fluorescence can be detected during the DNA amplification. $\mathrm{ROX}^{\mathrm{TM}}$ dye (5-carboxy-X-rhodamine, succinymidyl ester) was used as reference dye. For the qRT-PCR $1 \mu \mathrm{l}$ cDNA was added to $12.5 \mu \mathrm{l} 2$ SensiMix $^{\mathrm{TM}}$ SYBR Low-ROX mix, $0.5 \mu 1$ forward primer $(10 \mu \mathrm{M}), 0.5 \mu \mathrm{l}$ reverse primer $(10 \mu \mathrm{M})$ and water to a total volume of $25 \mu \mathrm{l}$. To normalize for cDNA differences between samples, the ribosomal protein RNA mS12 was used as reference. Primers used are listed in Table 3 and the conditions used for the qRT-PCR are described in Table 4.

Table 3: Primers used for the qRT-PCR anaylsis

\begin{tabular}{|l|l|l|}
\hline Primer name & Sequence & $\begin{array}{l}\text { Annealing } \\
\text { temperature }\end{array}$ \\
\hline mS12 forward & 5'-GAAGCTGCCAAGGCCTTAGA-3' & $60^{\circ} \mathrm{C}$ \\
\hline mS12 reverse & 5'-AACTGCAACCAACCACCTTC-3' & $60^{\circ} \mathrm{C}$ \\
\hline mPHD2 exon 3 forward & 5'-TTGCTGACATTGAACCCAAA-3 & $53^{\circ} \mathrm{C}$ \\
\hline mPHD2 exon 5 reverse & 5'-GGCAACTGAGAGGCTGTAGG-3' & $61^{\circ} \mathrm{C}$ \\
\hline
\end{tabular}


Table 4: Steps and thermal cycling conditions used for the quantitative real-time PCR

\begin{tabular}{|c|c|c|c|c|}
\hline \multicolumn{2}{|l|}{ Step } & Time & Temperature & Cycles \\
\hline \multicolumn{2}{|l|}{ Initial denaturation } & $10 \mathrm{~min}$ & $95^{\circ} \mathrm{C}$ & 1 \\
\hline \multirow{3}{*}{ Three step PCR } & denaturation & $30 \mathrm{sec}$ & $95^{\circ} \mathrm{C}$ & \multirow{3}{*}{40} \\
\hline & annealing & $20 \mathrm{sec}$ & $60^{\circ} \mathrm{C}$ & \\
\hline & elongation & $30 \mathrm{sec}$ & $72^{\circ} \mathrm{C}$ & \\
\hline \multirow{3}{*}{$\begin{array}{l}\text { Amplification of the } \\
\text { dissociation curve }\end{array}$} & denaturation & $1 \mathrm{~min}$ & $95^{\circ} \mathrm{C}$ & \multirow{3}{*}{1} \\
\hline & annealing & $30 \mathrm{sec}$ & $60^{\circ} \mathrm{C}$ & \\
\hline & denaturation & $30 \mathrm{sec}$ & $95^{\circ} \mathrm{C}$ & \\
\hline
\end{tabular}

The $C_{t}$ (threshold cycle) values, which are the number of cycles required for the fluorescent signal to cross the threshold, were analyzed using the MxPro program (MxPro-Mx3005P v4.10, Stratagene/ Agilent Technologies, Waldbronn, Germany). Statistical analysis of data was performed using GraphPad Prism 5.0 (GraphPad Software, Inc., San Diego, CA, USA).

\section{$\underline{\text { Protein extraction }}$}

Cells were washed twice with cold PBS and lysed in fresh protein lysis buffer (400 $\mathrm{mM} \mathrm{NaCl}$, $1 \mathrm{mM}$ EDTA, $10 \mathrm{mM}$ Tris/HCl, $\mathrm{pH}$ 8.0, 0.1\% TritonX100) containing the protease inhibitor cocktail cOmplete Mini (Roche Applied Science, Mannheim, Germany). The suspension was removed from the plate with a cell scraper and incubated on ice for $10 \mathrm{~min}$. The extract was centrifuged for $10 \mathrm{~min}$ at $4^{\circ} \mathrm{C}$ at $12000 \mathrm{rpm}$. The supernatant was transferred to a fresh tube and the protein concentration was determined by the Bradford protein assay reagent (Bio-Rad Laboratories GmbH, Munich, Germany). Per $1 \mu$ protein sample $200 \mu$ l Bradford protein assay reagent was added. Additionally, a standard curve was created by using different bovine serum albumin (BSA) concentrations ranging from $0.5 \mu \mathrm{g}$ to $6 \mu \mathrm{g}$ to calculate the unknown concentrations of the samples. The protein concentrations were determined by measuring the absorption at $595 \mathrm{~nm}$ using a microplate reader (Model 680, Bio-Rad) and calculated via the Microplate Manager ${ }^{\circledR}$ program (Microplate Manager ${ }^{\circledR}$ V.5.2.1., Bio-Rad).

\section{$\underline{\text { SDS-PAGE and Immunoblot analysis }}$}

Protein samples in Laemmli buffer containing sodium dodecyl sulphate (SDS) are denaturized and negatively charged and thus can be separated by size in an electric field using polyacrylamide gelelectrophoresis (PAGE). Reducing reagents like $\beta$-mercaptoethanol are additionally used to break down disulfide bonds and thus disrupt protein structure. SDSPAGE gels were used in concentrations of $10 \%$ for resolving gels and $5 \%$ for the stacking gel. 
First, the resolving gel was prepared and covered by isopropanol. After polymerization, the stacking gel was prepared and poured on top of the resolving gel after removing the isopropanol. The compositions of the used gels are listed in Table 5.

Table 5: Composition of the resolving- and stacking gel

\begin{tabular}{|l|l|l|}
\hline & Resolving gel (10\%) & Stacking gel (5\%) \\
\hline $\mathrm{H}_{2} \mathrm{O}$ dest. & $11.9 \mathrm{ml}$ & $6.8 \mathrm{ml}$ \\
\hline $30 \%$ Acrylamid/Bisacrylamid & $10.0 \mathrm{ml}$ & $1.7 \mathrm{ml}$ \\
\hline $1.5 \mathrm{M}$ Tris, $\mathrm{pH} 8.8$ & $7.5 \mathrm{ml}$ & - \\
\hline $1 \mathrm{M}$ Tris, $\mathrm{pH} 6.8$ & - & $1.25 \mathrm{ml}$ \\
\hline $10 \%$ SDS & $0.3 \mathrm{ml}$ & $0.1 \mathrm{ml}$ \\
\hline $10 \%$ APS & $0.3 \mathrm{ml}$ & $0.1 \mathrm{ml}$ \\
\hline TEMED & $0.012 \mathrm{ml}$ & $0.01 \mathrm{ml}$ \\
\hline
\end{tabular}

Differing amounts of protein (50-90 $\mu \mathrm{g})$ were supplemented with 6x Laemmli buffer (100 mM Tris pH 6.8, 4\% SDS, $0.2 \%$ bromophenol blue, 20\% glycerol, 5\% $\beta$ mercaptoethanol). The samples were denaturized for $5 \mathrm{~min}$ at $95^{\circ} \mathrm{C}$ and loaded on the gel. Protein size was determined using the prestained PageRuler ${ }^{\mathrm{TM}}$ (\#26616; Thermo Fisher Scientific Inc.). The electrophoresis was performed at a constant current of $40 \mathrm{~mA}$ with maximum voltage set at $300 \mathrm{~V}$ using the PerfectBlue Doppelgelsystem Twin M (Peqlab, Erlangen, Germany).

For further analysis, the proteins were transferred onto a nitrocellulose membrane (Amersham, Freiburg, Germany) using the semi-dry Western blot technique (PerfectBlue Semi-Dry Elektroblotter, Peqlab, Erlangen, Germany). The stacking gel was discarded beforehand. The nitrocellulose membrane, filter papers and resolving gel were soaked in transfer buffer (48 mM Tris, $39 \mathrm{mM}$ glycine, $0.037 \%$ SDS, $20 \%$ methanol). The membrane and gel were sandwiched between the filter papers and the transfer was performed with a constant current setting of $2 \mathrm{~mA} / \mathrm{cm}^{2}$ for $1 \mathrm{~h}$. After protein transfer the membrane was stained in Ponceau S solution. Nonspecific binding sites were blocked with 5\% milk in PBS for $2 \mathrm{~h}$ at RT. The detection of proteins was carried out by incubation with primary antibodies diluted in $5 \%$ milk in PBS at $4{ }^{\circ} \mathrm{C}$ overnight. The membrane was washed $3 \times 10$ min with PBS. Incubation with secondary HRP labelled antibodies diluted in 5\% milk in PBS was performed for $2 \mathrm{~h}$ at RT. The antibodies used and their dilutions are listed below: 
Table 6: Used primary- and secondary antibodies

\begin{tabular}{|c|c|c|c|}
\hline Primary antibody & Dilution & Secondary antibody & Dilution \\
\hline anti-HIF-1 $\alpha$ (NB100-479; & \multirow{3}{*}{ 1:1000 } & \multirow{4}{*}{$\begin{array}{l}\text { HRP-labelled anti-rabbit } \\
\text { (Sc-2004, Santa Cruz } \\
\text { Biotechnology, } \\
\text { Heidelberg, Germany) }\end{array}$} & \multirow{4}{*}{$1: 10000$} \\
\hline Novus, Littleton, USA) & & & \\
\hline $\begin{array}{l}\text { anti-PHD2 (NB100-2219; Novus, } \\
\text { Littleton, USA) }\end{array}$ & & & \\
\hline $\begin{array}{l}\text { anti- } \beta \text {-tubulin (ab6046, Abcam, } \\
\text { Cambridge, UK) }\end{array}$ & $1: 2000$ & & \\
\hline
\end{tabular}

The membranes were washed three times with PBS and membranes were incubated with $100 \mathrm{mM}$ Tris- $\mathrm{HCl}, \mathrm{pH} 8.5,2.65 \mathrm{mM} \mathrm{H}_{2} \mathrm{O}_{2}, 0.45 \mathrm{mM}$ luminol, and $0.625 \mathrm{mM}$ coumaric acid for 1 min. Chemiluminescence detection was performed using the LAS3000 system (Fuji) or by using chemiluminescence sensitive films (GE Healthcare, Munich, Germany).

\subsubsection{Results}

$\underline{\text { Strategy for generation of fibroblast-specific PHD2 knock out mice }}$

The generation of an inducible, fibroblast-specific PHD2 knock out mouse was performed by intercrossing $\operatorname{Tg}($ Colla2-cre/ERT $)$ deleter mice with Phd $2^{\text {floxflox }}$ mice. The deleter mice express the inducible Cre-recombinase under the control of the Col1 $\alpha 2$ promoter. A 'far upstream enhancer' region located 21.8 to $-18.8 \mathrm{~kb}$ upstream of the start site of transcription of the the proa2(I)collagen gene restricts Cre-expression in fibroblasts but not in other type I collagen-producing cells (Bou-Gharios et al., 1996). Once activated by binding of 4-OHT, the Cre-recombinase permits recombination of the floxed Phd2 exon 2 and 3 which encode for the catalytic domain of the PHD2 enzyme (Figure 3A). This leads to a frameshift mutation resulting in a translational stop. For gDNA analysis primers were used which anneal upstream (Primer intron 1) and downstream (Primer intron 3) of the floxed Phd2 exons 2 and 3. The excision of exon 2 and 3 leads to a shorter gene sequence and thus a smaller PCR product.

To activate the Cre-recombinase binding of 4-OHT to the mutated ERT is indispensable. Several TAM administration protocols were tested and evaluated for their PHD2 knock out efficacy on gDNA, mRNA, and protein level. Independent of the administration protocol genetic recombination could always be observed on gDNA level (Figure 3B).

First 8-12 weeks old animals were fed with TAM containing chow for 7 weeks (Figure 3C). Secondly, intraperitoneal injections of TAM were performed with increasing dosages ranging 
from $40 \mathrm{mg} / \mathrm{kg}$ body weight, $80 \mathrm{mg} / \mathrm{kg}$ body weight, and $100 \mathrm{mg} / \mathrm{kg}$ body weight up to $200 \mathrm{mg} / \mathrm{kg}$ body weight per day for 5 up to 10 consecutive days. Mice were studied at 3 weeks and 8-12 weeks of age. In addition, one single injection of $1 \mathrm{mg}$ TAM was performed in pregnant mice at day $12 \mathrm{PC}$. TAM is a prodrug which is metabolized mostly into its active 4-OHT form predominantly by the cytochrome P450 (CYP) enzymes including CYP2D6 and CYP3A4 (Jordan et al., 1977). 4-OHT has an up to 100 times higher affinity than TAM and its other metabolites for binding to estrogen receptors and thus a greater potency to activate the Cre-recombinase (Malet et al., 1988). The 4-OHT exists as trans (Z) and cis (E) isomers. The Z-isomer is the more potent than the E-isomer (100x less) (Murphy et al., 1990). Therefore, one group of animals received $50 \mathrm{mg} / \mathrm{kg}$ body weight active 4-OHT per day consisting of either $70 \%$ Z-isomer or $>98 \%$ Z-isomer. These mice were treated once weekly for three times starting at day 7 after birth or for 10 consecutive days of an age of 4 weeks. 4 weeks after the last application or birth of offspring primary fibroblasts were isolated from heart, kidney, tail and skin and cultivated. Tail tip specimens were taken for PHD2 knock out analysis on gDNA level; mRNA and protein extracts were isolated from the cultured fibroblasts and the PHD2 knock out efficacy was determined. Besides the in vivo applications primary cells were also treated with $1 \mu \mathrm{M} 4-\mathrm{OHT}$ for $72 \mathrm{~h}$ in vitro and cultivated under normoxic $\left(20 \% \mathrm{O}_{2}\right)$ or hypoxic $\left(1 \% \mathrm{O}_{2}\right)$ conditions. 4-OHT undergoes a cis-trans (E-Z) interconversion process that occurs when incubated in cell culture medium (Malet et al., 2002). Based on these data, a mixture of $70 \%$ Z-isomer and $30 \%$ E-isomer was used for in vitro studies. 
A
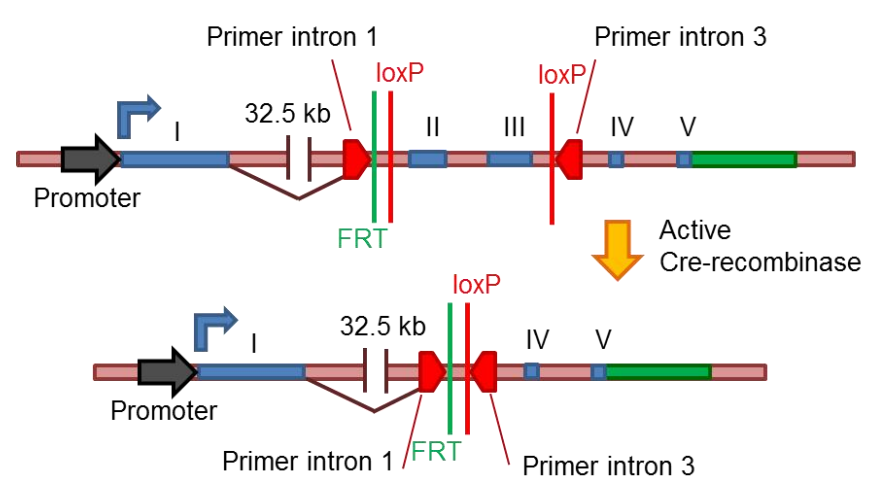

C

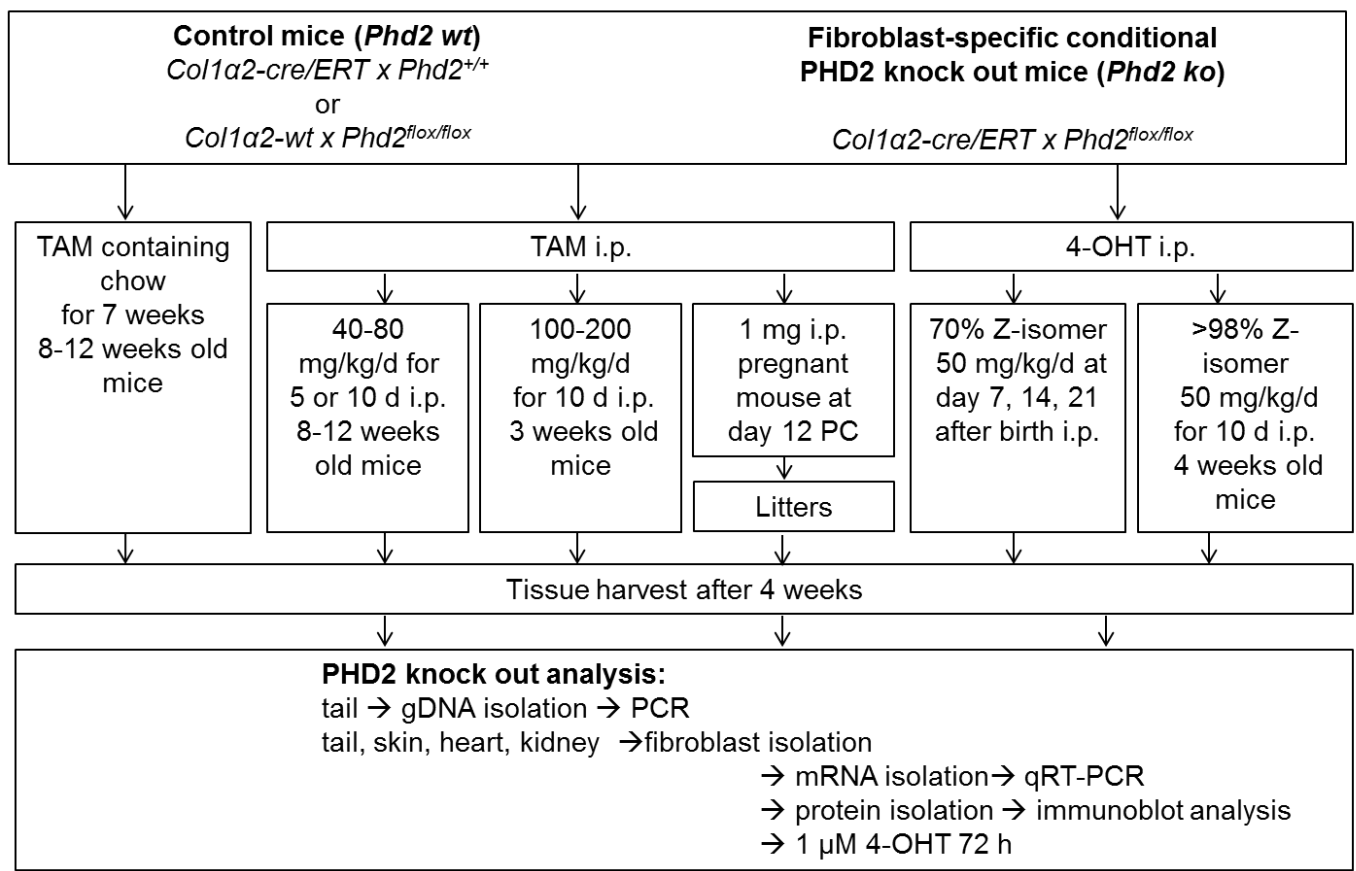

Figure 3: Generation of fibroblast-specific PHD2 knock out mice. A schematic drawing of the gene targeting strategy is shown. Exons 2 and 3 of the Phd 2 locus are flanked by two LoxP-sites. Exons 2 and 3 are deleted by the activated Cre-recombinase which could be detected by using primers that anneal before and after the LoxPflanked region. B PCRs were performed to demonstrate deletion of floxed exons in Phd 2 ko animals. C Treatment and analysis strategy for the induction of a fibroblast-specific PHD2 knock out are shown. Phd 2 ko or Phd 2 wt mice were treated with varying TAM administration protocols. In the first group animals were fed with TAM containing chow. In the second group i.p. injections of TAM were performed with increasing dosages and treatment periods. Additionally, single TAM injections i.p. were performed in pregnant mice at day $12 \mathrm{PC}$. The third group consists of animals which received either $70 \%$ Z- or $>98 \%$ Z-4-OHT. 4 weeks after the last application or birth of the offspring primary fibroblast were isolated from heart, kidney, tail and skin and analyzed for PHD2 knock efficacy on mRNA- and protein levels. Besides the in vivo applications primary cells were also treated with 4-OHT in vitro and analyzed afterwards. gDNA from tail tip specimens was analyzed by PCR. 
Tamoxifen has no effect on heart function

As TAM may induce acute cardiomyopathy (Koitabashi et al., 2009) echocardiography of animals treated with TAM i.p. or vehicle oil was performed weekly before, during and after the administration of the drug. To exclude Cre-mediated effects animals either expressing the Cre-recombinase $(P h d 2 \mathrm{ko})$ or without Cre-recombinase $(P h d 2 w t)$ were examined. Additionally, the body weight was monitored to evaluate the physical condition of the animals during injection periods. Treatment with TAM had no impact on animal body weight (Figure 4A) and no differences could be observed in FAS between the treatment groups (Figure 4B). Thus, it can be ruled out that TAM treatment leads to transient cardiomyopathy with the applied treatment protocols.

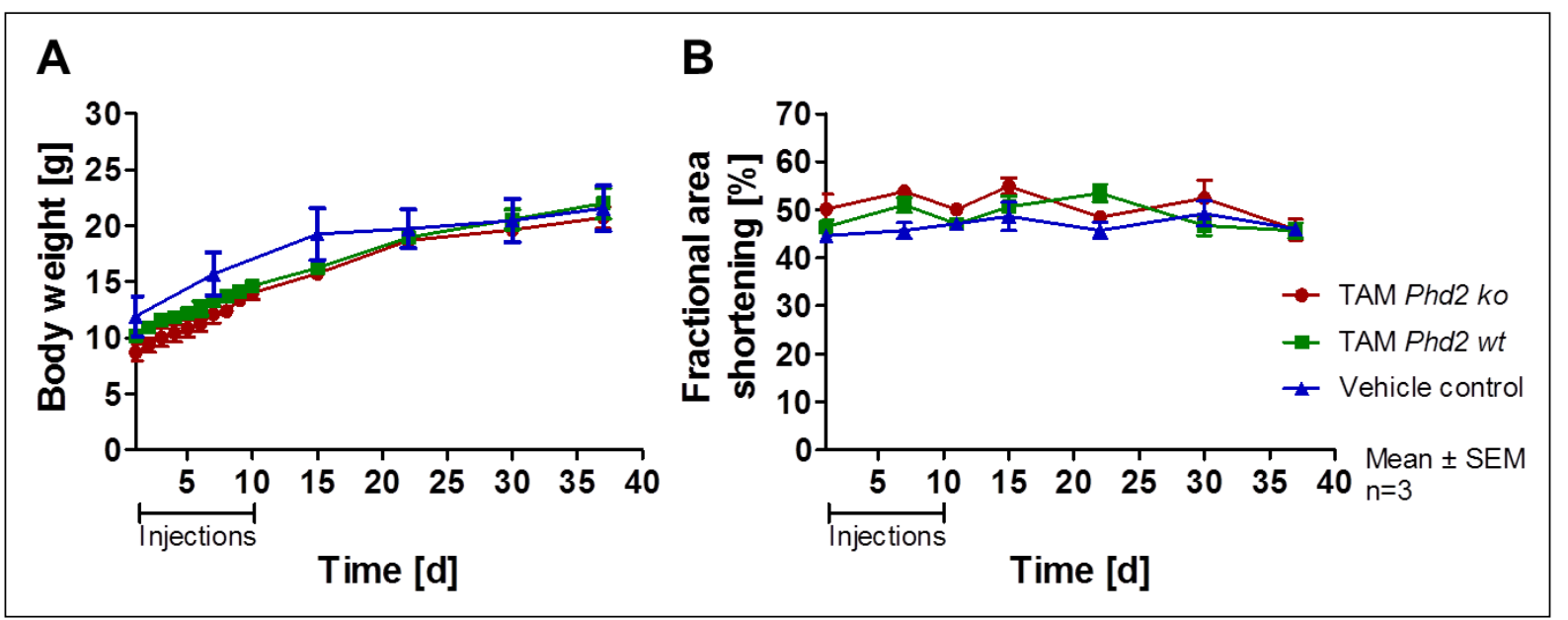

Figure 4: Tamoxifen treatment does not affect body weight and heart function. A Body weight and $B$ left ventricular fractional area shortening (FAS) of 3 weeks old mice were monitored before, during and after i.p. injections of $100 \mathrm{mg} / \mathrm{kg}$ TAM for $10 \mathrm{~d}$. Data represent mean values $\pm S E M, n=3$. No differences could be observed between TAM treated animals and the control group.

The PHD2 knock out efficacy is not sufficient in $P h d 2$ ko mice after TAM treatment

Independent of administration route, dosage, treatment period and animal age, a sufficient knock out of PHD2 in heart fibroblasts could not be achieved. This was observed on mRNA level (Figure 5A) and protein level (Figure 5B). Fibroblasts were also isolated from the kidneys, tail and skin. In neither tissue fibroblasts a significant knock out of PHD2 could be detected in normoxia or hypoxia (Figure 5). In an approach to achieve the knock out of PHD2 in the primary fibroblasts, cells were cultivated in the presence of 4-OHT. The PHD2 knock out efficacy remains unchanged by treatment of cells with 4-OHT in vitro and hypoxia (Figure 5B). 


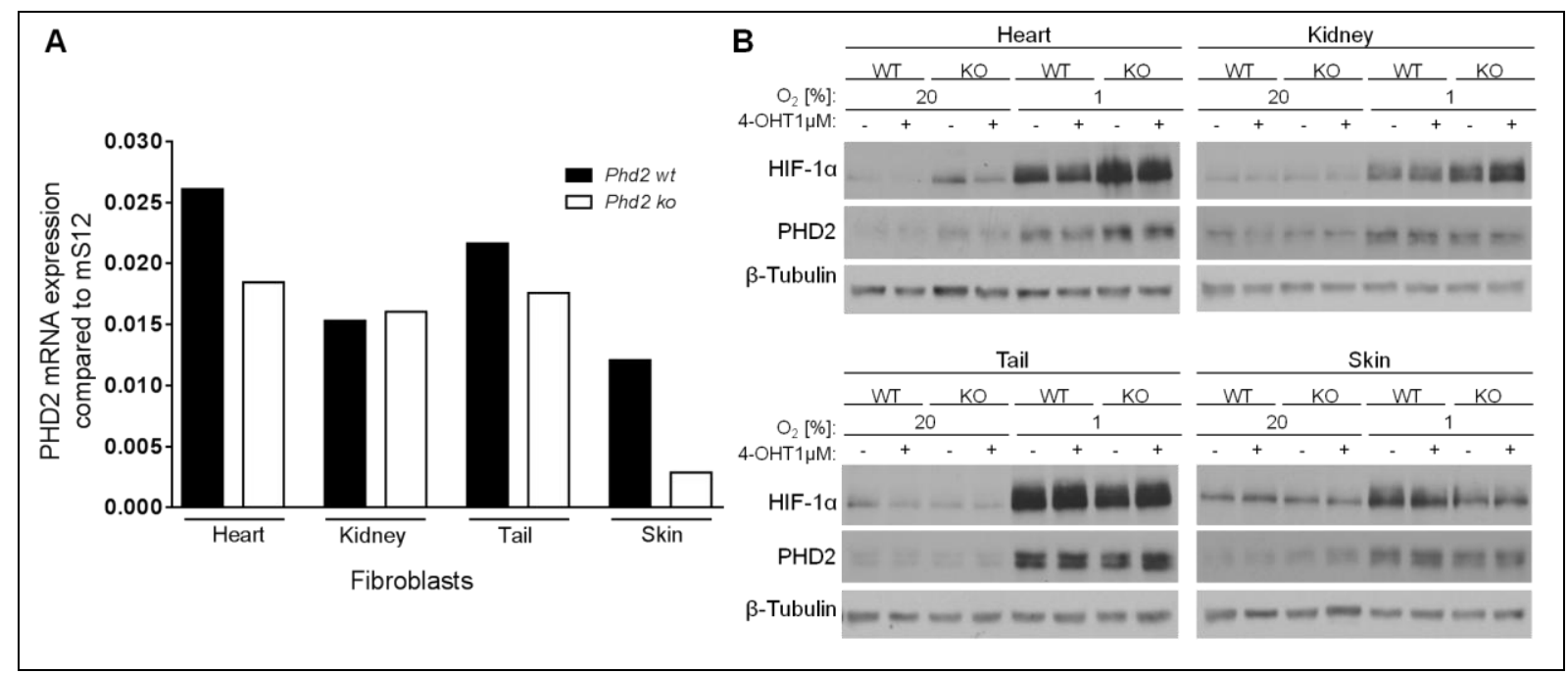

Figure 5: PHD2 knock out efficacy is not sufficient after TAM treatment. A PHD2 mRNA analysis of fibroblasts isolated from heart, kidneys, tail and skin of mice after TAM treatment. B Protein analysis of primary fibroblasts from Phd2 wt (WT) or Phd2 ko (KO) mice which received i.p. $200 \mathrm{mg} / \mathrm{kg}$ body weight TAM. Cells were cultivated under normoxic $\left(20 \% \mathrm{O}_{2}\right)$ or hypoxic $\left(1 \% \mathrm{O}_{2}\right)$ conditions and treated additionally with 4-OHT in vitro. Immunoblot analysis for HIF- $1 \alpha$ and PHD2; $\beta$-tubulin was used as loading control.

\subsubsection{Discussion}

Manipulation of the HIF pathway by interfering with PHD activity is an attractive strategy for cardiac tissue protection in myocardial ischemia (Katschinski, 2009; Hölscher et al., 2011; Vogler et al., 2015), Therefore, it is important to understand the effects not only in cardiomyocytes, but also in fibroblasts. However, the contribution of PHD2 and the HIF pathway to cardiac fibroblast function in the ischemic heart is not understood. To evaluate the role of PHD2 in cardiac fibroblasts, I focused on the generation of an inducible fibroblastspecific PHD2 knock out mouse. Mice were generated by intercrossing $\operatorname{Tg}($ Coll $\alpha 2$-cre/ERT $)$ deleter mice which express an inducible Cre-recombinase under the control of the Col1 $\alpha 2$ promoter with $P h d 2^{\text {floxflox }}$ mice. As several TAM administration protocols were described to activate the Cre-recombinase (Zheng et al., 2002; Hayashi and McMahon, 2002; Kiermayer et al., 2007; Denton et al., 2009), I evaluated their efficacy to generate a fibroblast-specific PHD2 knock out in this study. Genetic DNA recombination at the floxed PHD2 gene locus was observed with all TAM administration protocols; however hardly any PHD2 knock out was detected on mRNA and protein level.

The Col1 $\alpha 2$ promoter is mostly active during gestation with highest expression levels at E15.5 during murine embryonic development and decreases after birth (Bou-Gharios et al., 1996; Florin et al., 2004). Therefore, TAM injections were additionally performed in pregnant mice during embryonic gestation at day 12 PC. However, the supposedly higher promoter activity 
and thus higher Cre-recombinase expression could not improve the PHD2 knock out efficacy on mRNA and protein level.

TAM itself is a prodrug and metabolized mostly into its active 4-OHT form predominantly by the cytochrome P450 (CYP) enzymes including CYP2D6 (Jordan et al., 1977). 4-OHT has a higher affinity than TAM for binding to estrogen receptors and thus a greater potency to activate the Cre-recombinase (Malet et al., 1988). To address the question whether the used mice are poor metabolizer of TAM to 4-OHT due to a CYP2D6 variation (Gough et al., 1990), mice were treated with active 4-OHT. As 4-OHT exists as trans (Z) and the 100x less potent cis (E) isomer (Murphy et al., 1990), animals received predominantly the Z-isomer. However, also injection with the active 4-OHT could not improve the knock out efficacy.

Since the Col1 $\alpha 2$ promoter may become reactivated concomitant with the transdifferentiation of fibroblasts into myofibroblasts upon cultivation of isolated primary fibroblasts (Santiago et al., 2010), additional treatment of isolated fibroblasts was performed with 4-OHT in vitro. Besides this, the Col1a2 gene can be induced by $\mathrm{O}_{2}$ deprivation (Distler et al., 2007). Therefore, cells were additionally cultivated not only under normoxic $\left(20 \% \mathrm{O}_{2}\right)$, but also under hypoxic $\left(1 \% \mathrm{O}_{2}\right)$ conditions. However, hardly any improvement of the PHD2 knock out efficacy on mRNA and protein level could be detected.

Recently, Zimmermann et al., 2014 described the same inducible fibroblast-specific PHD2 knock out mouse as used in this study, but without indicating details about their TAM administration routes. The authors observed reduced PHD2 mRNA and protein levels in skin fibroblasts. However, the reduction in PHD2 mRNA and protein as described by Zimmermann et al., 2014 could not be achieved in this study with neither TAM administration protocol.

Without using cell type restricting enhancers, the Colla2 promoter is expressed in all cells of the mesenchymal origin including fibroblasts, osteoblasts and chondrocytes (Florin et al., 2004). This approach was used to investigate the function of PHD2 in skeletal development and the expression of PHD2 was successfully reduced in osteoblast lineage cells (Cheng et al., 2014). The authors do not analyze PHD2 expression levels in fibroblasts. Therefore it cannot be clarified whether these conditional PHD2 knock out mice would be suitable to analyze the function of PHD2 in cardiac fibroblasts.

Because TAM was shown to induce transient cardiomyopathy (Koitabashi et al., 2009), heart function was analyzed after TAM treatment. However even at high TAM dosages no cardiomyopathy was observed. Thus TAM might have mouse strain-specific effects. 
In summary I could observe Cre-mediated genetic recombination of the Phd2 loxP sites via all TAM administration protocols, however hardly any PHD2 knock out could be detected on mRNA and protein level. This reveals an insufficient recombination activity which may be caused by an incomplete activation of the Cre-recombinase by TAM and 4-OHT or a low expression level of the Cre-recombinase.

Thus, in future experiments a constitutive active fibroblast-restricted Cre-recombinase could be useful, however available mouse models which express the Cre-recombinase under the Col1a2 promoter (Cheng et al., 2014) as well as the FSP1 (fibroblast specific protein-1; S100A4) promoter (Bhowmick, et al., 2004) lack cardiac fibroblast-restricted expression patterns (Florin et al., 2004; Kong et al., 2013). Nonetheless, these mice could be of benefit for the analyses of fibroblastic properties after PHD2 knock out in the healthy and diseased heart. 


\section{Discussion}

HIF is the transcriptional master regulator of the response of cells to oxygen deprivation. Up to now more than $200 \mathrm{HIF}$ target genes are known that are involved in the cellular adaption to hypoxia (Semenza, 2002). PHDs play an important role in regulating the stability of HIF $\alpha$. By inhibiting the PHDs the activation of the HIF signaling cascade can be achieved in normoxia. HIF signaling has been discussed to be an attractive strategy to protect ischemic tissue (Kastschinski, 2009) and HIF mediated protection has been shown in many tissues and organs including brain, kidney, lung, skeletal muscle, and the heart (Bernhardt et al., 2007).

\subsection{PHD inhibition as a therapeutic approach in ischemic heart disease}

Ischemic heart disease occurs when oxygen delivery is impaired and is not sufficient for the metabolic needs of the heart. This is e.g. the case in patients with a blockage of a coronary artery or in individuals with acute MI.

In the 1990s it was shown that hypoxia prior to MI reduces the infarct size (Shizukuda et al., 1992, 1993). This finding could be linked to HIF-1 $\alpha$ as hearts from heterozygous HIF-1 $\alpha$ knock out mice, that were subjected to hypoxic preconditioning, were not protected against ischemia-reperfusion injury (Cai et al., 2003, 2008). In agreement with this, several genetic mouse models support the protective role of HIF in the heart (Kido et al., 2005, Hyvärinen et

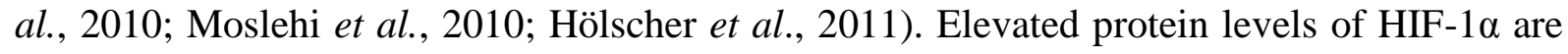
also found in the hearts of patients suffering from cardiomyopathy (Krishnan et al., 2009; Hölscher et al., 2012).

As small molecular inhibitors of the PHDs can activate the HIF pathway in vitro and in vivo the effect of the pharmaceutical HIF $\alpha$ stabilization for ischemic cardioprotection has been much discussed and analyzed (Xi et al., 2004; Dendorfer et al., 2005; Eckle et al., 2008; Bao et al., 2010; Ong et al., 2014). The results of these studies underline the potential of small molecular inhibitors for cardioprotection but also revealed problems for clinical application. In the initial studies cobalt chloride and the iron chelator DFO were used to inhibit PHD activity (Xi et al., 2004; Dendorfer et al., 2005; Philipp et al., 2006). Also the effect of DMOG, a 2OG analogue, was exploited (Eckle et al., 2008; Zhao et al., 2010). Even though a cardioprotective outcome was shown for all of these substances, it is important to note that the substances are not PHD-specific and inhibit other Fe(II) containing enzymes and the enzyme family of 2OG-dependent-dioxygenases (which includes the PHDs), respectively. With FG 2216 and GSK360A more selective PHD inhibitors were developed and were shown to 
improve cardiac function after myocardial infarction and ischemia reperfusion injury (Philipp et al., 2006; Bao et al., 2010; Ong et al., 2014). Besides selectivity of the PHD inhibitors another important parameter to be considered is the duration of treatment. The long-term treatment with GSK360A results in an increased hematocrit due to the induction of the HIF target gene EPO in the kidney and the liver (Bao et al., 2010). An increased hematocrit and subsequently higher blood viscosity leads to an increased afterload that could further harm infarcted and peri-infarcted cardiac tissue. Also studies using genetically modified mouse models indicate that a tight titration of HIF-1 $\alpha$ levels is essential for preventing polycythemia and the preservation of cardiac function (Minamishima et al., 2008; Takeda et al., 2008; Minamishima et al., 2009; Bekeredjian et al., 2010; Hölscher et al., 2012). Indeed, the cardiac-specific dysregulation of HIF-1 $\alpha$ levels is sufficient to induce dilated cardiomyopathy. Cardiomyocyte specific PHD2/3 double knock out mice show a very robust HIF-1 $\alpha$ stabilization and develop a dilated cardiomyopathy already at young age (Minamishima et al., 2009). In a cardiomyocyte-specific HIF-1 $\alpha$ transgenic mouse model the development of cardiomyopathy was observed with progressing age of the mice (Hölscher et al., 2012).

Thus, the data available to date show that manipulating the HIF system is principally well suited as a therapeutic approach to treat cardiac ischemia, however some risks occur. Especially long-term, excessive HIF activity is detrimental for cardiac function. Therefore it is important to induce a transient stabilization of HIF $\alpha$ to prompt the beneficial effects of the system whilst avoiding the risks. In this thesis the transient stabilization of HIF-1 $\alpha$ and HIF$2 \alpha$ could be achieved using the selective PHD inhibitor ICA (Vogler et al., 2015, Figure 2). Two injections of ICA were shown to be sufficient to protect the heart in acute myocardial infarction. Although ICA was shown to induce the expression of EPO in a model of renal ischemia (Wang et al., 2012), it is important to note that the short term PHD inhibition that is described in this thesis did not affect the hematocrit (Vogler et al., 2015, Figure 4a-d).

The cardioprotective effect of HIF has mostly been shown with interventions that precede ischemia (Abraham et al. (eds.), 2012). Post-conditional treatment however is a more practical approach for the therapeutic use in case of myocardial infarction or other ischemic diseases. In this thesis it could be shown that post-ischemic PHD inhibition with ICA exerts protective effects in acute myocardial infarction (Vogler et al., 2015, Figure 5d,e), indicating that there is a therapeutic time window to treat ischemic diseases.

The mechanism of HIF-mediated tissue protection in ischemia is not understood so far and is, considering the diverse HIF target genes, presumably diverse. Changes in the cell metabolism and vasodilation might be involved in fast, protective responses; angiogenesis and vascular 
remodeling could add to long term adaptive effects. Furthermore, the protective effect of HIF $\alpha$ stabilization cannot be linked to a specific cell. Many studies using genetically engineered mouse models show that PHD inhibition and HIF $\alpha$ stabilization in cardiomyocytes is beneficial in ischemic heart disease (Kido et al., 2005; Hyvärinen et al., 2010; Moslehi et al., 2010; Hölscher et al., 2011), however one study also describes the protective effect of PHD2 inhibition in cardiac endothelial cells (Kerkela et al., 2013).

Cardiac tissue undergoes complex remodeling processes after myocardial infarction. These processes involve disruption of supporting structures, myocyte hypertrophy, inflammation, and collagen deposition both at the site of infarction and at areas remote from the infarct (Sutton and Sharpe, 2000). Cardiac fibroblasts are integral to the repair process. Hence, it is important to learn about the function of cardiac fibroblasts in hypoxia and after PHD inhibition and to gain knowledge about a putative influence of the HIF pathway on the cardiac remodeling process. Therefore, an inducible, fibroblast-specific PHD2 knock out mouse model would be useful to study fibroblastic properties especially in the diseased heart. However, a fibroblast-specific, TAM-inducible PHD2 knock out mouse could not be established in the present thesis. This might be due to the fact that the Cre-recombinase is, in order to achieve expression in fibroblasts, expressed under the control of the Col1a2 promoter, which is most active just in early development. At later stages of development the promoter activity might not be sufficient to induce Cre-mediated recombination of the PHD2 locus after TAM treatment.

\subsection{The role of hypoxia and HIF-1 $\alpha$ in fibroblastic properties and actin dynamics}

As outlined above, in cardiovascular diseases (e.g. MI) fibroblasts play a central role in the myocardial remodeling process, which includes hypertrophy of cardiomyocytes (through paracrine interactions of fibroblasts and cardiomyocytes), migration and proliferation of fibroblasts and changes in the extent and composition of the cardiac extracellular matrix (Ieda et al., 2009; Sun et al., 2000; Turner et al., 2003). However, little is known about the morphological and functional consequences of hypoxia on fibroblasts. In this thesis it was observed that L929 fibroblasts respond to oxygen deprivation with morphological modifications, including an increase in cell area and volume. Furthermore cell adhesion, cell spreading and motility were altered in hypoxia. This went along with profound changes of the actin cytoskeleton. In hypoxia F-actin containing stress-fibers were much more prominent than under normoxic conditions. This prominent effect was linked to the stabilization of HIF- 
$1 \alpha$, as HIF-1 $\alpha$ knock down cells do not show increased F-actin formation in hypoxia. The remodeling of actin filaments in hypoxia with stress fiber formation has been observed in several cell types and might be a general phenomenon (Zieseniss, 2013). Enhanced actin polymerization and an increased assembly of F-actin rich parallel stress fibers were e.g. also shown in a human breast cancer cell line (MDA-MB-231) and were linked to HIF-1 $\alpha$ induced RhoA expression (Gilkes et al., 2014). RhoA is a member of the Rho family of GTPases (Hall, 2012), which control actin dynamics by activating downstream signaling molecules. One downstream target of RhoA signaling is the ROCK/LIM-domain kinase/cofilin pathway (Olson and Nordheim, 2010). The actin-binding and severing protein cofilin is inactivated after phosphorylation by LIM kinase which causes F-actin polymerization. In line with the observation of Gilkes et al., 2014 that RhoA activity is increased in hypoxia in a HIFdependent manner, it was shown in this thesis that downstream of RhoA cofilin phosphorylation in hypoxia is HIF-1 $\alpha$ dependent (Vogler et al., 2013, Figure 8). Furthermore in both studies a hypoxic increase of vinculin-containing focal adhesions is reported. In MDA-MB-231 cells focal adhesion formation is associated with increased cell motility in hypoxia (Gilkes et al., 2014). In L929 fibrosarcoma cells hypoxic cell spreading increases, however, cell velocity decreases in hypoxia (Vogler et al., 2013, Figure 2). As cytoskeletal dynamics are highly cell type dependent, it is not astonishing that despite the primarily similar observations of more stress fibers and focal adhesions in MDA-MB-231 and L929 cells, the migratory phenotype is different.

Recapitulating, the findings in this thesis add to the emerging evidence that cytoskeletal properties are changed in hypoxia in several cell types and that the RhoGTPases play an important role in the hypoxic regulation of the actin cytoskeleton. This regulation might partially be HIF-dependent even though the mechanisms are not understood in detail so far. It is feasible to speculate that the actin arrangement of cardiac fibroblasts is also affected by an ischemic (hypoxic) cardiac environment. 


\section{Summary and Outlook}

In this thesis the PHD enzyme inhibitor ICA was used to evaluate the effect of a pharmaceutical PHD inhibition in acute myocardial infarction. It could be shown that ICA exerts acute cardiac protective effects in myocardial ischemia resulting in a significantly reduced total infarct size. A treatment with the inhibitor done just twice was sufficient to induce a strong and rapid stabilization of HIF- $1 \alpha$ and HIF- $2 \alpha$ and their target genes. Notably, no increase in hematocrit was observed after two doses of ICA. Elevated hematocrit enhances the workload of the heart which is unfavorable in ischemic heart disease. Importantly, the cardio-protective effect of HIF pathway activation was not only observed in pre-conditional treatment but also after post-conditional application of ICA. This indicates that there is a therapeutic time window for the treatment with PHD inhibitors.

When considering PHD inhibitors and the activation of the HIF pathway as a therapeutic approach to treat e.g. ischemic heart diseases, fibroblasts should be taken into account as they are pivotal for the myocardial remodeling. To understand the role of PHD2 and the effects of $\mathrm{HIF} \alpha$ stabilization on fibroblastic properties, the generation of a fibroblast-specific PHD2 knock out mouse, which expresses a TAM-inducible Cre-recombinase under the control of the fibroblast-specific, enhanced Col1 $\alpha 2$ promoter, was attempted. Unfortunately, even though a Cre-mediated genetic DNA recombination of the Phd2 loxP sites was observed, hardly any PHD2 knock out was seen on mRNA and protein level. This could be due to an incomplete activation or inadequate expression level of the Cre-recombinase resulting in an insufficient recombination activity. An alternative approach to tackle the important question of the role of PHD inhibition and HIF $\alpha$ stabilization in fibroblasts in the setting of myocardial infarction could be the periostin (Postn)-Cre mouse model. In this transgenic mouse line the Crerecombinase is driven by a Postn promoter which is restricted to the non-myocyte lineage in the neonatal heart. The promoter is turned on after cardiac stress or disease onset. Using this mouse model it might be possible to generate a cardiac fibroblast-specific PHD2 knock out after myocardial infarction.

In vitro data generated in this thesis further underscore the importance to analyze fibroblastic properties in hypoxia/ischemia. Using the L929 fibroblast cell line it could be shown that hypoxia greatly changes cell morphology and function including the reorganization of the actin cytoskeleton. The precise mechanism how actin dynamics are controlled in hypoxia is not known, however, evidence is compiling that RhoGTPase signaling is modulated in hypoxia. Evidence from this thesis suggests that changes in RhoGTPase activity in hypoxia 
are partially HIF-dependent. In the future it will be interesting to analyze if and how RhoGEFs and RhoGAPs are involved in hypoxic cytoskeletal dynamics.

Overall this thesis helps to identify a pharmaceutical window in which the beneficial effects of the HIF response override potentially harmful side effects. Furthermore, I show that hypoxia has a profound impact on the regulation of the actin cytoskeleton of fibroblasts in vitro. Thus it is tempting to speculate that PHD inhibitors will also have an impact on cytoskeletal dynamics. Particularly with regard to the crucial role of fibroblasts in myocardial remodeling it is important to further understand the consequences of PHD inhibition on the signaling to the cytoskeleton. 


\section{Bibliography}

Abraham, D., et al. (Eds.) "Translational Vascular Medicine. Pathogenesis, Diagnosis, and Treatment." XIV. London: Springer, 2012: 17-25.

Anversa, P., et al. "Myocyte cell loss and myocyte hypertrophy in the aging rat heart." J.Am.Coll.Cardiol. 8.6 (1986): 1441-48.

Appelhoff, R. J., et al. "Differential function of the prolyl hydroxylases PHD1, PHD2, and PHD3 in the regulation of hypoxia-inducible factor." J.Biol.Chem. 279.37 (2004): 38458-65.

Aragonés, J., et al. "Deficiency or inhibition of oxygen sensor Phd1 induces hypoxia tolerance by reprogramming basal metabolism." Nat.Genet. 40.2 (2008): 170-80.

Augstein, A., et al. "Cell-specific and hypoxia-dependent regulation of human HIF-3 $\alpha$ : inhibition of the expression of HIF target genes in vascular cells." Cell Mol.Life Sci. 68.15 (2011): 2627-42.

Banerji, B., et al. "The inhibition of factor inhibiting hypoxia-inducible factor (FIH) by $\beta$ oxocarboxylic acids." Chem.Commun.(Camb.).43 (2005): 5438-40.

Bao, W., et al. "Chronic inhibition of hypoxia-inducible factor prolyl 4-hydroxylase improves ventricular performance, remodeling, and vascularity after myocardial infarction in the rat." J.Cardiovasc.Pharmacol. 56.2 (2010): 147-55.

Baranova, O., et al. "Neuron-specific inactivation of the hypoxia inducible factor $1 \alpha$ increases brain injury in a mouse model of transient focal cerebral ischemia." J.Neurosci. 27.23 (2007): 6320-32.

Beck, I., R. Weinmann, and J. Caro. "Characterization of hypoxia-responsive enhancer in the human erythropoietin gene shows presence of hypoxia-inducible 120-Kd nuclear DNA-binding protein in erythropoietin-producing and nonproducing cells." Blood 82.3 (1993): 704-11.

Bekeredjian, R., et al. "Conditional HIF-1 $\alpha$ expression produces a reversible cardiomyopathy." PLoS.One. 5.7 (2010): e11693.

Bernhardt, W. M., et al. "Organ protection by hypoxia and hypoxia-inducible factors." Methods Enzymol. 435 (2007): 221-45.

Berra, E., et al. "Hypoxia-inducible factor- $1 \alpha$ (HIF-1 $\alpha$ ) escapes $\mathrm{O}_{2}$-driven proteasomal degradation irrespective of its subcellular localization: nucleus or cytoplasm." EMBO Rep. 2.7 (2001): 615-20.

Berra, E., et al. "HIF prolyl-hydroxylase 2 is the key oxygen sensor setting low steady-state levels of HIF-1 $\alpha$ in normoxia." EMBO J. 22.16 (2003): 4082-90.

Bhowmick, N. A., et al. "TGF- $\beta$ signaling in fibroblasts modulates the oncogenic potential of adjacent epithelia." Science 303.5659 (2004): 848-51. 
Bishop, T., et al. "Abnormal sympathoadrenal development and systemic hypotension in PHD3 $^{-/-}$mice." Mol.Cell Biol. 28.10 (2008): 3386-400.

Bohl, S., et al. "Refined approach for quantification of in vivo ischemia-reperfusion injury in the mouse heart." Am.J.Physiol Heart Circ.Physiol 297.6 (2009): H2054-H2058.

Bou-Gharios, G., et al. "A potent far-upstream enhancer in the mouse proa2(I) collagen gene regulates expression of reporter genes in transgenic mice." J.Cell Biol. 134.5 (1996): 1333-44.

Braunwald, E. and R. A. Kloner. "Myocardial reperfusion: a double-edged sword?" J.Clin.Invest 76.5 (1985): 1713-19.

Burridge, K. "Are stress fibres contractile?" Nature 294.5843 (1981): 691-92.

Cai, Z., et al. "Hearts from rodents exposed to intermittent hypoxia or erythropoietin are protected against ischemia-reperfusion injury." Circulation 108.1 (2003): 79-85.

Cai, Z., et al. "Complete loss of ischaemic preconditioning-induced cardioprotection in mice with partial deficiency of HIF-1 $\alpha$." Cardiovasc.Res. 77.3 (2008): 463-70.

Camelliti, P., T. K. Borg, and P. Kohl. "Structural and functional characterisation of cardiac fibroblasts." Cardiovasc.Res. 65.1 (2005): 40-51.

Chachami, G., et al. "Transport of hypoxia-inducible factor HIF-1 $\alpha$ into the nucleus involves importins 4 and 7." Biochem.Biophys.Res.Commun. 390.2 (2009): 235-40.

Chavez, J. C., et al. "The transcriptional activator hypoxia inducible factor 2 (HIF-2/EPAS-1) regulates the oxygen-dependent expression of erythropoietin in cortical astrocytes." J.Neurosci. 26.37 (2006): 9471-81.

Chen, E. Y., M. Fujinaga, and A. J. Giaccia. "Hypoxic microenvironment within an embryo induces apoptosis and is essential for proper morphological development." Teratology 60.4 (1999): 215-25.

Cheng, S., et al. "Conditional disruption of the prolyl hydroxylase domain-containing protein 2 (Phd2) gene defines its key role in skeletal development." J.Bone Miner.Res. 29.10 (2014): 2276-86.

Chowdhury, R., et al. "Selective small molecule probes for the hypoxia inducible factor (HIF) prolyl hydroxylases." ACS Chem.Biol. 8.7 (2013): 1488-96.

Cleutjens, J. P., et al. "Collagen remodeling after myocardial infarction in the rat heart." Am.J.Pathol. 147.2 (1995): 325-38.

Dawe, H. R., et al. "ADF/cofilin controls cell polarity during fibroblast migration." Curr.Biol. 13.3 (2003): 252-57.

Dendorfer, A., et al. "Deferoxamine induces prolonged cardiac preconditioning via accumulation of oxygen radicals." Free Radic.Biol.Med. 38.1 (2005): 117-24. 
Denton, C. P., et al. "Inducible lineage-specific deletion of T $\beta$ RII in fibroblasts defines a pivotal regulatory role during adult skin wound healing." J.Invest Dermatol. 129.1 (2009): 194-204.

Distler, J. H., et al. "Hypoxia-induced increase in the production of extracellular matrix proteins in systemic sclerosis." Arthritis Rheum. 56.12 (2007): 4203-15.

Eckle, T., et al. "Hypoxia-inducible factor-1 is central to cardioprotection: a new paradigm for ischemic preconditioning." Circulation 118.2 (2008): 166-75.

Ema, M., et al. "A novel bHLH-PAS factor with close sequence similarity to hypoxiainducible factor $1 \alpha$ regulates the VEGF expression and is potentially involved in lung and vascular development." Proc.Natl.Acad.Sci.U.S.A 94.9 (1997): 4273-78.

Epstein, A. C., et al. "C. elegans EGL-9 and mammalian homologs define a family of dioxygenases that regulate HIF by prolyl hydroxylation." Cell 107.1 (2001): 43-54.

Ferrara, N. and H. P. Gerber. "The role of vascular endothelial growth factor in angiogenesis." Acta Haematol. 106.4 (2001): 148-56.

Florin, L., et al. "Cre recombinase-mediated gene targeting of mesenchymal cells." Genesis. 38.3 (2004): 139-44.

Gabbiani, G. "The myofibroblast in wound healing and fibrocontractive diseases." J.Pathol. 200.4 (2003): 500-03.

Gilkes, D. M., et al. "Hypoxia-inducible factors mediate coordinated RhoA-ROCK1 expression and signaling in breast cancer cells." Proc.Natl.Acad.Sci.U.S.A 111.3 (2014): E384-E393.

Gösswald, A., et al. "Prevalence of myocardial infarction and coronary heart disease in adults aged 40-79 years in Germany: results of the German Health Interview and Examination Survey for Adults Bundesgesundheitsblatt.Gesundheitsforschung.Gesundheitsschutz. $\quad 56.5-6 \quad$ (2013): $650-55$.

Gough, A. C., et al. "Identification of the primary gene defect at the cytochrome P450 CYP2D locus." Nature 347.6295 (1990): 773-76.

Gradin, K., et al. "Functional interference between hypoxia and dioxin signal transduction pathways: competition for recruitment of the Arnt transcription factor." Mol.Cell Biol. 16.10 (1996): 5221-31.

Gradin, K., et al. "The transcriptional activation function of the HIF-like factor requires phosphorylation at a conserved threonine." J.Biol.Chem. 277.26 (2002): 23508-14.

$\mathrm{Gu}, \mathrm{Y}$. Z., et al. "Molecular characterization and chromosomal localization of a third $\alpha$-class hypoxia inducible factor subunit, HIF3 $\alpha . "$ Gene Expr. 7.3 (1998): 205-13.

Hackett, P. H. and R. C. Roach. "High-altitude illness." N.Engl.J.Med. 345.2 (2001): 107-14.

Hall, A. "Rho GTPases and the actin cytoskeleton." Science 279.5350 (1998): 509-14. 
Hall, A. "Rho family GTPases." Biochem.Soc.Trans. 40.6 (2012): 1378-82.

Hara, S., et al. "Expression and characterization of hypoxia-inducible factor (HIF)-3 $\alpha$ in human kidney: suppression of HIF-mediated gene expression by HIF-3 $\alpha$." Biochem.Biophys.Res.Commun. 287.4 (2001): 808-13.

Hayashi, S. and A. P. McMahon. "Efficient recombination in diverse tissues by a tamoxifeninducible form of Cre: a tool for temporally regulated gene activation/inactivation in the mouse." Dev.Biol. 244.2 (2002): 305-18.

Heasman, S. J. and A. J. Ridley. "Mammalian Rho GTPases: new insights into their functions from in vivo studies." Nat.Rev.Mol.Cell Biol. 9.9 (2008): 690-701.

Herman, I. M. "Actin isoforms." Curr.Opin.Cell Biol. 5.1 (1993): 48-55.

Hirsilä, M., et al. "Characterization of the human prolyl 4-hydroxylases that modify the hypoxia-inducible factor." J.Biol.Chem. 278.33 (2003): 30772-80.

Hölscher, M., et al. "Cardiomyocyte-specific prolyl-4-hydroxylase domain 2 knock out protects from acute myocardial ischemic injury." J.Biol.Chem. 286.13 (2011): 1118594.

Hölscher, M., et al. "Unfavourable consequences of chronic cardiac HIF-1 $\alpha$ stabilization." Cardiovasc.Res. 94.1 (2012): 77-86.

Horwitz, A. R. and J. T. Parsons. "Cell migration--movin' on." Science 286.5442 (1999): 1102-03.

Hsieh, M. M., et al. "HIF prolyl hydroxylase inhibition results in endogenous erythropoietin induction, erythrocytosis, and modest fetal hemoglobin expression in rhesus macaques." Blood 110.6 (2007): 2140-47.

Huang, J., et al. "Sequence determinants in hypoxia-inducible factor-1 $\alpha$ for hydroxylation by the prolyl hydroxylases PHD1, PHD2, and PHD3." J.Biol.Chem. 277.42 (2002): 39792-800.

Huang, M., et al. "Short hairpin RNA interference therapy for ischemic heart disease." Circulation 118.14 Suppl (2008): S226-S233.

Hyvärinen, J., et al. "Hearts of hypoxia-inducible factor prolyl 4-hydroxylase-2 hypomorphic mice show protection against acute ischemia-reperfusion injury." J.Biol.Chem. 285.18 (2010): 13646-57.

Ieda, M., et al. "Cardiac fibroblasts regulate myocardial proliferation through $\beta 1$ integrin signaling." Dev.Cell 16.2 (2009): 233-44.

Ivan, M., et al. "HIF $\alpha$ targeted for VHL-mediated destruction by proline hydroxylation: implications for $\mathrm{O}_{2}$ sensing." Science 292.5516 (2001): 464-68.

Ivan, M., et al. "Biochemical purification and pharmacological inhibition of a mammalian prolyl hydroxylase acting on hypoxia-inducible factor." Proc.Natl.Acad.Sci.U.S.A 99.21 (2002): 13459-64. 
Iyer, N. V., et al. "Cellular and developmental control of $\mathrm{O}_{2}$ homeostasis by hypoxiainducible factor 1 $\alpha . "$ Genes Dev. 12.2 (1998): 149-62.

Jaakkola, P., et al. "Targeting of HIF- $\alpha$ to the von Hippel-Lindau ubiquitylation complex by $\mathrm{O}_{2}$-regulated prolyl hydroxylation." Science 292.5516 (2001): 468-72.

Jaffe, A. B. and A. Hall. "Rho GTPases: biochemistry and biology." Annu.Rev.Cell Dev.Biol. 21 (2005): 247-69.

Jiang, B. H., et al. "Dimerization, DNA binding, and transactivation properties of hypoxiainducible factor 1." J.Biol.Chem. 271.30 (1996): 17771-78.

Jordan, V. C., et al. "A monohydroxylated metabolite of tamoxifen with potent antioestrogenic activity." J.Endocrinol. 75.2 (1977): 305-16.

Jürgensen, J. S., et al. "Persistent induction of HIF-1 $\alpha$ and $-2 \alpha$ in cardiomyocytes and stromal cells of ischemic myocardium." FASEB J. 18.12 (2004): 1415-17.

Kallio, P. J., et al. "Signal transduction in hypoxic cells: inducible nuclear translocation and recruitment of the $\mathrm{CBP} / \mathrm{p} 300$ coactivator by the hypoxia-inducible factor- $1 \alpha . "$ EMBO J. 17.22 (1998): 6573-86.

Katschinski, D. M., et al. "Heat induction of the unphosphorylated form of hypoxia-inducible factor- $1 \alpha$ is dependent on heat shock protein-90 activity." J.Biol.Chem. 277.11 (2002): 9262-67.

Katschinski, D. M. "In vivo functions of the prolyl-4-hydroxylase domain oxygen sensors: direct route to the treatment of anaemia and the protection of ischaemic tissues." Acta Physiol (Oxf) 195.4 (2009): 407-14.

Kerkela, R., et al. "Activation of hypoxia response in endothelial cells contributes to ischemic cardioprotection." Mol.Cell Biol. 33.16 (2013): 3321-29.

Kido, M., et al. "Hypoxia-inducible factor 1-alpha reduces infarction and attenuates progression of cardiac dysfunction after myocardial infarction in the mouse." J.Am.Coll.Cardiol. 46.11 (2005): 2116-24.

Kiermayer, C., et al. "Optimization of spatiotemporal gene inactivation in mouse heart by oral application of tamoxifen citrate." Genesis. 45.1 (2007): 11-16.

Kohl, P., et al. "Electrical coupling of fibroblasts and myocytes: relevance for cardiac propagation." J.Electrocardiol. 38.4 Suppl (2005): 45-50.

Koitabashi, N., et al. "Avoidance of transient cardiomyopathy in cardiomyocyte-targeted tamoxifen-induced MerCreMer gene deletion models." Circ.Res. 105.1 (2009): 12-15.

Kong, P., et al. "Lack of specificity of fibroblast-specific protein 1 in cardiac remodeling and fibrosis." Am.J.Physiol Heart Circ.Physiol 305.9 (2013): H1363-H1372.

Krishnan, J., et al. "Activation of a HIF1 $\alpha$-PPAR $\gamma$ axis underlies the integration of glycolytic and lipid anabolic pathways in pathologic cardiac hypertrophy." Cell Metab 9.6 (2009): 512-24. 
Kuzuya, T., et al. "Delayed effects of sublethal ischemia on the acquisition of tolerance to ischemia." Circ.Res. 72.6 (1993): 1293-99.

Lando, D., et al. "Asparagine hydroxylation of the HIF transactivation domain: a hypoxic switch." Science 295.5556 (2002): 858-61.

Lee, P. J., et al. "Hypoxia-inducible factor-1 mediates transcriptional activation of the heme oxygenase-1 gene in response to hypoxia." J.Biol.Chem. 272.9 (1997): 5375-81.

Lee, S. H., et al. "Early expression of angiogenesis factors in acute myocardial ischemia and infarction." N.Engl.J.Med. 342.9 (2000): 626-33.

Li, Q. F., et al. "Hypoxia upregulates hypoxia inducible factor (HIF)-3 $\alpha$ expression in lung epithelial cells: characterization and comparison with HIF-1 $\alpha . "$ Cell Res. 16.6 (2006): 548-58.

Lieb, M. E., et al. "Mammalian EGLN genes have distinct patterns of mRNA expression and regulation." Biochem.Cell Biol. 80.4 (2002): 421-26.

Liu, G. S., et al. "Protection against infarction afforded by preconditioning is mediated by $\mathrm{A}_{1}$ adenosine receptors in rabbit heart." Circulation 84.1 (1991): 350-56.

Liu, Y., et al. "Hypoxia regulates vascular endothelial growth factor gene expression in endothelial cells. Identification of a 5' enhancer." Circ.Res. 77.3 (1995): 638-43.

Luo, J. C. and M. Shibuya. "A variant of nuclear localization signal of bipartite-type is required for the nuclear translocation of hypoxia inducible factors $(1 \alpha, 2 \alpha$ and $3 \alpha)$." Oncogene 20.12 (2001): 1435-44.

Makino, Y., et al. "Inhibitory PAS domain protein is a negative regulator of hypoxiainducible gene expression." Nature 414.6863 (2001): 550-54.

Makino, Y., et al. "Inhibitory PAS domain protein (IPAS) is a hypoxia-inducible splicing variant of the hypoxia-inducible factor-3 $\alpha$ locus." J.Biol.Chem. 277.36 (2002): 3240508 .

Malet, C., et al. "Tamoxifen and hydroxytamoxifen isomers versus estradiol effects on normal human breast cells in culture." Cancer Res. 48.24 Pt 1 (1988): 7193-99.

Malet, C., et al. "Effect of 4-hydroxytamoxifen isomers on growth and ultrastructural aspects of normal human breast epithelial (HBE) cells in culture." J.Steroid Biochem.Mol.Biol. 82.4-5 (2002): 289-96.

Marber, M. S., et al. "Cardiac stress protein elevation 24 hours after brief ischemia or heat stress is associated with resistance to myocardial infarction." Circulation 88.3 (1993): 1264-72.

Mathers, C. D. and D. Loncar. "Projections of global mortality and burden of disease from 2002 to 2030." PLoS.Med. 3.11 (2006): e442.

Maxwell, P. H., et al. "The tumour suppressor protein VHL targets hypoxia-inducible factors for oxygen-dependent proteolysis." Nature 399.6733 (1999): 271-75. 
Melillo, G., et al. "Functional requirement of the hypoxia-responsive element in the activation of the inducible nitric oxide synthase promoter by the iron chelator desferrioxamine." J.Biol.Chem. 272.18 (1997): 12236-43.

Metzen, E., et al. "Intracellular localisation of human HIF-1 $\alpha$ hydroxylases: implications for oxygen sensing." J.Cell Sci. 116.Pt 7 (2003): 1319-26.

Michael, L. H., et al. "Myocardial ischemia and reperfusion: a murine model." Am.J.Physiol 269.6 Pt 2 (1995): H2147-H2154.

Minamishima, Y. A., et al. "Somatic inactivation of the PHD2 prolyl hydroxylase causes polycythemia and congestive heart failure." Blood 111.6 (2008): 3236-44.

Minamishima, Y. A., et al. "A feedback loop involving the Phd3 prolyl hydroxylase tunes the mammalian hypoxic response in vivo." Mol.Cell Biol. 29.21 (2009): 5729-41.

Minchenko, A., et al. "Hypoxia-inducible factor-1-mediated expression of the 6phosphofructo-2-kinase/fructose-2,6-bisphosphatase-3 (PFKFB3) gene. Its possible role in the Warburg effect." J.Biol.Chem. 277.8 (2002): 6183-87.

Minet, E., et al. "Hypoxia-induced activation of HIF-1: role of HIF-1 $\alpha$-Hsp90 interaction." FEBS Lett. 460.2 (1999): 251-56.

Moslehi, J., et al. "Loss of hypoxia-inducible factor prolyl hydroxylase activity in cardiomyocytes phenocopies ischemic cardiomyopathy." Circulation 122.10 (2010): 1004-16.

Murphy, C. S., et al. "Structure-function relationships of hydroxylated metabolites of tamoxifen that control the proliferation of estrogen-responsive T47D breast cancer cells in vitro." Mol.Pharmacol. 38.5 (1990): 737-43.

Murry, C. E., R. B. Jennings, and K. A. Reimer. "Preconditioning with ischemia: a delay of lethal cell injury in ischemic myocardium." Circulation 74.5 (1986): 1124-36.

Myllylä, R., et al. "Ascorbate is consumed stoichiometrically in the uncoupled reactions catalyzed by prolyl 4-hydroxylase and lysyl hydroxylase." J.Biol.Chem. 259.9 (1984): 5403-05.

Nobes, C. D. and A. Hall. "Rho, rac, and cdc42 GTPases regulate the assembly of multimolecular focal complexes associated with actin stress fibers, lamellipodia, and filopodia." Cell 81.1 (1995): 53-62.

Nobes, C. D. and A. Hall. "Rho GTPases control polarity, protrusion, and adhesion during cell movement." J.Cell Biol. 144.6 (1999): 1235-44.

Nytko, K. J., et al. "Vitamin C is dispensable for oxygen sensing in vivo." Blood 117.20 (2011): 5485-93.

O'Rourke, J. F., et al. "Oxygen-regulated and transactivating domains in endothelial PAS protein 1: comparison with hypoxia-inducible factor-1 $\alpha . "$ J.Biol.Chem. 274.4 (1999): 2060-71. 
Ohashi, K., et al. "Rho-associated kinase ROCK activates LIM-kinase 1 by phosphorylation at threonine 508 within the activation loop." J.Biol.Chem. 275.5 (2000): 3577-82.

Okazaki, K. and E. Maltepe. "Oxygen, epigenetics and stem cell fate." $\underline{\text { Regen.Med. } 1.1}$ (2006): 71-83.

Olson, E. N. and A. Nordheim. "Linking actin dynamics and gene transcription to drive cellular motile functions." Nat.Rev.Mol.Cell Biol. 11.5 (2010): 353-65.

Ong, S. G., et al. "HIF-1 reduces ischaemia-reperfusion injury in the heart by targeting the mitochondrial permeability transition pore." Cardiovasc.Res. 104.1 (2014): 24-36.

Patten, R. D., et al. "Ventricular remodeling in a mouse model of myocardial infarction." Am.J.Physiol 274.5 Pt 2 (1998): H1812-H1820.

Pellegrin, S. and H. Mellor. "Actin stress fibres." J.Cell Sci. 120.Pt 20 (2007): 3491-99.

Peng, J., et al. "The transcription factor EPAS-1/hypoxia-inducible factor $2 \alpha$ plays an important role in vascular remodeling." Proc.Natl.Acad.Sci.U.S.A 97.15 (2000): 838691.

Pfeffer, M. A. and E. Braunwald. "Ventricular remodeling after myocardial infarction. Experimental observations and clinical implications." Circulation 81.4 (1990): 116172.

Philipp, S., et al. "Stabilization of hypoxia inducible factor rather than modulation of collagen metabolism improves cardiac function after acute myocardial infarction in rats." Eur.J.Heart Fail. 8.4 (2006): 347-54.

Philipp, S., et al. "Desferoxamine and ethyl-3,4-dihydroxybenzoate protect myocardium by activating NOS and generating mitochondrial ROS." Am.J.Physiol Heart Circ.Physiol 290.1 (2006): H450-H457.

Pugh, C. W., et al. "Activation of hypoxia-inducible factor-1; definition of regulatory domains within the $\alpha$ subunit." J.Biol.Chem. 272.17 (1997): 11205-14.

Ridley, A. J. and A. Hall. "The small GTP-binding protein rho regulates the assembly of focal adhesions and actin stress fibers in response to growth factors." Cell 70.3 (1992): 38999.

Ridley, A. J., et al. "The small GTP-binding protein rac regulates growth factor-induced membrane ruffling." Cell 70.3 (1992): 401-10.

Rosenberger, C., et al. "Activation of hypoxia-inducible factors ameliorates hypoxic distal tubular injury in the isolated perfused rat kidney." Nephrol.Dial.Transplant. 23.11 (2008): 3472-78.

Safran, M., et al. "Mouse model for noninvasive imaging of HIF prolyl hydroxylase activity: assessment of an oral agent that stimulates erythropoietin production." Proc.Natl.Acad.Sci.U.S.A 103.1 (2006): 105-10. 
Santiago, J. J., et al. "Cardiac fibroblast to myofibroblast differentiation in vivo and in vitro: expression of focal adhesion components in neonatal and adult rat ventricular myofibroblasts." Dev.Dyn. 239.6 (2010): 1573-84.

Schofield, C. J. and P. J. Ratcliffe. "Oxygen sensing by HIF hydroxylases." Nat.Rev.Mol.Cell Biol. 5.5 (2004): 343-54.

Semenza, G. L., et al. "Hypoxia response elements in the aldolase A, enolase 1, and lactate dehydrogenase A gene promoters contain essential binding sites for hypoxia-inducible factor 1." J.Biol.Chem. 271.51 (1996): 32529-37.

Semenza, G. L. "Physiology meets biophysics: visualizing the interaction of hypoxiainducible factor $1 \alpha$ with p300 and CBP." Proc.Natl.Acad.Sci.U.S.A 99.18 (2002): 11570-72.

Semenza, G. L. "Hypoxia-inducible factor 1 and cardiovascular disease." Annu.Rev.Physiol 76 (2014): 39-56.

Seth, P., et al. "Novel estrogen and tamoxifen induced genes identified by SAGE (Serial Analysis of Gene Expression)." Oncogene 21.5 (2002): 836-43.

Shizukuda, Y., et al. "Hypoxic preconditioning of ischaemic canine myocardium." Cardiovasc.Res. 26.5 (1992): 534-42.

Shizukuda, Y., et al. "Hypoxic preconditioning attenuates stunning caused by repeated coronary artery occlusions in dog heart." Cardiovasc.Res. 27.4 (1993): 559-64.

Smirnova, N. A., et al. "Catalytic mechanism and substrate specificity of HIF prolyl hydroxylases." Biochemistry (Mosc.) 77.10 (2012): 1108-19.

Souders, C. A., S. L. Bowers, and T. A. Baudino. "Cardiac fibroblast: the renaissance cell." Circ.Res. 105.12 (2009): 1164-76.

Steinhoff, A., et al. "Cellular oxygen sensing: Importins and exportins are mediators of intracellular localisation of prolyl-4-hydroxylases PHD1 and PHD2." Biochem.Biophys.Res.Commun. 387.4 (2009): 705-11.

Stubbs, C. J., et al. "Application of a proteolysis/mass spectrometry method for investigating the effects of inhibitors on hydroxylase structure." J.Med.Chem. 52.9 (2009): 2799805 .

Sun, Y., et al. "Infarct scar as living tissue." Basic Res.Cardiol. 97.5 (2002): 343-47.

Sutton, M. G. and N. Sharpe. "Left ventricular remodeling after myocardial infarction: pathophysiology and therapy." Circulation 101.25 (2000): 2981-88.

Takeda, K., et al. "Placental but not heart defects are associated with elevated hypoxiainducible factor $\alpha$ levels in mice lacking prolyl hydroxylase domain protein 2." Mol.Cell Biol. 26.22 (2006): 8336-46.

Takeda, K., et al. "Regulation of adult erythropoiesis by prolyl hydroxylase domain proteins." Blood 111.6 (2008): 3229-35. 
Tandara, A. A. and T. A. Mustoe. "Oxygen in wound healing-more than a nutrient." World J.Surg. 28.3 (2004): 294-300.

Tao, Z. Y., et al. "Temporal changes in matrix metalloproteinase expression and inflammatory response associated with cardiac rupture after myocardial infarction in mice." Life Sci. 74.12 (2004): 1561-72.

Tian, H., S. L. McKnight, and D. W. Russell. "Endothelial PAS domain protein 1 (EPAS1), a transcription factor selectively expressed in endothelial cells." Genes Dev. 11.1 (1997): 72-82.

Tian, H., et al. "The hypoxia-responsive transcription factor EPAS1 is essential for catecholamine homeostasis and protection against heart failure during embryonic development." Genes Dev. 12.21 (1998): 3320-24.

Tojkander, S., G. Gateva, and P. Lappalainen. "Actin stress fibers-assembly, dynamics and biological roles." J.Cell Sci. 125.Pt 8 (2012): 1855-64.

Tomasek, J. J., et al. "Myofibroblasts and mechano-regulation of connective tissue remodelling." Nat.Rev.Mol.Cell Biol. 3.5 (2002): 349-63.

Tuderman, L., R. Myllylä, and K. I. Kivirikko. "Mechanism of the prolyl hydroxylase reaction. 1. Role of co-substrates." Eur.J.Biochem. 80.2 (1977): 341-48.

Turner, N. A., et al. "Chronic $\beta_{2}$-adrenergic receptor stimulation increases proliferation of human cardiac fibroblasts via an autocrine mechanism." Cardiovasc.Res. 57.3 (2003): 784-92.

Vandekerckhove, J. and K. Weber. "At least six different actins are expressed in a higher mammal: an analysis based on the amino acid sequence of the amino-terminal tryptic peptide." J.Mol.Biol. 126.4 (1978): 783-802.

Vliegen, H. W., et al. "Myocardial changes in pressure overload-induced left ventricular hypertrophy. A study on tissue composition, polyploidization and multinucleation." Eur.Heart J. 12.4 (1991): 488-94.

Vogler, M., et al. "Hypoxia modulates fibroblastic architecture, adhesion and migration: a role for HIF-1 $\alpha$ in cofilin regulation and cytoplasmic actin distribution." PLoS.One. 8.7 (2013): e69128.

Vogler, M., et al. "Pre- and post-conditional inhibition of prolyl-4-hydroxylase domain enzymes protects the heart from an ischemic insult." Pflugers Arch. (2015).

Wang, G. L., et al. "Hypoxia-inducible factor 1 is a basic-helix-loop-helix-PAS heterodimer regulated by cellular $\mathrm{O}_{2}$ tension." Proc.Natl.Acad.Sci.U.S.A 92.12 (1995): 5510-14.

Wang, Z., et al. "The protective effect of prolyl-hydroxylase inhibition against renal ischaemia requires application prior to ischaemia but is superior to EPO treatment." Nephrol.Dial.Transplant. 27.3 (2012): 929-36.

Wegner, A. "Head to tail polymerization of actin." J.Mol.Biol. 108.1 (1976): 139-50. 
Wegner, A. and G. Isenberg. "12-fold difference between the critical monomer concentrations of the two ends of actin filaments in physiological salt conditions." Proc.Natl.Acad.Sci.U.S.A 80.16 (1983): 4922-25.

Wenger, R. H. "Mammalian oxygen sensing, signalling and gene regulation." J.Exp.Biol. 203.Pt 8 (2000): 1253-63.

Wenger, R. H. "Cellular adaptation to hypoxia: $\mathrm{O}_{2}$-sensing protein hydroxylases, hypoxiainducible transcription factors, and $\mathrm{O}_{2}$-regulated gene expression." FASEB J. 16.10 (2002): 1151-62.

Williams, R. S. and I. J. Benjamin. "Protective responses in the ischemic myocardium." J.Clin.Invest 106.7 (2000): 813-18.

Winder, S. J. "Structural insights into actin-binding, branching and bundling proteins." Curr.Opin.Cell Biol. 15.1 (2003): 14-22.

Wykoff, C. C., et al. "Hypoxia-inducible expression of tumor-associated carbonic anhydrases." Cancer Res. 60.24 (2000): 7075-83.

$\mathrm{Xi}$, L., et al. "Cobalt chloride induces delayed cardiac preconditioning in mice through selective activation of HIF-1 $\alpha$ and AP-1 and iNOS signaling." Am.J.Physiol Heart Circ.Physiol 287.6 (2004): H2369-H2375.

Zhao, H. X., et al. "Attenuation of myocardial injury by postconditioning: role of hypoxia inducible factor-1 $\alpha . "$ Basic Res.Cardiol. 105.1 (2010): 109-18.

Zheng, B., et al. "Ligand-dependent genetic recombination in fibroblasts : a potentially powerful technique for investigating gene function in fibrosis." Am.J.Pathol. 160.5 (2002): 1609-17.

Zieseniss, A. "Hypoxia and the modulation of the actin cytoskeleton - emerging interrelations." Dovepress Hypoxia. 2 (2014): 11-21.

Zimmermann, A. S., et al. "Epidermal or dermal specific knockout of PHD-2 enhances wound healing and minimizes ischemic injury." PLoS.One. 9.4 (2014): e93373. 


\section{Acknowledgements}

An dieser Stelle möchte ich mich ganz herzlich bei allen bedanken, die zum Gelingen dieser Arbeit beigetragen haben.

Mein besonderer Dank gilt Prof. Dr. Dörthe M. Katschinski für die Möglichkeit an diesem sehr interessanten Thema zu arbeiten und für die umfassende Unterstützung mit vielen fachlichen Ratschlägen und Anregungen. Zudem bedanke ich mich für die Möglichkeit, meine Forschungsergebnisse auf mehreren nationalen und internationalen Konferenzen präsentieren zu können.

Des Weiteren gilt mein besonderer Dank Dr. Anke Zieseniss, die mir während der gesamten Zeit mit einer sehr guten Betreuung und vielen Ratschlägen zur Seite stand. Besonders in der Endphase dieser Arbeit waren diese Unterstützung und ihre guten Ideen eine große Hilfe.

Zudem bedanke ich mich ganz herzlich bei meinen Thesis Committee Mitgliedern Prof. Dr. Susanne Lutz und Prof. Dr. Jörg Großhans für die stets wertvollen Anregungen und hilfreichen Ratschläge bei meinen Thesis Committees.

Mein Dank gilt auch Prof. Dr. Hubertus Jarry, PD Dr. Kaomei Guan-Schmidt und Prof. Dr. Jürgen Brockmöller für die sofortige Bereitschaft als Prüfer zur Verfügung zu stehen.

Ich bedanke mich auch ganz besonders für die großartige Möglichkeit an das IRTG 1816 assoziiert zu werden und die damit verbundene Gelegenheit am King's College in London die Methodik der RhoGTPase activity assays zu erlernen. Dabei möchte ich mich ganz herzlich bei Prof. Anne Ridley und Dr. Ritu Garg für die sehr gute Betreuung während meines Aufenthaltes in ihrem Labor, die hervorragende Einarbeitung in die RhoGTPase assays und die Bereitstellung der Plasmide bedanken.

Zudem bedanke ich mich bei Katja El-Armouche und Dr. Christina Würtz für die sehr gute Betreuung, stete Hilfsbereitschaft und Erreichbarkeit.

Ich danke Prof. Dr. Kai-Uwe Eckardt, Prof. Dr. Carsten Willam, Prof. Dr. Nicolai Burzlaff, Dr. med. Gunnar Schley und Eva Heinze für die Bereitstellung von ICA und die tolle Kooperation in dem ICA Projekt. Zudem danke ich ganz herzlich Dr. Malte Tiburcy und Elif Levent für die Bereitstellung der ODD-Luc EHMs.

Dr. Sabine Vogel danke ich für die hervorragende Einarbeitung in die in vitro Methoden und die Unterstützung während der Experimente.

Mein besonderer Dank gilt auch Dr. Amke Rena Hesse für die außerordentliche Einarbeitung, Betreuung und Hilfe bei den Tierversuchen.

Annette Hillemann und Sabine Krull danke ich ganz herzlich für ihre große Hilfe bei den zahlreichen Genotypisierungen, den Zellkultur- und Analysemethoden.

Zudem danke ich allen aktuellen und ehemaligen Mitgliedern der AG Katschinski... Katja, Marieke, Sabine, Amke, Anke, Aline, Liza, Annemarie, Angelika, Johannes, Stephanie, Johannes, Shun, Lena, Cynthia, Annette, Sabine, Melanie, Doris, Pia und Ulrike für die tolle Zeit, die stete Hilfsbereitschaft und wertvollen Tipps.

Herrn Prof. Dr. Hubertus Jarry, Frau Dr. Sarah Kimmina sowie den Mitarbeitern der Zentralen Tierexperimentellen Einrichtung der UMG danke ich ganz herzlich für die freundliche Zusammenarbeit und die stete Hilfsbereitschaft.

Besonders möchte ich mich aber auch bei meinem Mann und meiner Familie bedanken, die mich alle die Jahre immer unterstützt haben und so zum Gelingen dieser Arbeit beigetragen haben. 


\section{Curriculum vitae}

Personal data:

Name:

Maiden Name:

Date of birth:

Place of birth:

Higher educations:

June 2012 - May 2015

Oct. 2010 - May 2012

Oct. 2007 - Sep. 2010

Professional experience:

April 2007 - July 2007

July 2006 - March 2007

In-firm training:

Aug. 2003 - June 2006
Melanie Vogler

Müller

$13^{\text {th }}$ September 1984

Heilbad Heiligenstadt, Germany

$\mathrm{PhD}$ student at the Institute of Cardiovascular Physiology, Georg-August-University in Göttingen, Germany Thesis title: "Cardiac and fibroblastic properties after HIF-1 $\alpha$ stabilization"

Master of Science in Molecular Medicine at Georg-AugustUniversity in Göttingen, Germany

Thesis title: "Importance of Krüppel-like factor 4 (KLF4) for the angiogenic properties of endothelial cells and monocytes"

Bachelor of Science in Molecular Medicine at Georg-AugustUniversity in Göttingen, Germany

Thesis title: "Vergleichende Analyse von BAFF Signalwegen in Lymphomzelllinien"

Chemical laboratory assistant at MCI Miritz Citrus Ingredients in Kirchgandern, Germany

Chemical laboratory assistant at Symrise GmbH \& Co. KG in Holzminden, Germany

Training as chemical laboratory assistant at Symrise GmbH \& Co. KG in Holzminden, Germany

$\underline{\text { School education: }}$

Graduation:

A-levels: June 2003

$1995-2003$

Public grammar school "Johann Georg Lingemann" in Heilbad Heiligenstadt, Germany

$1991-1995$ 


\section{Publications}

Melanie Vogler, Sabine Vogel, Sabine Krull, Katja Farhat, Pia Leisering, Susanne Lutz, Christina M. Wuertz, Dörthe M. Katschinski, Anke Zieseniss.

Hypoxia modulates fibroblastic architecture, adhesion and migration: a role for HIF-1a in cofilin regulation and cytoplasmic actin distribution.

PLoS.One. 8.7 (2013): e69128

Melanie Vogler, Anke Zieseniss, Amke R Hesse, Elif Levent, Malte Tiburcy, Eva Heinze, Nicolai Burzlaff, Gunnar Schley, Kai Uwe Eckardt, Carsten Willam, Dörthe M Katschinski. Pre- and post-conditional inhibition of prolyl-4-hydroxylase domain enzymes protects the heart from an ischemic insult.

Pflügers Arch. (2015): DOI 10.1007/s00424-014-1667-z

Frauke S. Czepluch, Melanie Vogler, Hendrik Kuschicke, Julia Meier, Rajinikanth Gogiraju, Dörthe M. Katschinski, Joachim Riggert, Gerd Hasenfuss, Katrin Schäfer.

Functional role of the transcription factor Krüppel-like factor $\mathbf{4}$ in endothelial cells and its association with coronary artery disease.

(Manuscript under revision) 


\section{Conferences and Retreats}

02.06 .2014

IRTG Summer Symposium

Göttingen, Germany

Poster Presentation

08. - 12.06.2013 Meeting HypoxiaNet: Regulatory aspects in cells, tissues and organisms Oulu, Finland

Poster Presentation

05. - 06.09.2013 $\quad 4^{\text {th }} \mathrm{PhD}$ Retreat Molecular Medicine

Einbeck, Germany

Oral presentation

20. - 23.09.2012 Meeting HypoxiaNET: Sensing Hypoxia in the cell and the organism Essen, Germany

Poster presentation

06. - 07.09.2012 $\quad 3^{\text {rd }} \mathrm{PhD}$ Retreat Molecular Medicine

Wernigerode, Germany

Poster Presentation 


\section{Internships}

Supported by the International Research Training Group 1816 (IRTG 1816) which was established in 2012 and is funded by the Deutsche Forschungsgemeinschaft (DFG) and the King's College London British Heart Foundation Centre of Research Excellence.

13.07.14 - 02.08.14 RhoGTPase activity assays of L929 cells with or without DMOG Supervisor: Prof. Anne Ridley

King's College London

Randall Division of Cell and Molecular Biophysics

New Hunt's House

Guy's Campus 